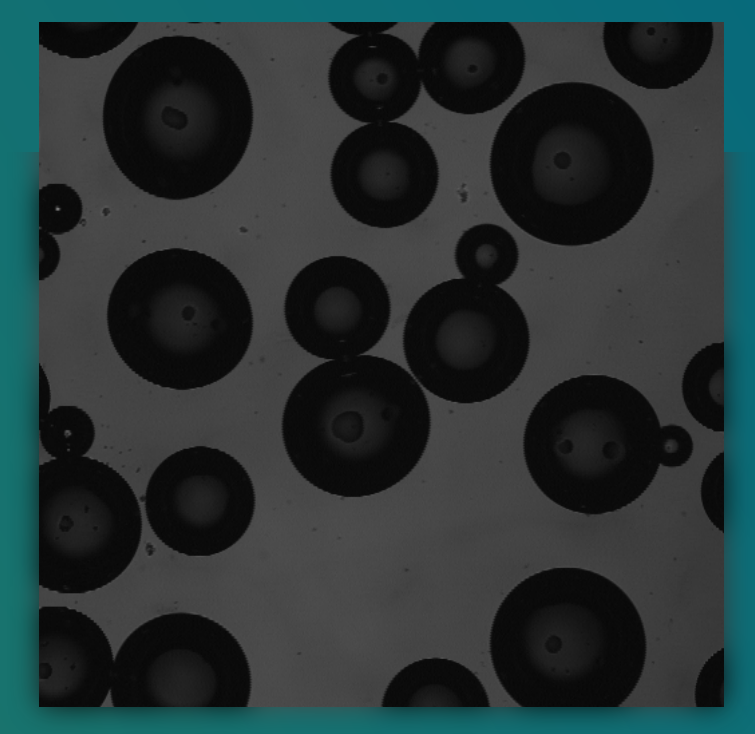

\title{
BUBBLE FORMATION AND CONCENTRATION FIELDS IN WATER ELECTROLYSIS
}

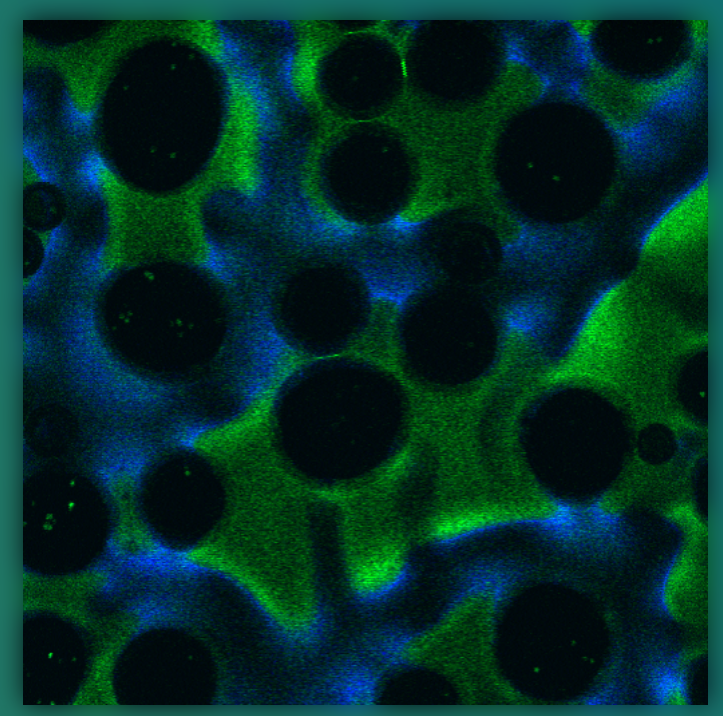


Bubble formation and concentration fields in water electrolysis

Nakul Pande 


\section{Thesis committee members:}

Prof. Dr. J. L. Herek (chairman)

Prof. Dr. Detlef Lohse (promoter)

Prof. Dr. Guido Mul (promoter)

Dr. Dominik Krug (co-promoter)

Dr. Bastian T. Mei (co-promoter)

Prof. Dr. J. G. E. Gardeniers

Prof. Dr. Jan C. T. Eijkel

Prof. Dr. Marc T. M. Koper

Prof. Dr. et Ing. habil. Kerstin Eckert

Helmholtz-Zentrum Dresden-Rossendorf
UT, Enschede

UT, Enschede

UT, Enschede

UT, Enschede

UT, Enschede

UT, Enschede

UT, Enschede

University of Leiden

TU Dresden/

TU Eindhoven, Eindhoven

The work in this thesis was carried out at the Physics of Fluids group and PhotoCatalytic Synthesis group of the Faculty of Science and Technology of the University of Twente. This research received financial support from The Netherlands Organization for Scientific Research (NWO) in the framework of the fund New Chemical Innovations, project ELECTROGAS (731.015.204), with financial support of Nuoryon, Shell Global Solutions, Magneto Special Anodes (an Evoqua Brand), and Elson Technologies.

Dutch title: Bubbel vorming en concentratie velden in water elektrolyse

Cover: Experimental image showing bubbles, electroconvective patterns (green) and regions of high $\mathrm{pH}$ (blue) on a hydrogen-evolving platinum electrode.

Publisher:

Nakul Pande, Physics of Fluids, PhotoCatalytic Synthesis, University of Twente, P.O. Box 217, 7500 AE Enschede, The Netherlands

Copyright (C) 2021. All rights reserved.

No part of this work may be reproduced or transmitted for commercial purposes, in any form or by any means, electronic or mechanical, including photocopying and recording, or by any information storage or retrieval system, except as expressly permitted by the publisher.

ISBN: $978-90-365-5133-5$

DOI: $10.3990 / 1.9789036551335$ 


\title{
BUBBLE FORMATION AND CONCENTRATION FIELDS IN WATER ELECTROLYSIS
}

\section{DISSERTATION}

\author{
to obtain
}

the degree of doctor at the University of Twente, on the authority of the rector magnificus,

Prof. Dr. Ir. A. Veldkamp,

on account of the decision of the Doctorate Board, to be publicly defended

on Friday the 26th of February 2021 at 16:45

$$
\text { by }
$$

Nakul Pande

Born on the 28th of October 1990

in Tripoli, Libya 
This dissertation has been approved by the promoters:

Prof. Dr. Detlef Lohse

Prof. Dr. Guido Mul

and the co-promoters:

Dr. Bastian T. Mei

Dr. Dominik Krug 


\section{Contents}

\begin{tabular}{ll}
\hline Introduction & 1
\end{tabular}

$\begin{array}{llll}1 & \text { Short-time current increase on a Nickel disc-electrode } & 7\end{array}$

1.1 Introduction . . . . . . . . . . . . . . . . . . 8

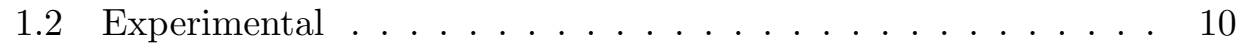

1.3 Results and Discussion . . . . . . . . . . . . . . . . . . . . . . 12

1.4 Conclusion and Outlook . . . . . . . . . . . . . . . 17

\begin{tabular}{|lll}
2 & Measurement of $\mathrm{pH}$ changes near electrodes & 19
\end{tabular}

2.1 Introduction . . . . . . . . . . . . . . . . 20

2.2 Experimental Methods . . . . . . . . . . . . . . . . . . . 21

2.3 Results and Discussion . . . . . . . . . . . . . . . . . . . . . . . . . . 25

2.4 Conclusion $\ldots \ldots \ldots \ldots \ldots$

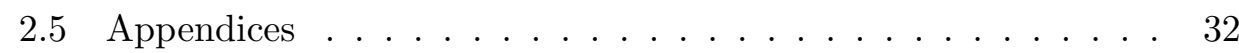

3 The effect of buoyancy driven convection and bubble clusters $\begin{array}{ll}\text { on the growth and dissolution of bubbles } & 47\end{array}$

3.1 Introduction $\ldots \ldots \ldots \ldots \ldots \ldots \ldots \ldots$

3.2 Experimental setup . . . . . . . . . . . . . . . . . . . . 49

3.3 Numerical setup . . . . . . . . . . . . . . . . 51

3.4 Results and discussion . . . . . . . . . . . . . . . . . . 54

3.5 Conclusion $\ldots \ldots \ldots \ldots \ldots \ldots$

3.6 Appendix . . . . . . . . . . . . . . . . . . . . . . 61

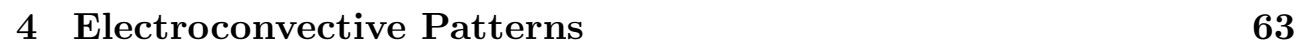

4.1 Introduction . . . . . . . . . . . . . . . . . . . . 64

4.2 Experimental Setup . . . . . . . . . . . . . . . . . . . . 64

4.3 Results and Discussion . . . . . . . . . . . . . . . . . . . . 66

4.4 Conclusion $\ldots \ldots \ldots \ldots \ldots$ 
4.5 Appendices $\ldots \ldots \ldots \ldots \ldots \ldots \ldots \ldots$

$\begin{array}{llr}5 & \text { Future Work } & 85\end{array}$

5.1 Immediate Research projects . . . . . . . . . . . . . 86

5.2 Additional Recommendations . . . . . . . . . . . . . . . 90

\begin{tabular}{ll}
\hline Bibliography & 93
\end{tabular}

\begin{tabular}{ll}
\hline Summary & 107
\end{tabular}

$\begin{array}{ll}\text { Samenvatting } & 109\end{array}$

\begin{tabular}{ll}
\hline Acknowledgements & 111
\end{tabular} 


\section{General Introduction}

The subject matter of this thesis attempts to understand the combined effect of bubbles and ion transport in gas-evolving electrochemical cells by measuring ion concentration fields and imaging bubbles on electrodes. Electrochemical processes find urgent application in the fields of energy storage (batteries, fuels) and $\mathrm{CO}_{2}$ capture [1, 2] and reduction [3], among others [4, 5]. Many of these systems involve the interaction of bubbles, dissolved gas and ions at the electrode. For example, the electrochemical processes of chlorine production, chlorate synthesis, (sea)water electrolysis and selective hydrogenation, which require selective production of gases for their cost effective operation, involve vigorous bubble generation at the electrodes. In this work, the well-studied hydrogen evolution reaction is used as a model system to study bubbles and ion concentrations on electrodes. 


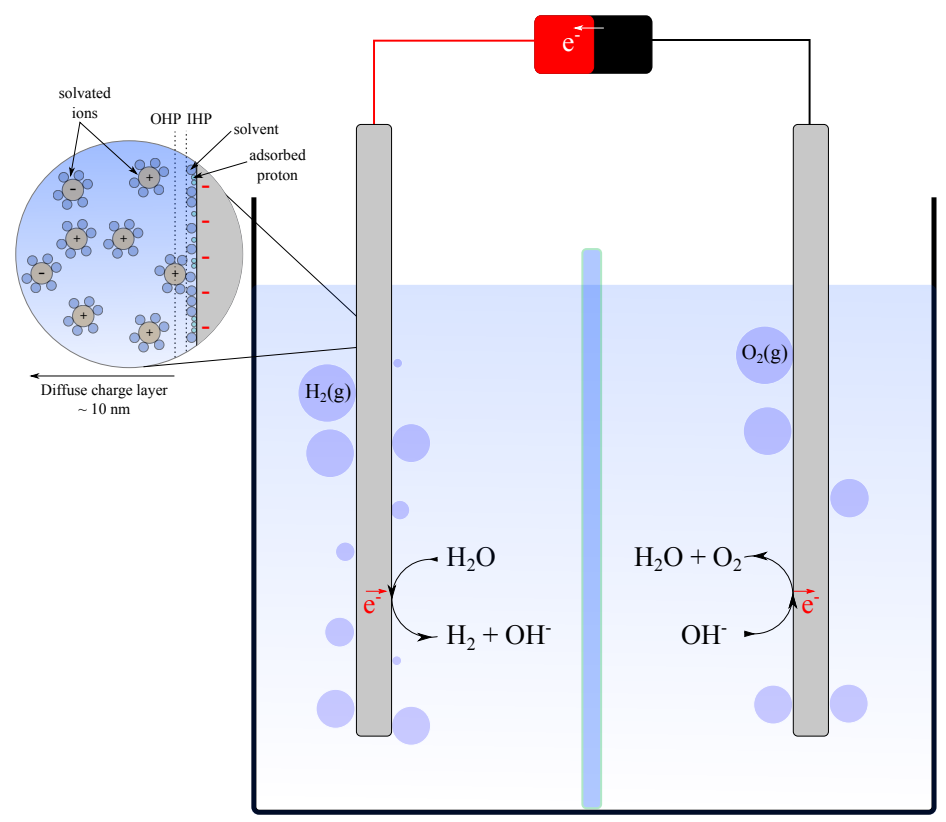

Figure 1: Schematic of a water electrolysis cell. The grey electrodes are inserted in a bath containing electrolyte separated by an ion-exchange membrane (blue). On application of a potential difference ( $>1.23 \mathrm{~V})$, hydrogen and oxygen bubbles are produced on the electrodes via their respective half-reactions. A zoomed in view of the basic structure of the double layer: the location of the Inner/Outer Helmholtz Plane (IHP/OHP) and the diffuse layer at the negative electrode has also been shown (adapted, in part, from [6])

\section{Overview and Motivation}

In 2015, 196 countries adopted the Paris Agreement with the aim to limit global temperature rise by reducing emissions of greenhouse gases such as $\mathrm{CO}_{2}$ and $\mathrm{CH}_{4}$. [7]. Within the European Union, the European commission has further laid down a set of policy initiatives (Green Deal) with the overall aim of achieving climate neutrality by 2050 [8]. This has accelerated the transition to renewable energy sources. However, intermittency in the sources of renewable energy leads to the requirement of energy storage solutions to manage the electrical grid load. Among these, energy storage as hydrogen using electrolysis is promising, and hydrogen is projected to have up to an $18 \%$ share of the final global energy demand by 2050 [9]. 
Currently, hydrogen production is referred to as either green, blue, grey or brown depending on its carbon friendly spectrum from high to low. Blue hydrogen depends on fossil fuels, and is generated through steam methane reforming, where steam reacts with methane from natural gas to generate hydrogen along with a small amount of $\mathrm{CO}_{2}$ as a byproduct. Green hydrogen, on the other hand is produced electrochemically and is a zero-carbon version. In order to help meet the targets of the Paris Agreement, hydrogen production must transition from blue to green. This shift can potentially help decarbonize a range of industries such as long-haul transport, iron and steel, and the manufacture of useful chemicals [10]. The vision is the production of hydrogen through electrolysis powered by solar, wind, hydro-power, geothermal, or another renewable source.

While the production of blue hydrogen is commercially proven at a large scale, electrolysis is not. One of the major challenges for widespread use of green hydrogen, is its higher cost compared to hydrogen obtained from fossil-fuels [10]. To reduce the cost of this process, a fundamental understanding of water electrolysis is required. This includes both the electron and ion transport mechanisms for all types of water electrolysis cells. In addition to water electrolysis, these studies would lead to an improvement in existing electrolytic technologies, such as chlorine production. Thus there is both a significant financial and environmental incentive to pursue this line of research.

Fig. 1 shows a schematic of a typical electrolytic cell, which is composed of a minimum of two electronic conductors or electrodes (usually metals) inserted in an ionic conductor or electrolyte. When a potential difference above a certain threshold value (the thermodynamic Red-Ox potential) is applied it drives a chemical change at each electrode. Water electrolysis is one such example where water decomposes into hydrogen and oxygen at a potential difference $>1.23 \mathrm{~V}$.

$$
2 \mathrm{H}_{2} \mathrm{O} \stackrel{>1.23 \mathrm{~V}}{\longrightarrow} 2 \mathrm{H}_{2}+\mathrm{O}_{2}
$$

The above overall chemical reaction is composed of two independent halfreactions at each electrode/electrolyte interface:

$$
\begin{aligned}
2 \mathrm{H}_{2} \mathrm{O} & +2 \mathrm{e}^{-} \longrightarrow \mathrm{H}_{2}+2 \mathrm{OH}^{-} \\
2 \mathrm{OH}^{-} & \longrightarrow \frac{1}{2} \mathrm{O}_{2}+2 \mathrm{e}^{-}+\mathrm{H}_{2} \mathrm{O}
\end{aligned}
$$

Thus hydrogen is produced at an 'electron-rich' negative electrode while oxygen is produced at the positive electrode as shown in Fig. 1 . 
Besides Faradaic reactions; i.e. the charge transfer at the electrode which leads to chemical conversion; there can also be non-Faradaic effects such as charge build-up in the form of a electrical double layer as shown in Fig. 1. This is especially evident in the absence of any chemical change, when a transient current can be measured for an applied potential difference. Therefore, for a constant potential difference, the total measured current has both a Faradaic and a non-Faradaic contribution.

To better understand the current flow in an electrolytic cell, it is useful to view it in terms of elementary electrical circuit elements, such as resistors and capacitors. For instance, since charge can build up on the electrode-electrolyte interface, each electrode effectively acts as a capacitor. Additionally, electrode reactions can occur at both electrodes and the rate of product formation at each electrode increases with the polarization of the electrode-electrolyte interface. Charge transfer which leads to chemical conversion at the electrode, can to a first order be approximated as a resistor where the current is proportional to the potential difference at the electrode-electrolyte interface. Each electrode is thus equivalent to at least the following elements: a double-layer capacitor (non-Faradaic current) in parallel with a charge-transfer resistance (Faradaic current). Note that here, within the charge transfer resistance, we inherently include the limitations of mass transfer of the electro-active ion to the electrode, also called concentration polarization.

These resistances are connected in series with the solution resistance to complete the electrical circuit. Additionally, an electrolytic cell may also operate with an ion-exchange membrane to separate the obtained products. In such a case the electrical resistance imposed by the membrane also needs to be taken into account.

However, in gas evolving electrolytic cells, there are additional resistances on the electrode. Bubbles may substantially increase the cell resistance by reducing the conductivity of the bulk solution [11] (bulk bubbles) or by blocking the electrode surface and reducing contact with the electrolyte (surface bubbles). Surface attached bubbles can further influence the cell resistance by affecting the potential distribution [12, 13]. In general, bubbles sticking to the electrode surface are generally considered to be detrimental $14-18$ to overall cell performance. There has been some research in the past to measure the growth rates of such surface attached bubbles 19 22, and some which correlate the bubble growth rate with the measured electrical quantities 16 , 23. 24. However, bubbles can also enhance the electrode reaction rate by removing dissolved gas from the near the electrode 13,25 . This enhancement 
rate is particularly relevant for fast electrode reactions, where the current is limited by mass transport. It is therefore crucial to understand how gas evolution, current, and bubble growth are correlated. This further requires an understanding of the underlying transport processes that drive reacting ions to the electrode surface and remove product gases from these surfaces.

In the present thesis, ion concentration fields and bubbles are measured on electrodes primarily to understand the role of transport processes in electrochemical cells. Hydrogen evolution with its fast reaction rate in aqueous solutions on metals, here primarily platinum electrodes, is ideally suited to study the limitations that mass transport (to and from the electrode) poses to the measured current. The experimental setups involve combined electrochemical i.e current and potential, and optical measurements. A confocal microscope (Nikon A1R) is used as the optical measurement setup, since it allows measurements with high spatial resolution. Additionally it allows simultaneous measurements: the top view with the transmission channel, and three separate fluorescence channels for bottom view measurement. The particular experimental setup used in each chapter is described therein.

\section{A guide through the thesis}

- In Chapter 1 general observations on hydrogen (bubble) evolution are presented by imaging an entire inverted nickel electrode in a buffer electrolyte solution. This specific electrolyte solution was used with the aim of keeping the reactant $\mathrm{H}^{+}$concentration constant to ensure that any change in the current is brought on by the dissolved (or surface adsorbed/attached) hydrogen gas or by the bubbles.

- Chapter 2 builds on the conclusions of Chapter 1 and presents a technique to measure time-dependent proton concentration $(\mathrm{pH})$ in solution using confocal fluorescence microscopy. Measurement of near-electrode $\mathrm{pH}$ is vital to many different electrode reactions in aqueous solutions and provides insight into the local surface chemistry in particular to the influence that bubbles have on the electrode reaction rate.

- In Chapter 3, the rate of bubble growth and dissolution rate is measured as it serves as an indicator of the dissolved gas concentration. Combined with the reactant $\mathrm{H}^{+}$concentration, the measurement of product $\mathrm{H}_{2}$ 
concentrations at the electrode can help predict the electrochemical cell response.

- Finally, in Chapter 4, a particular case of convective instability (electroconvection) is analyzed. It is shown that (at least) in a binary electrolyte, currents greater than the diffusion transport limit can be driven in electrocatalytic systems.

Overall, each chapter presents a self-contained study with the overarching goal to better understand gas-evolving electrochemical systems. Some research questions that are a direct consequence of the results of Chapter 1-4 are addressed in Chapter 5. Additional research directions are also recommended. 


\section{Chapter 1}

\section{Short-time current increase on a Nickel disc-electrode}

Gas evolving electrochemical reactions induce bubble formation and growth at surfaces of electrodes. To study one such situation, hydrogen evolution on nickel electrodes, short time chronoamperometric experiments were performed in combination with in-situ microscopy. The entire electrode of $3.14 \mathrm{~mm}^{2}$ was imaged with confocal microscopy and the current response of the electrode then correlated to the observed bubble growth features. Somehow counterintuitively, first a $2-3 \%$ increase in current was observed consistently when a bubble grows close to the electrode on the edge of the electrode holder, made of a polymer. This is argued to be due to the removal of surface attached gas from the electrode. Next, we observe a consecutive regime of decreasing current, in which large bubbles accumulate on the surface. Interestingly, when these surface attached bubbles coalesce, a steep change in current is observed, which is accompanied by a burst of small bubbles nucleating on the surface previously occupied by the large bubble. These phenomena are qualitatively discussed on the basis of existing literature, and implications for improvements for electrodes on which gases are produced, are outlined.

Published as: N Pande, G. Mul, D. Lohse and B.T. Mei, Correlating the Short-Time Current Response of a Hydrogen Evolving Nickel Electrode to Bubble Growth, J. Electro. Chem. Soc. (2019). 


\section{$1.1 \quad$ Introduction}

Electrochemical hydrogen production using water electrolysis has been an increasingly important area of study in relation to solutions for storage of renewable energy. Like in any other gas-evolving chemical reaction, during electrochemical hydrogen evolution bubble formation and growth at the electrode surface can occur [14, 15. Gas molecules produced at the electrode surface initially form discrete domains of surface attached gas, also called 'surface nanobubbles $26-30$. These nanobubbles grow and coalesce to form micron-size bubbles, 'microbubbles', before finally detaching 27. Because of its ubiquity, the growth dynamics of such microbubbles on surfaces has been an active area of research be it in electrolysis, catalysis, or simply by gas oversaturation $19,20,22,24,31,33]$. In the context of electrochemical systems specifically, bubbles sticking to the electrode surface are generally considered to be detrimental $14-18$ for the overall cell performance. It therefore is crucial to understand how the gas evolution, the current, and bubble growth are correlated. In particular, it becomes critical to disentangle the interplay between the current at the electrode and the bubble growth. Given this context, there has been significant research in the past to measure the growth rates of such electrochemically generated gas bubbles 1921 . The bubble growth rates are commonly parameterized as $20-22$

$$
R=\beta t^{x}
$$

where $\mathrm{R}$ the radius of the bubble, described as function of time $\mathrm{t}$; $\mathrm{x}$ is the so-called time coefficient, $\beta$ the so-called growth coefficient. Depending on the ratio of the bubble to the electrode size, broadly, two limiting cases have been identified: diffusion controlled $(\mathrm{x}=1 / 2)$ and surface reaction controlled 20, 22 $(\mathrm{x}=1 / 3)$, corresponding to Damköhler numbers $D a \gg 1$ and $D a \ll 1$, respectively. At the same time though, some studies have looked at the effect of bubbles on the electrochemical properties of the cell [13, 16]. Sides and Tobias [12], solving for the potential distribution around a bubble, have shown that the primary current around the bubble is depressed. Following up on this work, Dukovic and Tobias [13 used numerical simulations to explore the effect of attached bubbles on the current distribution and over-potential. They solved a set of coupled steady-state partial differential equations for the concentration of the dissolved gas and the electrode potential for a base case of hydrogen evolution on a nickel electrode. When treating the combined effects of surface over-potential and dissolved gas concentration, they noted 
(a)

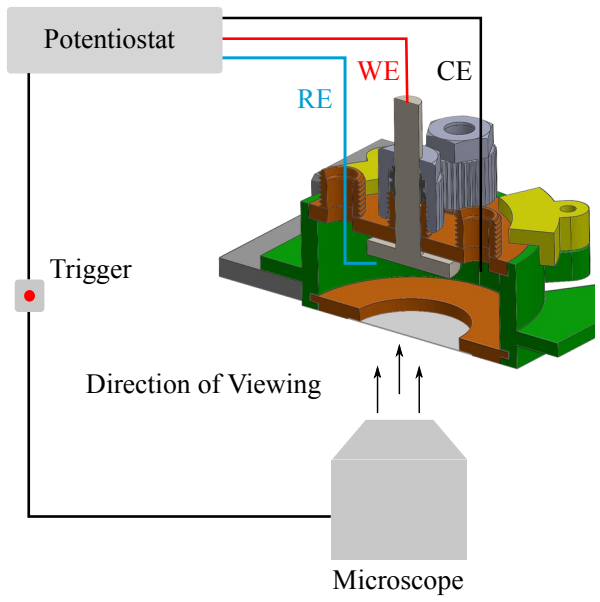

(b)

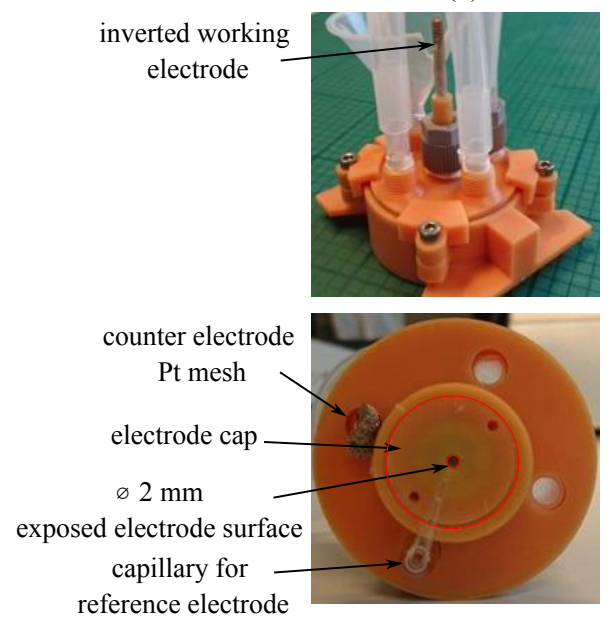

Figure 1.1: (a) Schematic of the experimental setup. The microscope is used to image the electrode through a transparent glass window at the bottom of the cell. The working electrode (red), reference electrode (blue) and the counter electrode (black) are connected to the potentiostat which is triggered together with the microscope. (b) An image of the assembled cell (top). The inverted working electrode is highlighted. The bottom image shows the three electrode assembly as seen from the direction of viewing. An electrode cap with a $2 \mathrm{~mm}$ hole (highlighted with red circles) exposes only a $2 \mathrm{~mm}$ diameter portion of the working electrode region to the electrolyte.

that the current density was highest at the point of attachment of the bubble on the electrode. They explained this counterintuitive enhancement effect as arising from a depression in the dissolved gas concentration, which ultimately suppresses the concentration over-potential at the electrode. Therefore, while it is recognizable that surface coverage due to bubbles may hinder the overall reaction rate, this enhancement effect is clearly counterintuitive. Among more recent works, are experiments that have measured the electrical response at a hydrogen evolving platinum electrode, simultaneously imaging bubbles 23 . 24. While these measurements allowed bubble growth rates to be determined accurately, the side-view images make it difficult to correlate the electrical response to the bubble growth. 
To try and address this issue, we used a home-built electrochemical cell allowing for optical characterization of the entire working electrode surface. Unlike the other studies on this subject in the past [16, 19, 22], an inverted working electrode is used in the cell. This cell design inhibited gravity-induced bubble detachment and any resulting rising bubble-induced bulk liquid motion. Furthermore, polydimethylsiloxane (PDMS) was used to confine the working electrode, additionally acting as the weakest spot for bubble nucleation out of hydrogen oversaturated solutions. With this specific set-up the chronoamperometric current response was correlated to bubble growth, while bubbles primarily nucleate near the working electrode at early stages of electrolysis, and only at later stages growth of micron-sized bubbles on the working electrode was observed. The inverted electrode design helped to disentangle the current response of the bubble growth from that of bubble detachment induced fluid motion. Moreover, a top-view measurement (in contrast to a side-view projection usually employed in literature) helped to better locate the bubble on the electrode, and correlate it with the current obtained. Our measurements highlight the role of bubbles near the gas-evolving electrode in increasing the current, by possibly removing dissolved gas from the electrode surface. Our measurements, thus, imply that the design of structured electrodes (by placing sites of bubble growth, i.e. hydrophobic nucleation sites, adjacent to catalytically active spots) would increase the cell efficiency, something that has been suggested in the past for porous electrodes [34, and employed most recently in the context of bubbles by Linde et al. [22, 35] for planar electrodes.

\subsection{Experimental}

Electrochemical cell: A home-built three-electrode cell (Fig. 1.1) with 0.05 $\mathrm{M}$ sodium phosphate buffer solution ( $\mathrm{pH}$ 6.9) as the electrolyte was used in the experiments. The cell was printed (Rapidshape GP-101 resin) to required design. The working electrode was a nickel disc polished with $0.3 \mu \mathrm{m}$ alumina paste. The electrochemical cell was fabricated such that only a portion of the working electrode was exposed to the electrolyte. This was done by designing a special cap for the working electrode with a $2 \mathrm{~mm}$ diameter hole (shown in Fig. 1.1(b)), and lining the inner surface with polydimethylsiloxane (PDMS). PDMS, being inherently hydrophobic, ensured a good, leak-proof fit. The counter electrode used is a platinum mesh, with an area much larger than the working electrode. $\mathrm{Ag} / \mathrm{AgCl}$ electrode $(\mathrm{BASi}$, in $3 \mathrm{M} \mathrm{NaCl}$ ) with an attached glass capillary acted as reference. Chronoamperometric measurements were 
(a)

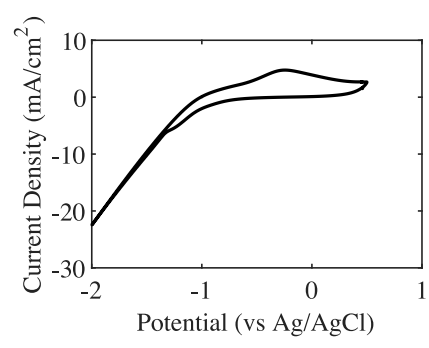

(b)

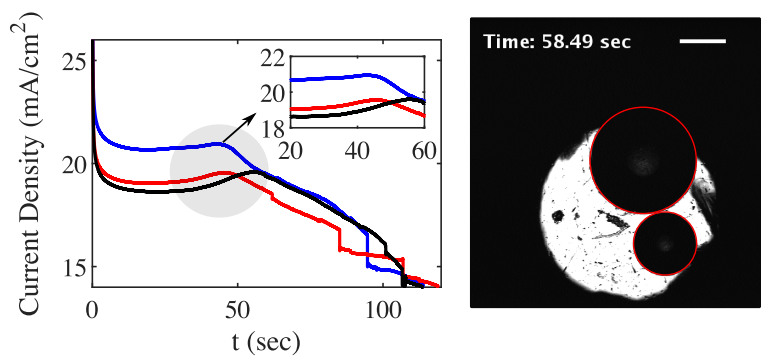

Figure 1.2: (a) Cyclic voltammogram of the nickel electrode, of a $1 \mathrm{~mm}$ diameter, in $0.05 \mathrm{M}$ sodium phosphate buffer solution. The operating potential of -2 $\mathrm{V}$ is in the hydrogen evolution region. (b) Plot of the absolute current density against time for different experiments. The inset highlights the increase in current. Applied potential: $-2 \mathrm{~V}$ vs $\mathrm{Ag} / \mathrm{AgCl}$ reference electrode in a $0.05 \mathrm{M}$ sodium phosphate buffer solution ( $\mathrm{pH}$ 6.9). A typical microscopy image is also shown (Scale bar: $0.5 \mathrm{~mm}$ ). The bubbles appear as a changing shadow (red circle) on the electrode surface. It is important to note that only red circled spots are $\mathrm{H}_{2}$ bubbles. All other dark spots visible on the bright electrode are electrode features.

performed with a VersaStat 3 potentiostat (Princeton Applied Research) at a fixed potential of $-2 \mathrm{~V}$ with respect to the $\mathrm{Ag} / \mathrm{AgCl}$ reference electrode. The resulting current response was analyzed and correlated to the evolved bubbles. Here the absolute value of the current density has been used in the presented figures. After each measurement, the entire electrode was covered as bubbles did not detach from the electrode surface. The cell was degassed at $\approx 0.4$ atm, for 30 minutes before and in between successive experiments to remove surface-attached bubbles.

Bubbles growing on the inverted working electrode were observed using an inverted laser scanning microscope (Nikon confocal microscope A1 system, Nikon Corporation, Tokyo, Japan) with a 4x dry objective (CFI Plan Apo Lambda $4 \mathrm{x} / 0.2$, numerical aperture $=0.2$, working distance $=20 \mathrm{~mm})$. The microscope was used in a reflection configuration24, so the metal electrode appeared as a bright spot in the images. A $561 \mathrm{~nm}$ laser was used with the microscope focused on the electrode surface. The images were obtained at about 10 frames/second. They were $512 \times 512$ pixels in size with a scale of $6.23 \mu \mathrm{m} /$ pixel. 


\subsection{Results and Discussion}

Fig. 1.2(a) shows the stable cyclic voltammogram obtained for the system under study. The onset potential of hydrogen evolution can be seen to be around $-0.8 \mathrm{~V}$ vs $\mathrm{Ag} / \mathrm{AgCl}$. We therefore choose an operating potential much lower than that, namely $-2 \mathrm{~V}$ vs $\mathrm{Ag} / \mathrm{AgCl}$, so that the hydrogen evolution reaction is kinetically fast, which is amenable for bubble growth. It should be noted that the cyclic voltammogram has been taken on a $1 \mathrm{~mm}$ electrode, therefore with a smaller size electrode cap (as opposed to $2 \mathrm{~mm}$ for the rest of the experiments). The bubbles appear as a changing shadow on the images of the bright Ni electrode. Fig. 1.2(b) shows a typical image obtained along with current-time curves. Since the shadow shows the projected image of the bubble (red circles) on the electrode, it is a measure of the bubble's maximal diameter, and not of its contact diameter. The absolute current density measured results from the reaction on the bubble-free electrode area (total area - bubble contact area), which is not measured here. The different colors show successive runs (blue-red-black), affirming qualitatively repeatable behavior (Fig. 1.2(b)).

As highlighted in Fig. 1.3(a) the current initially shows a steep drop from around 900 to $600 \mu \mathrm{A}$ (corresponding current density: about 29 to $19 \mathrm{~mA} / \mathrm{cm}^{2}$ ), which is the expected electrical response to a step-potential [6]. The current then achieves a seemingly steady value for about 20 seconds. Although there is constant hydrogen production, no microbubbles are observed on the electrode itself, as can be seen in Fig. 1.2(b). During this time bubbles likely grow out of $\mathrm{H}_{2}$ oversaturated solution at the PDMS lined electrode edge and the electrode cap polymer. Both materials are hydrophobic and more susceptible to bubble growth. Due to the lack of contrast of the bubble against the PDMS background these bubbles cannot be observed by confocal microscopy.

Following this early phase, we then observe a current increase from about 0.47 to $0.95 \mathrm{~mA} / \mathrm{cm}^{2}$ (a $2.5 \%$ increase over the expected steady-state value). This increase occurs at $\approx 20 \mathrm{~s}$, by which time, 0.018 coulombs of charge, or an equivalent 61.2 nano-moles of hydrogen have been produced at the electrode. At such time, bubbles are seen also to grow at the edges of the electrode. This increase is unexpected, but seen in successive experiments as well, in agreement with the inset of Fig. 1.2(b). There is some variation in the steadystate and corresponding current increase in succeeding experiments - varying between an increase of $0.25 \mathrm{~mA} / \mathrm{cm}^{2}$ for the blue curve (a $1.2 \%$ increase over the background), to $0.95 \mathrm{~mA} / \mathrm{cm}^{2}$ for the black curve (a $5.2 \%$ increase over the background). The variation in the different experiments can be explained by a 

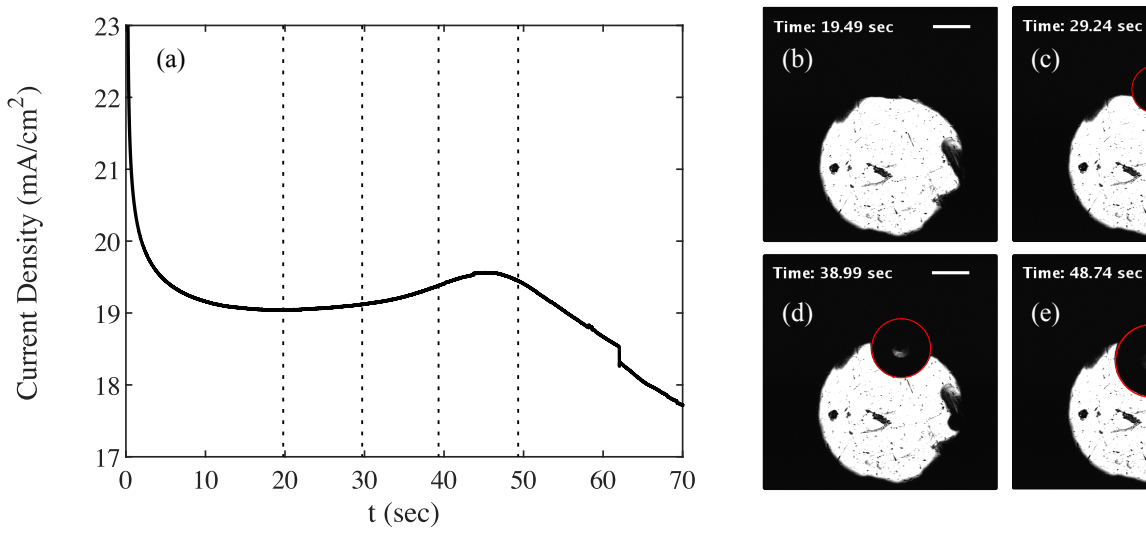

(c)
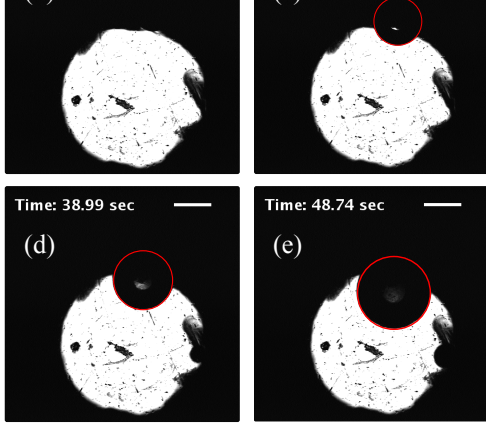

Time: $\mathbf{4 8 . 7 4} \mathrm{sec}$

(e)

Figure 1.3: The measured absolute current density and microscopy images at different time instances. The increase in current is seen simultaneously with bubble growth from the edge of the electrode. Scale bar: $0.5 \mathrm{~mm}$

partial hydrogen coverage. The electrode is not removed from the electrolyte in between experiments, and adsorbed hydrogen molecules (surface nanobubbles) might reduce the effective reaction area of the electrode also explaining the monotonic decrease in steady state value of the current. Still it is important to note that an increase in current density correlates with the growth of a bubble close to the electrode surface on the hydrophobic PDMS. Fig. 1.3 shows the current density increase, side by side with the images of the electrode at that time, for a typical experiment. Natural convection (due to changes in ion concentration close to the electrode) can be excluded due to the design of the experiment [36]. Thus, following the observations by Dukovic and Tobias [13], this observed increase could be attributed to the removal of dissolved gas close to the electrode surface by this "scavenger" bubble. A schematic of the possible mechanism is shown in Fig. 1.4. In the absence of the bubble, part of the surface is blocked by the formed gas, preventing any reaction at those locations. The presence of the bubble increases the flux of gas away from the electrode, thereby allowing larger availability of reaction sites for $\mathrm{H}_{2} \mathrm{O} / \mathrm{H}^{+}$ions at the foot of the bubble. This current enhancement thanks to the bubbles will be discussed in more detail in the following section.

Quantitatively, the increase in gas evolution can be compared with the fraction of gas going into the neighboring bubble, i.e. the bubble growing at the perimeter of the electrode. Assuming the bubble to be a perfect sphere (the 

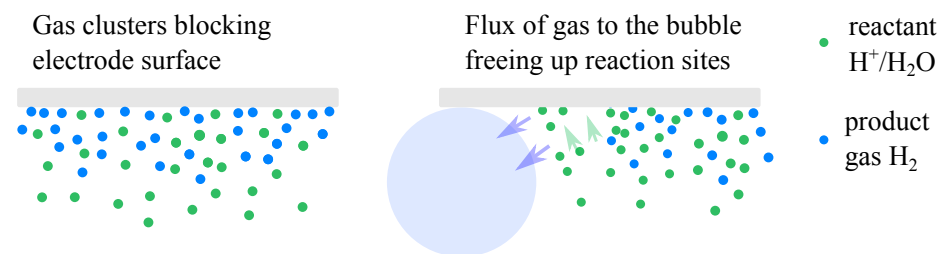

Figure 1.4: Schematic of the possible mechanism responsible for increased current, highlighted in the box. Left: The case without the bubble, corresponding to Fig. 1.3(b). Right: The case with the bubble, corresponding to Fig. 1.3(c)(e). The bubble removes surface attached gas close to its contact point with the electrode, thereby freeing up reaction sites for hydrogen ions. The arrows indicate the proposed direction of the ion/gas motion.

bubble resembles more of a spherical cap dictated by its contact angle, but this serves as a rough estimate), the rate of gas intake by the bubble is given by its change in mass

$$
\rho \frac{d V}{d t}=\frac{\rho}{M} 4 \pi R^{2} \frac{d R}{d t}
$$

where $\mathrm{M}$ is the molar mass of hydrogen. Clearly the gas evolution rate is in good agreement with the calculated intake of the idealized bubble as shown in Fig. 1.7. Further on, the current reaches a peak value and finally decreases to a steady rate. There is likely to be a competition between the current increase due to removal of surface attached gas (or nanobubbles), and current decrease because of physical coverage of electrode by the microbubble, as can be seen in Fig. 1.3(e). This would cause the current to peak before eventually decreasing, as more bubbles accumulate on the electrode, effectively blocking the electrode surface.

Another interesting phenomenon can be easily observed in the second phase of the chronoamperometric measurement. Fig. 1.5 shows the current response to bubble coalescence events for two different experiments. The current profile shows steep changes which we show to correlate (Fig. 1.5) with instances of bubble coalescence. The process of coalescence is sometimes followed by the growth of multiple small bubbles on the electrode. Fig. 1.5 (a) highlights one such instance.

As more of the electrode surface is covered by the bubbles, the current eventually does start to decrease. Remarkably, different experiments have a similar slope (Fig. 1.2(b)). After about 80 seconds, the image of the electrode surface was obscured by the growing bubble, preventing any further observations. 
(a)
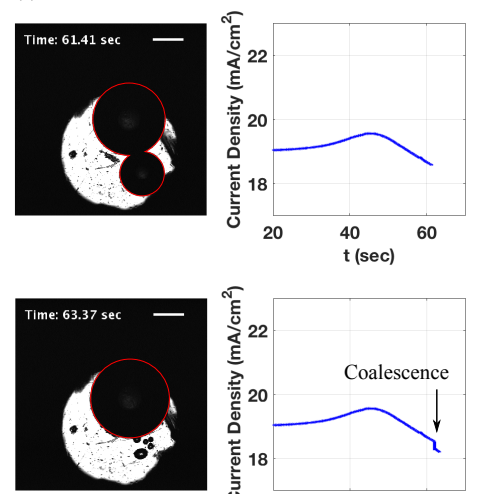

(b)
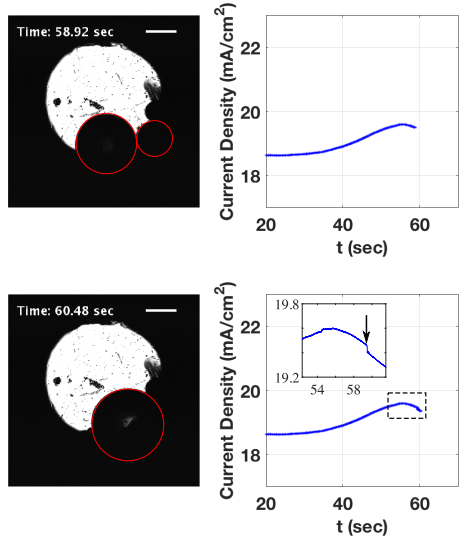

Figure 1.5: Instances of bubble coalescence and simultaneous current response for two separate experiments (a) and (b). Top and bottom show instances before and after bubble coalescence respectively. Coalescence appears in the images as a disappearance of one bubble and the increased size of another.The red outline highlights the coalescing bubbles. Scale bar: $0.5 \mathrm{~mm}$

Bubble induced current increase: Current increase during bubble growth has been observed in recent experiments by other groups as well [23, 24]. In experiments on bubble growth on $\approx 100 \mu \mathrm{m}$ platinum electrodes, Fernández et al. [24] and Yang et al. 23] observed a decrease in over-potential and an increase in current respectively while the bubble was growing. Yang et al. [23] explained this as resulting from the reduction in the bubble covered electrode area. In contrast to this, in our experiments, a bubble is seen growing from the edge, towards the electrode when we see a current increase. Therefore, a decrease in bubble covered electrode area is doubtful. Considering the schematic shown in Fig. 1.4, the removal of surface attached gas could explain the increase in current following the appearance of the bubbles in the vicinity of the electrode. Given the inverted design of the experiment, the physical phenomenon most likely governing this scavenging is diffusion. Close to the electrode, the diffusive flux is $D \frac{c_{e}-c_{s}}{\delta}$. Here $c_{e}$ is the gas concentration at the electrode surface and $c_{s}$ is the saturation gas concentration at bubble surface. Thus, the flux increases drastically for decreasing distance $\delta$ between the electrode and a bubble. It is this flux that removes the surface attached gas, freeing the electrode surface for further electrolysis. This hypothesis is further bolstered by experiments measuring the formation of hydrogen nanobubbles on HOPG 


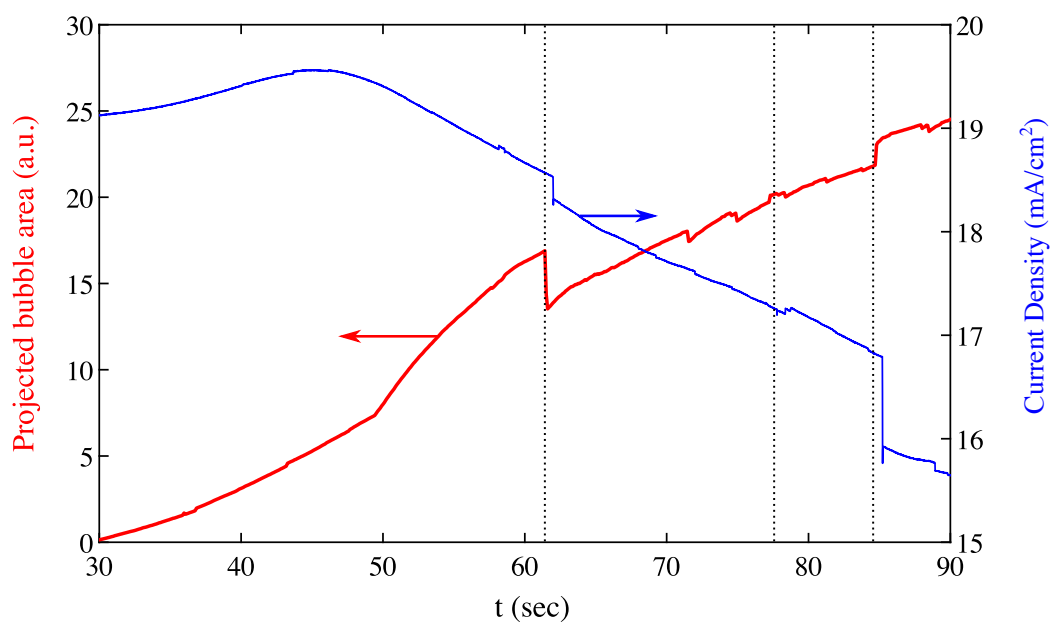

Figure 1.6: Relative change in the projected area of the bubbles on the electrode after 30 seconds $\frac{\text { area-area }_{t=30}}{\text { area }_{t=30}}$, correlated with the abrupt changes in the current density. This increase in area is calculated by tracking the changing pixel area of the bubble shadow on the electrode. It is presented here as the fractional increase in projected bubble area (arbitrary units a.u.) after $t=30$ s. The black vertical lines highlight the times when abrupt changes in area are followed by a change in current

(Highly Oriented Pyrolytic Graphite) surfaces [27], where, using tapping mode AFM, a reduction in the number of nanobubbles (or surface attached gas clusters) was seen when a microbubble appeared on the electrode surface. In the electrochemical literature, it is known that supersaturation of the electrolyte with product gas, or the depletion of the reacting ion, locally at the electrode surface, results in an overpotential component related to these concentrations [13, 16, 25, 37]. Hence, any reduction of gas concentration at the electrode surface (a phenomena that would occur close to the bubble on the electrode) results in a lowering of the concentration overpotential, thereby enhancing the current 13,25 . In an analogous problem of vapor bubbles produced during boiling, this enhancement effect manifests as cooling of the substrate during bubble growth in boiling [38, 39], due to the required latent heat. To correlate the current response to bubble coalescence events, we tracked the total projected area of the bubbles from the images obtained for a particular experiment. This could be easily done by tracking the area of the growing shadow on the electrode image. Any sudden changes in this area should indicate bub- 
ble coalescence. As anticipated, the abrupt changes in current followed from changes in projected bubble area. This can be seen in Fig 1.6. Yang et al. [23] saw sharp changes in current when bubbles detached from the electrode surface. Similarly, in our case, after bubble coalescence, the electrode surface is bubble-free. Since there are possibly two competing effects at play here, their joint effect on the current is not straightforward. The electrode surface equivalent to the bubble contact area is freed because of bubble detachment. This should lead to an increase in current at the electrode. On the other hand though, the electrode comes into contact with the supersaturated electrolyte, which leads to nucleation of many small, novel bubbles, which likely inhibit the current. Altogether, the current is susceptible to sharp changes following the removal of a bubble from its surface. When after coalescence a bubble disappears, the nucleation of multiple small bubbles on the electrode surface is not surprising. The already gas supersaturated electrolyte on coming in contact with the gas-producing electrode surface leads to the sudden eruption of bubbles. This, again, is seen in experiments by Yang et al. 23 after bubble detachment. Since the contact area of any of the bubbles could not be measured directly in this experiment, their direct electrode coverage and effect on current changes is an open question and a subject of ongoing research.

\subsection{Conclusion and Outlook}

In this chapter, we have reported the results of short time chronoamperometric experiments on an inverted nickel electrode. The current is intricately linked with the dynamics of bubbles that grow on its surface. Coalescence events have a sharp and abrupt signature on the current measured. Moreover, direct evidence of the increase in current because of a pre-existing "scavenger bubble" has been presented. We hypothesize that bubbles increase the current by removing dissolved and surface attached gas from the electrode, increasing the number of available reaction sites. This increase in reaction rate close to the bubble, should be reflected as non-uniformity in the ion flux at the electrode as well. Finding the spatial distribution of the ion concentration in the solution near the electrode surface will indeed confirm this hypothesis, and is currently being investigated. There has been a long-held notion that bubbles only impact the electrolytic cell negatively [14, 15]; but now we have shown an instance where it is otherwise. Our results also suggest a way of designing efficient electrodes: having a patterned surface, with air cavities or hydrophobic spots placed adjacent to catalytically active sites. Such a design 


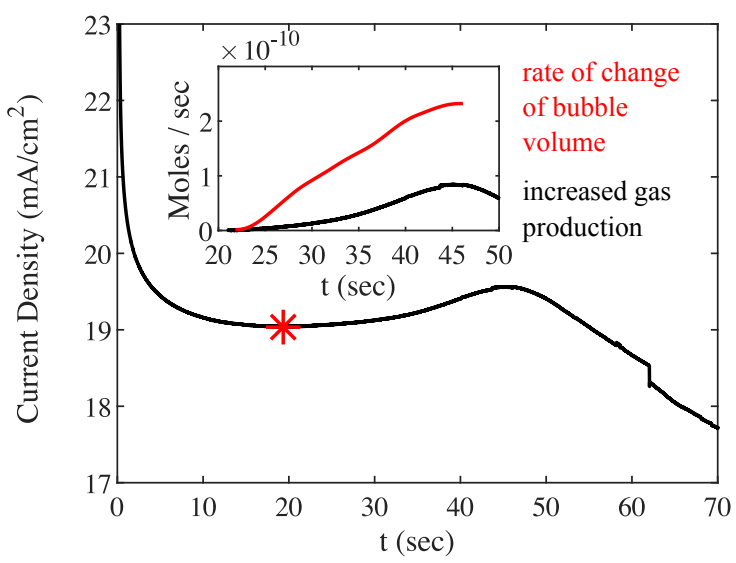

Figure 1.7: The red star marks the point of minimum current density, or the background current (over which we calculate bubble induced enhancement). The inset compares the increased gas production above this background with the rate of absorption by the idealized bubble. The increased gas production $=\frac{\text { current-current }_{\text {background }}}{n F}$; rate of absorption by spherical bubble $=\frac{\rho}{M} 4 \pi R^{2} \frac{d R}{d t}$, red curve)

should allow for greater current with optimal catalyst use. 


\section{Chapter 2}

\section{Measurement of $\mathrm{pH}$ changes near electrodes}

Confocal fluorescence microscopy is a proven technique, which can image nearelectrode $\mathrm{pH}$ changes. For a complete understanding of electrode processes, time-resolved measurements are required, which have not yet been provided. Here we present the first measurements of time-resolved $\mathrm{pH}$ profiles with confocal fluorescence microscopy. The experimental results compare favorably with a one-dimensional reaction-diffusion model; this holds up to the point where the measurements reveal three-dimensionality in the $\mathrm{pH}$ distribution. Specific factors affecting the $\mathrm{pH}$ measurement such as attenuation of light and the role of dye migration are also discussed in detail. The method is further applied to reveal the buffer effects observed in sulfate-containing electrolytes. The work presented here is paving the way toward the use of confocal fluorescence microscopy in the measurement of $3 \mathrm{D}$ time-resolved $\mathrm{pH}$ changes in numerous electrochemical settings, for example in the vicinity of bubbles.

Published as: N Pande, S.K. Chandrasekar, D. Lohse, G. Mul, J.A. Wood, B.T. Mei, D. Krug, Electrochemically Induced pH Change: Time-Resolved Confocal Fluorescence Microscopy Measurements and Comparison with Numerical Model, J. Phys. Chem. Let. (2020). 


\section{$2.1 \quad$ Introduction}

Electrochemical reactions in aqueous solutions are strongly affected by the $\mathrm{pH}$ near the electrode. In corrosion science, potential-pH phase diagrams [40] (Pourbaix diagrams) best summarize this relationship. Moreover, in applications of energy storage and material conversion (e.g., $\mathrm{CO}_{2}$ and $\mathrm{N}_{2}$ reduction to useful products), where protons in solution are consumed, there is a direct link between the $\mathrm{pH}$ and the efficiency of the electrochemical cell. Measuring and understanding $\mathrm{pH}$ profiles near electrodes is therefore essential and can provide insight into the local surface chemistry and help design efficient electrochemical systems. This is particularly relevant in the reduction of $\mathrm{CO}_{2}$, where sensitivity to the near electrode $\mathrm{pH}$ may limit the desired product formation [41-43]. An effective technique to detect $\mathrm{pH}$ changes is the use of indicator molecules, such as fluorescein, whose fluorescence changes with $\mathrm{pH}$. Unlike point measurements, e.g., via scanning electrochemical microscopy [44], imaging fluorescence fields allows for spatially resolved $\mathrm{pH}$-measurement. When coupled with confocal microscopy, this approach offers an even higher spatial resolution, and has already demonstrated its potential in electrochemical applications [45]. For example, Unwin et al. [46, 47] measured three-dimensional steady-state $\mathrm{pH}$ profiles on microelectrodes. Cannan et al. [46] determined the $\mathrm{pH}$ change accompanied by the reduction of benzoquinone to hydroquinone. Similarly, Rudd et al. 47] measured the $\mathrm{pH}$ profiles induced by the reduction of water and oxygen on gold electrodes. They considered different electrode shapes and compared their results with a steady-state reaction-diffusion model. Leenheer and Atwater [48] applied the fluorescence method in a flow cell to compare the steady-state $\mathrm{pH}$ profiles formed (for hydrogen evolution) on patterned $\mathrm{Au}$ electrode surfaces. Furthermore, they measured $\mathrm{pH}$ profiles on various electrode materials, thereby suggesting this technique as a screening tool for identifying electrocatalysts. Similar to Rudd et al. [47], they compared their measurements with a steady-state model, one including laminar flow.

Although fluorescent measurements of spatiotemporal $\mathrm{pH}$ profiles near ionselective membranes have been recently undertaken [49], with related electrokinetic modeling by Andersen et al. [50], such measurements are lacking for electrolytic systems and near the electrodes. Here, besides electric field effects, large gradients in $\mathrm{pH}$ are created because of chemical reactions at the electrode surface. Time resolution is then essential to capture the dynamics at the electrode-electrolyte interface. One such application would be the measurement of $\mathrm{pH}$ profiles around growing hydrogen bubbles in solution, which may 
reveal transient reaction hot-spots [51, 52]. Similarly, other situations involving phase change, simultaneous electrode reactions, or bulk buffer reactions during electrolysis require time-resolved measurements for their accurate characterization. Certainly, a further development of time-resolved measurements techniques is urgently needed to understand dynamic processes occurring at electrode/electrolyte interfaces in electrochemical processes. In spite of the need, to the best of our knowledge, a quantitative comparison of time-resolved $\mathrm{pH}$ measurements and modeling using fluorescent dyes is not yet available in the literature. In this contribution we demonstrate the feasibility of using fluorescent dyes to measure spatiotemporally varying $\mathrm{pH}$ profiles in solution by comparing the $\mathrm{pH}$ changes arising from electrochemical oxygen reduction with a time dependent reaction-diffusion model. We further apply this technique to highlight buffer effects in sulfate-containing electrolytes.

\section{$2.2 \quad$ Experimental Methods}

For the working electrode, a $3 \mathrm{~nm}$ thick chromium (under) layer was used for better adhesion between the platinum film and the glass slide. The sheet resistance of the resulting thin film electrode was about $69 \Omega$. The electrical connection to the working electrode was made with a platinized titanium point contact. Prior to the measurement, the $\mathrm{pH}$ of the solution was adjusted to a $\mathrm{pH}$ value of 5 by addition of appropriate amounts of $0.1 \mathrm{M} \mathrm{HClO}_{4}$ (or 0.5 $\mathrm{M} \mathrm{H}_{2} \mathrm{SO}_{4}$ for sulfate electrolytes). The $\mathrm{pH}$ of the solution before the start of each experiment (as well as the calibration solutions shown in Fig. 2.1(b)) was measured using the Hannah Instruments Edge-pH meter that has an accuracy of $\pm 0.02 \mathrm{pH}$ units. All chemicals were purchased from Sigma-Aldrich.

\subsubsection{Confocal fluorescence $(\mathrm{pH})$ microscopy}

To carry out the measurements, an electrochemical cell assembly was mounted on top of an inverted confocal microscope. A schematic of the setup which also contains the relevant dimensions is shown in Fig. 2.1(a). The electrochemical housing was made of Teflon. In all measurements, a platinized titanium mesh was rolled up and placed as a ring at about $4 \mathrm{~cm}$ from the working electrode. This assembly successfully prevented any interference of the counter electrode reaction with the $\mathrm{pH}$ measurement. A $10 \mathrm{~nm}$ thick platinum film evaporated on a circular glass slide (thickness $170 \mu \mathrm{m}$, diameter $50 \mathrm{~mm}$ ), formed the working electrode. $\mathrm{A} \mathrm{BASi}{ }^{\circledR} \mathrm{Ag} / \mathrm{AgCl}$ (in $3 \mathrm{M} \mathrm{NaCl}$ ) was used as a reference 


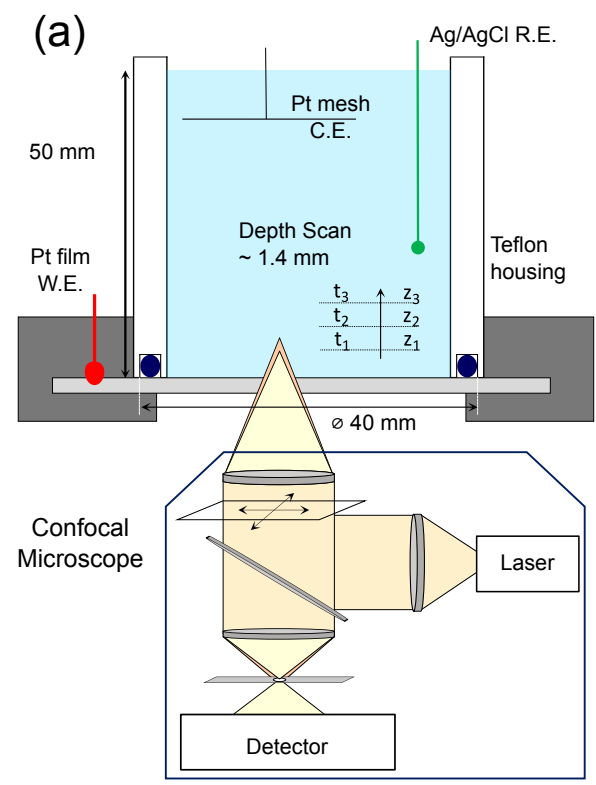

(b)

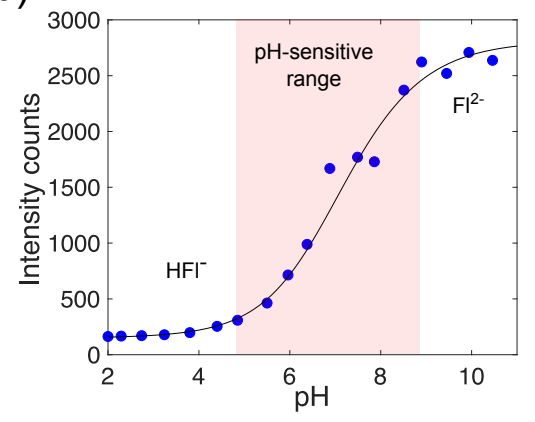

Figure 2.1: (a) Schematic of the experimental setup. The electrochemical cell was placed on the inverted confocal laser scanning microscope. The transparent working electrode allowed for depth-wise $(z)$ measurement of fluorescent intensity. (b) Calibration results for the $\mathrm{pH}$ dependence of fluorescein. The experimental data (filled circles) shown here are the mean of three measurements of intensity at each $\mathrm{pH}$ (error bars are smaller than the marker size). A sigmoidal function (black line; see Appendix for details of fit) is fitted to all three measurements at each $\mathrm{pH}$. The measurements were performed in $1 \mathrm{mM}$ $\mathrm{Na}_{2} \mathrm{SO}_{4}$ containing $8 \mu \mathrm{M}$ fluorescein. $\mathrm{pH}$ was adjusted to the required value by addition of $\mathrm{H}_{2} \mathrm{SO}_{4}$. 
electrode. Unless otherwise stated, $0.5 \mathrm{M} \mathrm{NaClO}_{4}$ with $8 \mu \mathrm{M}$ Sodium Fluorescein was used as electrolyte. The measurements involved taking fluorescence images along the scanned direction $z$ (in a serial fashion as shown in Fig. 2.1(a)). The mean of each image was then taken as the measured intensity at the corresponding $z$-position. The fluorescence signal was found to be compromised up to a distance $z \approx 100 \mu \mathrm{m}$ above the surface (see experimental section and Appendix for further details). Therefore, any fluorescence intensity (and resulting $\mathrm{pH}$ ) information was only obtained above this threshold.

Fluorescein $(\mathrm{Fl})$ is a popular choice to probe $\mathrm{pH}$ changes in electrochemical cells [46 48, 53, 54]. The $\mathrm{pH}$ sensitivity of $\mathrm{Fl}$ is well documented 55,57 and arises from the existence of different protonated forms of the molecule in solution. The fluorescence emission of constant $\mathrm{pH}$ solutions was measured for the intensity-to-pH calibration (as shown in Fig. 2.1(b)). These results were fitted with an analytical function to allow for a conversion from $\mathrm{Fl}$ intensities obtained in the experiments to $\mathrm{pH}$. The laser and confocal settings were kept constant throughout the study such that the curve in Fig. 2.1(b) applies to all experiments. The dye is found to be particularly $\mathrm{pH}$-sensitive in the range $5 \lesssim p H \lesssim 10$ (indicated by the shading in Fig. [2.1(b)), as evidenced by the pronounced increase of fluorescence emission intensity measured with increasing $\mathrm{pH}$ within this interval. However, the highly nonlinear intensity-pH relationship suggests that measurement results beyond $p H \gtrsim 8.5$ value should be taken with caution. Details on the fit and the repeatability are provided in the Appendices. The effect of dye migration induced by the electric field has also been addressed therein. Migration is detrimental to the present technique, which assumes a homogeneous dye distribution. It was found that a certain minimum supporting electrolyte concentration is necessary to keep migration effects at bay.

Last, to compare with experimental results, we also simulated the $\mathrm{pH}$ profiles during reaction. Since the supporting electrolyte concentration is high, we adopted a reaction-diffusion model for the simulations of the general form

$$
\frac{\partial c_{k}}{\partial t}=D_{k} \frac{\partial^{2} c_{k}}{\partial z^{2}} \pm f(c)
$$

where $c_{k}(z, t)$ is the concentration of species $k, D_{k}$ the corresponding diffusion constant, and $f(c)$ is a non-linear function representing reaction terms. Here 

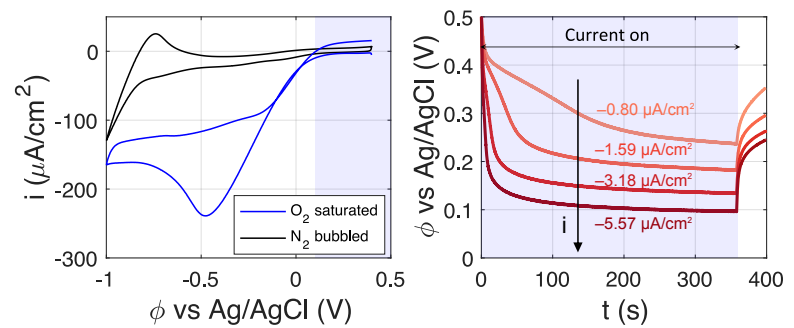

Figure 2.2: Left: First cycle of the cyclic voltammogram (CV) measured at $10 \mathrm{mV} / \mathrm{s}$ for the Pt working electrode in $\mathrm{O}_{2}$ saturated and $\mathrm{N}_{2}$ bubbled solutions $\left(\mathrm{pH} 5 \mathrm{HClO}_{4}+0.5 \mathrm{M} \mathrm{NaClO}_{4}+8 \mu \mathrm{M} \mathrm{Fl}\right)$ in our setup. The shaded region shows the potential range measured in chronopotentiometric $(\mathrm{CP})$ experiments. Right: The $\mathrm{CP}$ curves obtained for the $\mathrm{O}_{2}$ saturated case. The shaded region indicates the time over which the constant current is applied. The corresponding current density for each curve is mentioned.

the chemical reactions considered are

$$
\begin{aligned}
& \mathrm{H}^{+}+\mathrm{OH}^{-} \underset{k_{b}}{\stackrel{k_{f}}{\rightleftharpoons}} \mathrm{H}_{2} \mathrm{O} \\
& \mathrm{H}^{+}+\mathrm{Fl}^{2-} \underset{k_{b_{F l}}}{\stackrel{k_{f F l}}{\rightleftharpoons}} \mathrm{HFl}^{-},
\end{aligned}
$$

where the equilibrium constants are $\frac{k_{b}}{k_{f}}=K_{W}$ and $\frac{k_{b, F l}}{k_{f, F l}}=K_{f, e q}$. The $\mathrm{p} K_{a}$ of $\mathrm{H}_{2} \mathrm{Fl}$ is lower than the $\mathrm{pH}$ considered here and therefore it can be ignored. Assuming that the concentration of water is large and therefore essentially constant during the experiment, the equations have been solved for the concentration of three species: $\mathrm{H}^{+}, \mathrm{OH}^{-}, \mathrm{Fl}^{2-}$. Further details of the exact reaction-diffusion equations (with their boundary conditions) and the numerical technique (including validation) are presented in the supporting information. The contribution of capacitive current has also been taken into account. However, since the exact value of the capacitance (C) is not known in our measurements, results for $\mathrm{C}$ values in the range $0 \leq C \leq 120 \mu \mathrm{F} / \mathrm{cm}^{2}$ have also been presented in Fig. 2.3(c). Further experimental and numerical details can be found in the Appendices. 


\subsection{Results and Discussion}

\subsubsection{Time-resolved $\mathrm{pH}$ measurements}

A cyclic voltammogramm (CV) of an $\mathrm{O}_{2}$ saturated solution $\left(\mathrm{pH} 5 \mathrm{HClO}_{4}+\right.$ $0.5 \mathrm{M} \mathrm{NaClO}_{4}+8 \mu \mathrm{M} \mathrm{Fl}$ ), along with the measured potential of the Pt working electrode for some of the constant current experiments is shown in Fig. 2.2. For reference, an additional CV is included for the same configuration but with a solution bubbled with $\mathrm{N}_{2}$. For the current densities, $i$, and run-times considered here, it is estimated (using an initial concentration corresponding to $1 \mathrm{~atm}$ $\mathrm{O}_{2}$ pressure) that the oxygen at the electrode surface never gets completely depleted. This is also evident from the differences between the CV's of the $\mathrm{O}_{2}$ saturated and $\mathrm{N}_{2}$ bubbled solutions in Fig. 2.2. Hence it can be concluded that oxygen reduction, and not water or proton reduction, is the primary reaction occurring at the electrode. The measured potential window of operation in our constant current experiments is between $0.1 \mathrm{~V}$ and $0.5 \mathrm{~V}$ vs $\mathrm{Ag} / \mathrm{AgCl}$ (at a starting $\mathrm{pH}$ of 5 ), which translates to $0.6 \mathrm{~V}-1.1 \mathrm{~V}$ vs RHE. Given that an ovepotential of [58] $|\Delta \phi| \gtrsim 0.3 \mathrm{~V}$ (over the thermodynamic potential of 1.23 $\mathrm{V}$ vs RHE) is required to drive the $\mathrm{O}_{2}$ reduction reaction on platinum, the potentials measured in our experiments are consistent with $\mathrm{O}_{2}$ reduction occurring at the electrode. However, since the $\mathrm{O}_{2}$ reduction reaction depends on the $\mathrm{pH}$ of the solution [59, 60], the proper flux boundary conditions for $\mathrm{OH}^{-}$ and $\mathrm{H}^{+}$are complicated (consumption of $\mathrm{H}^{+}$or production $\mathrm{OH}^{-}$depending on the reaction). Nevertheless, the calculated $\mathrm{pH}$ profiles shown here were found to be independent of this. Finally, it is important to mention that fluorescein is stable under the conditions applied [61 63]. The obtained emission intensity profiles and the resulting $\mathrm{pH}$ distributions (at $0.5 \mathrm{M} \mathrm{NaClO}_{4}$ supporting electrolyte concentration) are summarized in Fig. 2.3(a) for various (constant) applied current densities. In all cases considered here, $i$ is limited to values traditionally considered minute for electrochemistry. Despite such low current densities, the $\mathrm{pH}$ change and the corresponding thickness of the depletion layer are significant. Fig. 2.3(a) shows the attenuation corrected mean intensity of fluorescein emission as a function of distance $z$ from the electrode surface. Independent of the applied current density, a steep front is seen to propagate into the solution already at early times, $\mathrm{t}<300 \mathrm{~s}$. This feature also translates to the corresponding pH-profiles. It should be noted, however, that intensity levels within the resulting 'shoulder' close to the electrode reach the saturation limit and due to the uncertainties described above, $\mathrm{pH}$-results are grayed out in these instances. Nevertheless, the experimental results are 
(a) Experiments

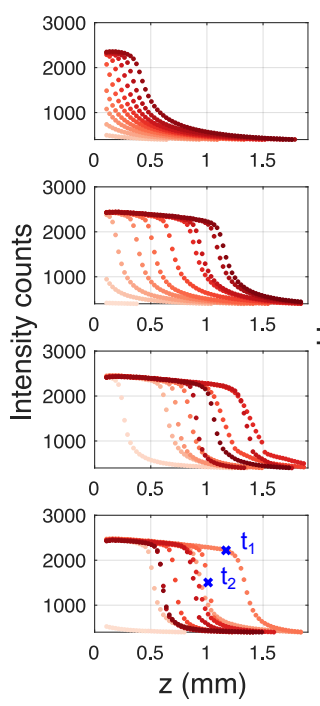

(b) Model

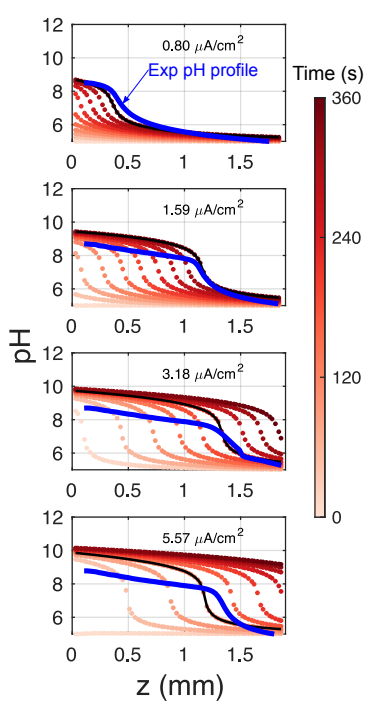

(c) Depletion length

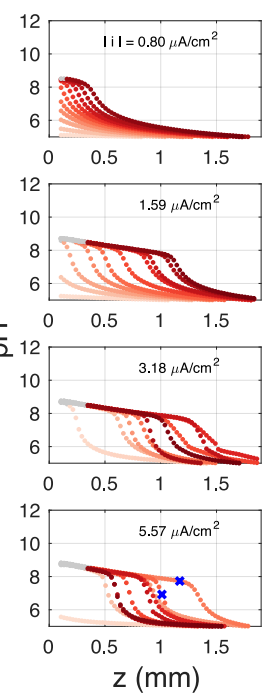

\section{(C) Depletion length}
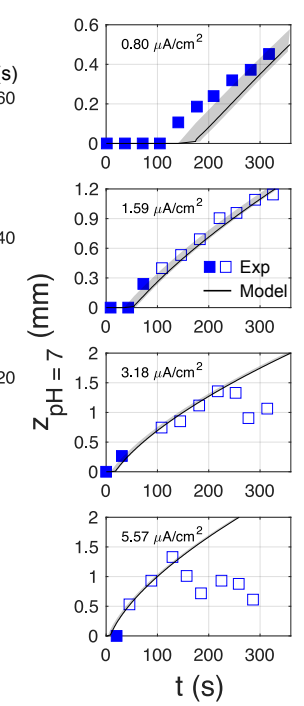

Figure 2.3: Experimental versus model results. The experimental measurement is restricted to $z>0.1 \mathrm{~mm}$ because of limitations of the optical setup (see Appendix for details) (a) Attenuation and depth corrected fluorescein intensity profiles. Corresponding $\mathrm{pH}$ profiles calculated using the calibration curve. $\mathrm{pH}>8.5$ has been grayed out because of the uncertainty in measurement described in the text. $t_{1}$ and $t_{2}$ have been marked for use in Fig. 2.4. (b) Model results (with $\mathrm{C}=88 \mu \mathrm{F} / \mathrm{cm}^{2}$ ) calculated at experimental times. The solid lines are drawn to compare $\mathrm{pH}$ profiles of the experiment (blue) with the model (black). (c) Comparison of depletion length $z_{p H=7}$ of experiment versus model. The shaded region indicates the model results over a range of capacitance $0 \leq C \leq 120 \mu \mathrm{F} / \mathrm{cm}^{2}$ (solid line with $\mathrm{C}=88 \mu \mathrm{F} / \mathrm{cm}^{2}$ ). Open squares show the location of the $\mathrm{pH}$ front after the first appearance of the inhomogeneity as shown in Fig. 2.4. 
in good agreement with the simulated $\mathrm{pH}$ profiles shown in Fig. 2.3(b) (see solid lines). Interestingly, also in the simulations the $\mathrm{pH}$ is near constant close to the electrode for $|i| \geq 1.59 \mu \mathrm{A} / \mathrm{cm}^{2}$, yet with $p H=9-10$ the values are slightly outside the experimental sensitivity range. Even at current densities of $\sim 1 \mu \mathrm{A} / \mathrm{cm}^{2}$, the depletion layer or the penetration depth of the $\mathrm{pH}$ profile reaches $\sim 1 \mathrm{~mm}$ into the electrolyte. At higher current densities, this depletion length grows faster and extends further into the bulk of the solution.

It can be seen, however, that for the two highest current densities considered here, the intensity as well as the $\mathrm{pH}$ profiles recede at later times (corresponding to darker shadings of the markers), whereas the model predicts a monotonic outward propagation of the front. To enable a quantitative comparison, we track the position $z_{p H=7}$ at which the $\mathrm{pH}=7$ is encountered as a proxy for the front location. As Fig. 2.3 (c) shows, the $\mathrm{pH}$ front propagation in the experiments is well captured by the model for the two lower current density cases presented here. At higher current densities and at late times, though, the $\mathrm{pH}$ front in experiments either recedes or saturates. This is also true for repeat measurements made (see Appendix section 2.5.4). However, this effect appears to be an artifact of the way the mean fluorescein intensities are calculated. Consistent with the 1D assumption, only a measure of the mean across the entire image (i.e. a plane parallel to the electrode) is considered. For example, at $t_{1}$ (for $|i|=5.59 \mu \mathrm{A} / \mathrm{cm}^{2}$, see Fig. 2.3(a)), this is appropriate as highlighted in Fig. 2.4(a). At $t_{2}$ though, the intensity distribution displayed in Fig. 2.4(a) becomes distinctly inhomogeneous as seen in Fig. 2.4(b). This implies that $2 \mathrm{D}$ or $3 \mathrm{D}$ effects become relevant, which are not captured in the one-dimensional model.

To determine the location and time at which $3 \mathrm{D}$ effects become relevant, we consider the standard deviation $(\sigma)$ normalized with the mean intensity $(\mu)$ of the image as shown in Fig. 2.4(c). To minimize the effect of high frequency spatial noise, the image was box-filtered with a filter size of 50 pixels before calculating $\sigma$. Fig. 2.4(c) captures the uniform image intensity for $|i|=0.8$ $\mu \mathrm{A} / \mathrm{cm}^{2}$ as a near constant $\sigma / \mu$. In contrast, a visible peak in $\sigma / \mu$ at the depletion front $z=z_{p H=7}$ is observed for all other cases. At the two highest current densities considered, the unsteadiness in fluorescein intensity develops over time as well. The onset time $\left(t_{\text {ons }}\right.$ defined as $\left.\sigma / \mu>0.1\right)$ of this instability thus calculated is, in Fig. 2.4(d), found to sharply reduce with increasing current densities which is well approximated by an inverse proportionality. It is conceivable then that this instability occurs only after a certain threshold number of $\mathrm{H}^{+}$ions have been depleted from solution. The distance $\delta$ at which 
(a) Homogenous

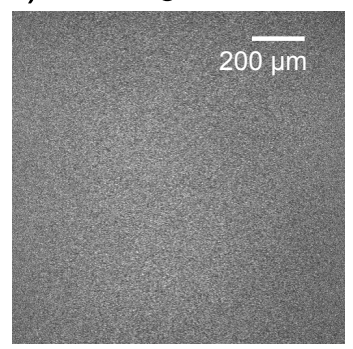

(b) Inhomogenous

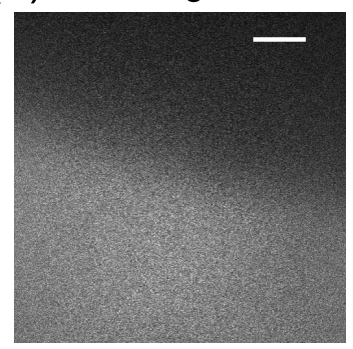

(c) Identifiying Inhomogenity

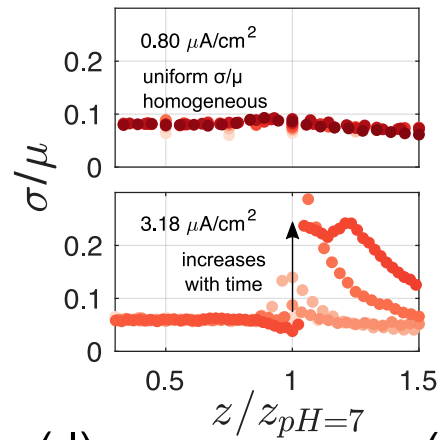

(d)

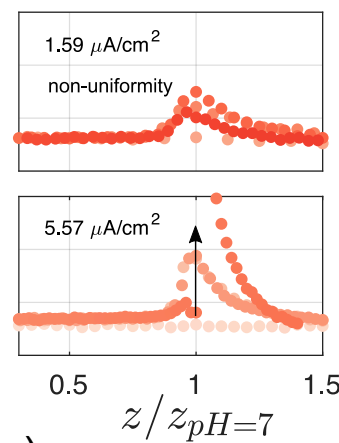

(e)
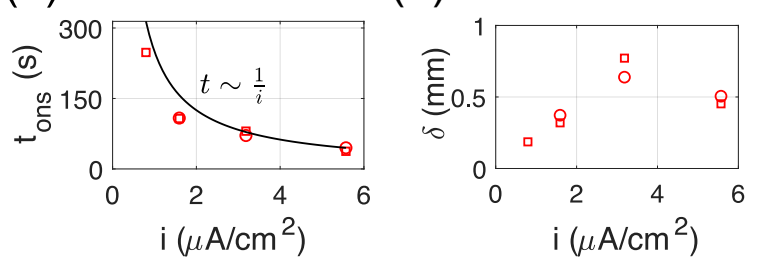

Figure 2.4: Inhomogeneous fluorescein intensity in a plane. Example of fluorescein intensity images $\left(|i|=5.59 \mu \mathrm{A} / \mathrm{cm}^{2}\right)$ at times marked in Fig. 2.3 . (a) homogeneous image at time $t_{1}$, and (b) inhomogeneous at time $t_{2}$. (c) $\sigma / \mu$ versus depth for all current densities. The same color bar as in Fig. 2.3 applies. Sharp changes in $\sigma / \mu$ are used to pick out times and positions where this nonuniformity is observed. (d) The onset time $t_{\text {ons }}$ vs current density. The solid line in panel $\mathrm{d}$ corresponds to $t_{\text {ons }}=\frac{250}{i} \mathrm{~s}$ and is arbitrarily chosen to highlight the inverse relationship between $t_{\text {ons }}$ and $i$. (e) The location $z=\delta$ at which the inhomogeneity is first observed vs the current density. Different symbols are repeat measurements. 

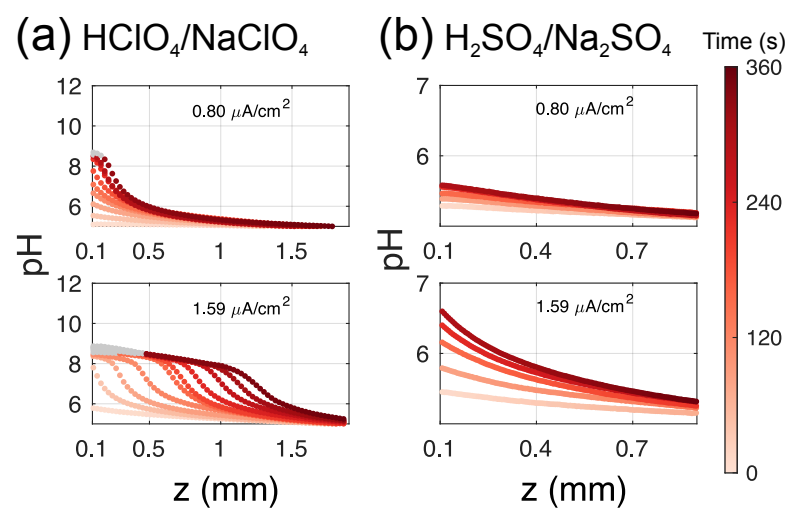

Figure 2.5: Comparison of $\mathrm{pH}$ profiles for (a) perchlorate $\left(\mathrm{NaClO}_{4} / \mathrm{HClO}_{4}\right)$ and (b) sulfate $\left(\mathrm{Na}_{2} \mathrm{SO}_{4} / \mathrm{H}_{2} \mathrm{SO}_{4}\right)$ electrolytes. All measurements were performed in $0.5 \mathrm{M}$ supporting salt concentration containing $8 \mu \mathrm{M} \mathrm{Fl}$. pH was adjusted to $\mathrm{pH} 5$ by addition of respective acid. All solutions were bubbled with $\mathrm{N}_{2}$ before starting the experiment. $\mathrm{pH}>8.5$ has been grayed out because of the uncertainty in the measurements described in the text. Interval between successive red lines $\approx 30 \mathrm{~s}$.

this non-uniformity is first measured, shows no clear trend: the non-uniformity first increases until $|i|=3.18 \mu \mathrm{A} / \mathrm{cm}^{2}$ and then decreases again slightly later. Since we only look at a small portion of the electrode though, deviations from a 1-D profile can occur much earlier, at a different $\delta$. It is unlikely that the reaction at the counter electrode plays any role in the appearance of instability as it is sufficiently far away compared to the measured depletion lengths of $\sim$ $2 \mathrm{~mm}$. Possible reasons could then be the presence of electric field effects or induced fluid flow in the system [64], which have not been modelled. However, despite the early appearance of inhomogeneity, the $\mathrm{pH}$ profiles in experiments are similar to the model results up to distances and times that are much larger (see Fig. 2.3(c): filled and open symbols, and blue/black lines in 2.3(b)). It may be possible then that the departure of $\mathrm{pH}$ profiles in experiments, from a $1 \mathrm{D}$ diffusion approximation, occurs only after a certain minimum $\sigma / \mu$ (and corresponding inhomogeneity) is reached.

\subsubsection{Sulfate buffer effect}

In addition to the above measurements, we proceed to evaluate the developing $\mathrm{pH}$ profiles in sulfate containing electrolytes, e.g. in the $\mathrm{Na}_{2} \mathrm{SO}_{4} / \mathrm{H}_{2} \mathrm{SO}_{4}$ 
system. This system is frequently used (for example sulfuric acid is commonly used to study $\mathrm{O}_{2}$ reduction) but, in contrast to perchlorate electrolytes, may induce additional buffer capacity, thus changing the $\mathrm{pH}$ profiles. In fact, $\mathrm{H}_{2} \mathrm{SO}_{4}$ has two dissociation constants, the second corresponds to the dissociation of $\mathrm{HSO}_{4}{ }^{-}$with a $\mathrm{p} K_{a}$ of around 2 65 67]. Fig. 2.5 compares the $\mathrm{pH}$ profiles measured for the sulfate case to those obtained with perchlorate electrolyte, for the two lowest current densites. It is evident that the $\mathrm{pH}$ profiles develop significantly slower in sulfate-containing electrolytes. For example, for $|i|=1.59 \mu \mathrm{A} / \mathrm{cm}^{2}$, the $\mathrm{pH}$ profiles in the $\mathrm{Na}_{2} \mathrm{SO}_{4} / \mathrm{H}_{2} \mathrm{SO}_{4}$ system have no clear front propagating in the solution; the profiles rather become increasingly steep close to the electrode surface with time, while for the perchlorate solution depletion lengths $z_{p H=7} \approx 1.5 \mathrm{~mm}$ are achieved.

To try to further explain the experimental results, we consider the $\mathrm{p} K_{a}$ of $\mathrm{HSO}_{4}{ }^{-}$, which, although is well below our starting $\mathrm{pH}(\mathrm{pH}=5)$, due to the presence of the large concentration of $\mathrm{SO}_{4}{ }^{2-}$ in solution, creates a reservoir of $\mathrm{HSO}_{4}{ }^{-}$ions which act as a source of protons in solution and stabilizes the solution against $\mathrm{pH}$ changes. We attempt to capture this effect in the $1 \mathrm{D}$ model as our results in the supplement show. This buffer effect is most likely present in experimental measurements in literature with sulfate electrolytes [44, 48]. For example, Leenheer and Atwater 48 measured the $\mathrm{pH}$ on patterned gold electrodes in $\mathrm{Na}_{2} \mathrm{SO}_{4}$ solutions, with different pattern shapes and area. However, their steady state simulations predicted a depletion zone much larger than experiments. Similarly, the buffering effect of $\mathrm{Li}_{2} \mathrm{SO}_{4}$ solutions may also be present in the recent measurements by Monteiro et al. 44. A comparison such as ours, between perchlorate and sulfate electrolytes, should help to quantify the magnitude of this effect and help better interpret results.

\subsection{Conclusion}

To summarize, we have successfully demonstrated the use of fluorescein to measure time-resolved $\mathrm{pH}$ profiles in solution. The results of a time-dependent reaction-diffusion model compare reasonably well with the experimental data. However, the inhomogeneity of $\mathrm{pH}$ in a plane that develops at 'high currents' clearly shows the need for time-varying local $\mathrm{pH}$ measurements. The crucial aspects to consider when using fluorescence microscopy for $\mathrm{pH}$ measurement, like optical distortions and signal attenuation, have been carefully examined. Furthermore, the concentration of the supporting electrolyte is shown to influence migration of fluorescent dyes and should be considered to avoid pitfalls in $\mathrm{pH}$ 
measurement in electrochemical systems. For sulfate containing electrolytes, our analysis reveals buffering effects, which likely explain the difference between the measured diffusion profiles and those observed in experiments in the past 48 .

Fluorescence microscopy offers time-resolved and relatively non-intrusive measurement of $\mathrm{pH}$ instantly over a large area. Since the principle of measurement presented here is applicable to other fluorescent dyes with a different $\mathrm{pH}$ detection range, this technique can be used for a wide range of electrochemical systems to elucidate electrode dynamics. This holds in particular for $\mathrm{CO}_{2}$ reduction on gas diffusion electrodes, since the second $\mathrm{p} K_{a}$ of carbonic acid lies in the fluorescein detection region. Our developed method can be directly implemented to quantify mass transport, the role of bicarbonate concentrations etc. in the electrolyte. More generally, the measurement technique presented here offers insight into the dynamics of ions in solution, important to many electrochemical systems, none more so than in electrochemical cells to unravel the role of start-stop transients. Detailed information of the $\mathrm{pH}$ distribution will provide a better understanding of electrode processes and aid in the overall design of electrochemical systems for eventual use in large scale electrolysis. 


\subsection{Appendices}

\subsubsection{Experimental Methods}

A Nikon inverted laser scanning confocal fluorescent microscope (Nikon confocal microscope A1 system, Nikon Corporation, Tokyo, Japan) with a 10x dry objective (CFI Plan Fluor 10x/0.3, numerical aperture $=0.3$, working distance $=16 \mathrm{~mm}$ ) was used in the resonant scanning mode (33 ms per image) to measure a $1.28 \mathrm{~mm} \times 1.28 \mathrm{~mm}$ region $\left(512 \times 512\right.$ pixel $\left.^{2}\right)$ chosen close to the center of the electrode. A $488 \mathrm{~nm}$ excitation laser was chosen to excite $\mathrm{Fl}$, while the emission was collected in a $515-550 \mathrm{~nm}$ wavelength window. The pinhole $(29.4 \mu \mathrm{m})$ cuts off any out of focus light allowing to image thin volume sections. Close to 70 measurement cross sections with $20 \mu \mathrm{m}$ distance from each other were scanned repeatedly, resulting in a total measured depth of 1.4 $\mathrm{mm}$. The scanning along $z$ proceeded from below the electrode surface into the solution and was repeated at a typical rate of $2 \mathrm{~Hz}$. The acquisition frequency was limited by the movement of the stage in the z-direction. To determine the location of the electrode surface we measure the light reflection [68] from the working (glass slide) electrode. Fig. 2.6 shows the mean reflection and fluorescein intensity signals measured simultaneously, starting from below the glass slide. The fluorescein signal does not provide clear information on the (electrode) surface location, hence the reflection signal is used. The presence of the glass slide causes two reflection maxima $115 \mu \mathrm{m}$ apart, which can be used to establish the surface positions. Therefore, before starting each experiment, the reflection signal is measured (by scanning optical sections $5 \mu \mathrm{m}$ apart) to determine where the surface of the electrode is located. It should be noted that even though a simplified Point Spread Function (PSF) has been assumed in the following analysis, the actual PSF will likely be more complicated due to the many different refractive index media (air-glass-chromiumplatinum-water). While increasing the numerical aperture (NA) will increase the z-resolution 69 (z-resolution $\propto 1 / \mathrm{NA}^{2}$ ), the choice was limited due to significant reduction in the measured fluorescent intensity signal at the electrode interface for high NA objectives as shown in Fig. 2.6. This was likely due to the high refractive index contrast between the glass-metal interface, which at the large incident angles of a high NA objective, may cause considerable loss of transmitted light due to internal reflection.

In the experiments, sections in the scanned direction are taken by the programmed movement of the optical stage $(20 \mu \mathrm{m}$ apart in the experiments in the main text). The distances measured $\left(z_{m}\right)$ in this way (from the elec- 


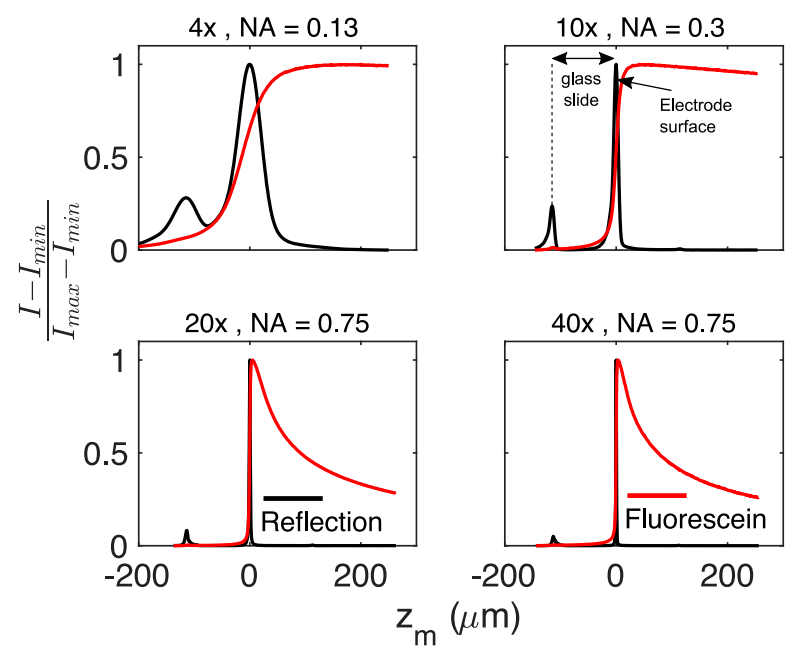

Figure 2.6: Surface reflection and fluorescein intensity for three different $\mathrm{Nu}-$ merical Apertures (NA's) and 4 different magnifications for a constant $\mathrm{pH}$ and Fluorescein concentration solution (E-cell off). Maxima in the surface reflection corresponds to the electrode surface.

trode surface), however, do not take into account distortion in the light path due to variations in the refractive index (air vs. aqueous electrolyte). Visser and Oud [70] give the relationship between the actual focal distance $(\Delta z)$ to stage movement $\left(\Delta z_{m}\right)$ as $\Delta z=\Delta z_{m} n$, where $n$ is the refractive index of the medium. To verify the appropriateness of this correction in our case, we consider the measured glass slide thickness of $115 \mu \mathrm{m}\left(\Delta z_{m}\right)$. Using $n_{\text {glass }}=1.5$, the corrected glass slide thickness then is $\Delta z=115 \mu \mathrm{m} \times n_{\text {glass }}=172.5 \mu \mathrm{m}$, very close to the actual value of $170 \mu \mathrm{m}$. We carry out a similar correction for the refractive index of the electrolyte solution (using $n_{\text {sol }}=1.33$ ) such that $z=n_{\text {sol }} z_{m}$. So while the total measured depth is $z_{m}^{\max } \approx 1.4 \mathrm{~mm}$, the corrected depth is $z^{\max } \approx 1.9 \mathrm{~mm}$. 


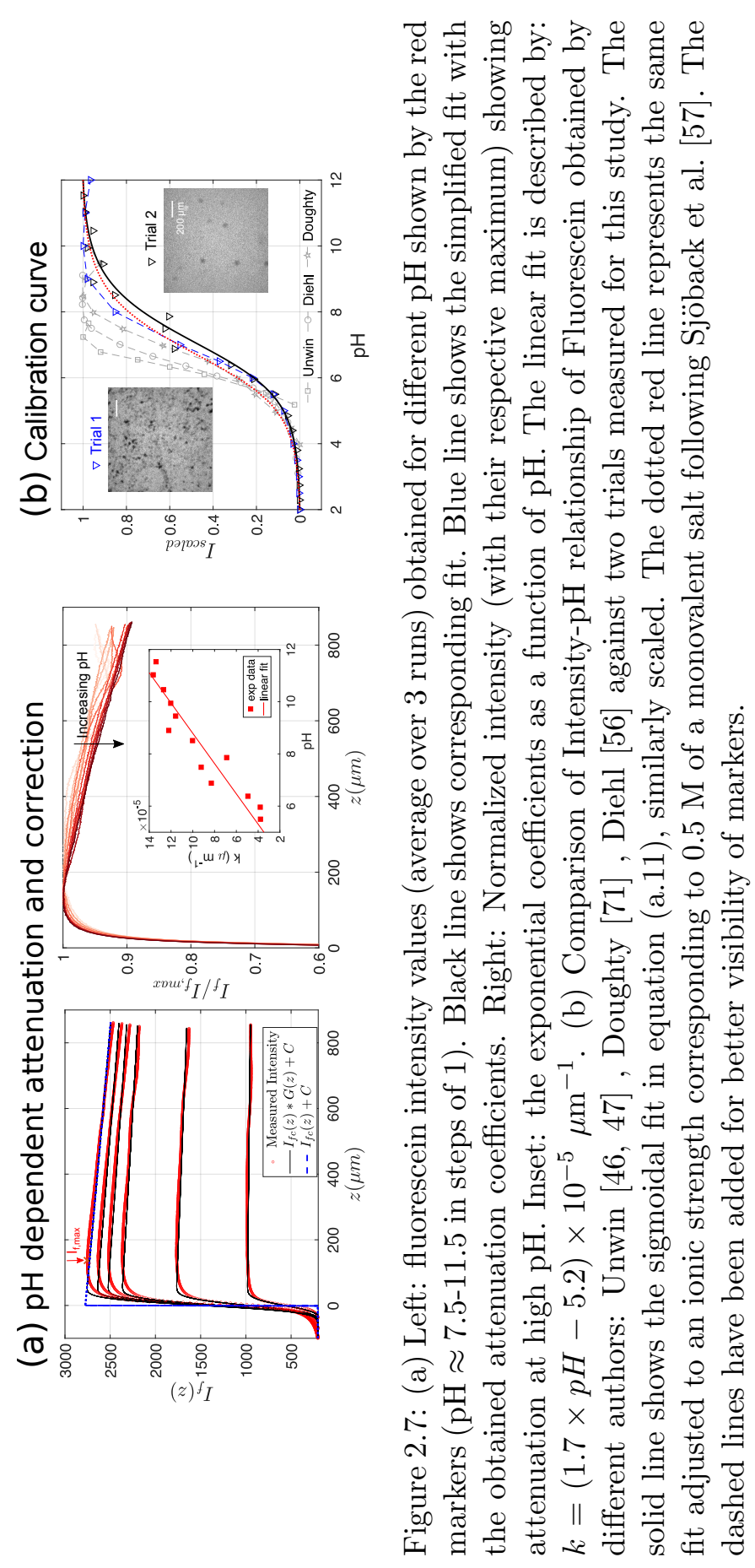


Any measurement of fluorescence requires considering the path dependent attenuation of the excitation as well as the emitted fluorescent light. Since the numerical aperture of the objective used in our experiments is small, following Ohser et al. [72, the dependence of the emitted fluorescent light $\left(I_{e m}(z)\right)$ on the excitation intensity $\left(I_{e x}(z)\right)$ and the concentration of fluorophore $(c(z))$ at a point $z$ in the solution, along with the fluorescence efficiency $\left(\alpha_{1}, \mathrm{pH}\right.$ dependent in the case of Fluorescein) can be written as:

$$
I_{e m}(z)=I_{e x}(z) \alpha_{1} c(z)
$$

Since in our case, the absorbance of the fluorophore is $\mathrm{pH}$ dependent [57], and the $\mathrm{pH}$ itself is $z$ dependent, the path dependent attenuation of the excitation intensity can be written as:

$$
I_{e x}(z)=I_{e x 0}\left(e^{-\int_{0}^{z} \epsilon_{1}(p H(\tau)) c(\tau) d \tau}\right)
$$

where $\epsilon_{1}$ is the $\mathrm{pH}$ dependent attenuation coefficient of the excitation light and $I_{e x 0}$ is the excitation intensity at $z=0$. Similarly if there is an attenuation $\left(\epsilon_{2}\right)$ of the emitted light $I_{e m}(z)$, the measured fluorescence intensity $I_{f}(z)$ goes as:

$$
I_{f}(z)=I_{e m}(z)\left(e^{-\int_{z}^{0} \epsilon_{2}(p H(\tau)) c(\tau)(-d \tau)}\right)
$$

Since we use a constant concentration of fluorophore and laser settings in all our experiments, combining equations (a.4, a.5 and (a.6):

$$
I_{f}(z)=I_{f 0}\left(e^{-\int_{0}^{z} k(p H(\tau)) d \tau}\right)
$$

where $I_{f 0}=\alpha_{1} I_{e x 0} c$ is the unattenuated fluorescence intensity, and $k=\left(\epsilon_{1}+\right.$ $\left.\epsilon_{2}\right) c$ is the overall attenuation factor. Hence a optical path history dependent correction factor of $e^{\int_{0}^{z} k(p H(\tau)) d \tau}$ must be multiplied with the fluorescence intensity, $I_{f}(z)$, measured at a point to get the corresponding corrected value $I_{f 0}$. It should be noted that for higher numerical aperture objectives, an attenuation correction such as shown in Visser and Oud [73] must be used.

To determine $k$, we measured the fluorescence intensity as a function of $z$ for different constant $\mathrm{pH}$ solutions ( $k$ is constant for a constant $p H$ ) similar to that shown in Fig. 2.7(a). We expect the fluorescence intensity at a particular $\mathrm{pH}$ to be exponentially decaying step function $\left(I_{f c}(z)\right.$ given by equation a.7 with $k=$ const) and its maximum at the electrode surface, $z=0$. The actual profiles, however, are smooth close to the electrode surface, most likely due to the point spread function (psf in the $z$ direction) of the optical system. 
Taking the simplest assumption of a gaussian psf i.e. $G(z)=\frac{1}{\sigma \sqrt{2 \pi}} e^{-\frac{z^{2}}{2 \sigma^{2}}}$ (with the standard deviation $\sigma$ ), the resulting profiles must then be a convolution of $I_{f c}(z)$ with $G(z)$, and should have the analytical form:

$$
\begin{aligned}
I_{f c}(z) * G(z)=I_{f 0} e^{-k z} e^{\frac{\sigma^{2} k^{2}}{2}} & \\
& \left(1-\frac{1}{2} \operatorname{erfc}\left(\frac{z}{\sigma \sqrt{2}}-\frac{k \sigma}{\sqrt{2}}\right)\right.
\end{aligned}
$$

where, $\operatorname{erfc}$ is the complementary error function. Consequently, we fit a function of the form $I_{f c}(z) * G(z)+C$, with four fitting parameters $I_{f 0}, k, \sigma$ and $C$ (where $C$ is a parameter related to small constant unknown effects). The resulting fit is overlaid on the original data of constant $\mathrm{pH}$ solutions (average of 3 measurements) in fig $2.7 \mathrm{a}$. The fit is reasonable, however differences in the location of their maximum indicates that the psf is likely more complicated than a gaussian function. Based on the $I_{f 0}$ and $k$ and $C$ obtained, we further plot $I_{f c}(z)+C$ which shows that the psf smoothening is important only at the electrode surface. In our measurements, we therefore correct only for this attenuation and not the psf smoothening. The measurement is compromised below the location of the intensity maximum $\left(I_{f, \max }\right.$ in Fig. $\left.2.7(\mathrm{a})\right)$ of the profiles $(\approx 100 \mu \mathrm{m})$ and has not been shown in the main text. The attenuation correction factor $k$ as a function of $\mathrm{pH}$ is plotted in the inset of figure, and has been fitted with a line. At the $n$-th stack from the electrode surface (with a distance $\Delta z=20 \times 1.33 \mu \mathrm{m}$ ), the measured fluorescein intensity then must be of the form:

$$
I_{f}(z)=I_{f 0} e^{-\sum_{\eta=0}^{n-1} k(p H(\eta)) \Delta z}+C
$$

The unattenuated fluorescein intensity $\left(I_{f, \text { org }}\right.$, which is now $\left.I_{f, \text { org }}=I_{f 0}+C\right)$ can now be calculated based on the $k$ and $C$ and is:

$$
I_{f, o r g}=\left(I_{f}(z)-C\right) e^{\sum_{\eta=0}^{n-1} k(p H(\eta)) \Delta z}+C
$$

Lastly, it should be noted that the correction in equation a.10 obtained (using $k$ and $C$ ) is calculated at each position based on the uncorrected $\mathrm{pH}$. However any error associated with this is expected to be minimal.

Fig. 2.7(b) compares the intensity variation of Fluorescein emission with $\mathrm{pH}$ measured by the authors to corresponding results in literature. For our calibration, the maximum of the fluorescence intensity measured along the scanned direction $\left(I_{f, \max }\right.$ in Fig. 2.7(a)), for different constant $\mathrm{pH}$ solutions is taken 
as the reference intensity. The intensity variation with $\mathrm{pH}$ (as shown in Fig. 2.1(b) in the main text), obtained so, is rescaled to the range from 0 to 1 , to render the data comparable with literature results (which were similarly rescaled where needed). The general trend matches in all cases, however, there is significant spread especially at the upper limit of the $\mathrm{pH}$-sensitive region. The different ionic strengths of the calibration solution could be a possible reason for these differences [57]. However, this effect is small as the red dotted line, which represents our calibration curve corrected to an ionic concentration of a $0.5 \mathrm{M}$ monovalent salt (using the equation in Sjöback et al. [57]; assuming that the parameter $\gamma$ in our fit behaves like an effective pKa), in Fig. 2.7(c) shows. Moreover, since the fluorescence intensity at a point in the sample is related to the the local concentration of the fluorophore, the laser excitation intensity, the optical path history of the light, the voltage of the photo-multiplier tube etc., the differences could be due to a number of reasons and it is not straightforward to compare the values of fluorescence intensity, for different $\mathrm{pH}$, across optical setups. Rather, laser and camera settings must remain constant between calibration and experiment for a faithful conversion of intensity values to $\mathrm{pH}$. Even then, there are small differences between the repeats of our calibration measurements (new $\mathrm{pH}$ solutions and different electrode) in Fig. 2.7(a) and these could be traced to presence of small contaminants on the electrode surface. The inset of Fig. 2.7(a) shows an example of a fluorescein intensity image $($ at $\mathrm{pH}=10)$ obtained for each of the two calibration trials done. The difference between the repeats provides a sense of the calibration error as similar (and to varying degrees) contamination could be present in the experiments. However, since the calibration curve is similar in the lower limit of the $\mathrm{pH}$-sensitive region, the effect on the location of the $\mathrm{pH}$ shoulder is minimal. Still, trial 2 (having the cleaner electrode) is used in our measurements and is shown Fig. 2.1(b) in the main text. Lastly, the intensity dependence on $\mathrm{pH}$ (in Fig. 2.1(b) in the main text) is fit with a function of the form

$$
\ln \left(I_{f, \max }\right)=\alpha+\frac{\beta}{1+e^{-(p H-\gamma)}}
$$

with fit parameters $\alpha(4.991 \pm 0.034), \beta(2.946 \pm 0.039)$ and $\gamma(5.857 \pm 0.060)$. A robust least-squares regression with a logistic function weight (implemented as 'nlinfit' in MATLAB) is used for fitting the data. The residuals of the regression appeared to be normally distributed (at all points except the two measurement triplicates between $\mathrm{pH} 6$ and 8 that are not on the line in Fig. 


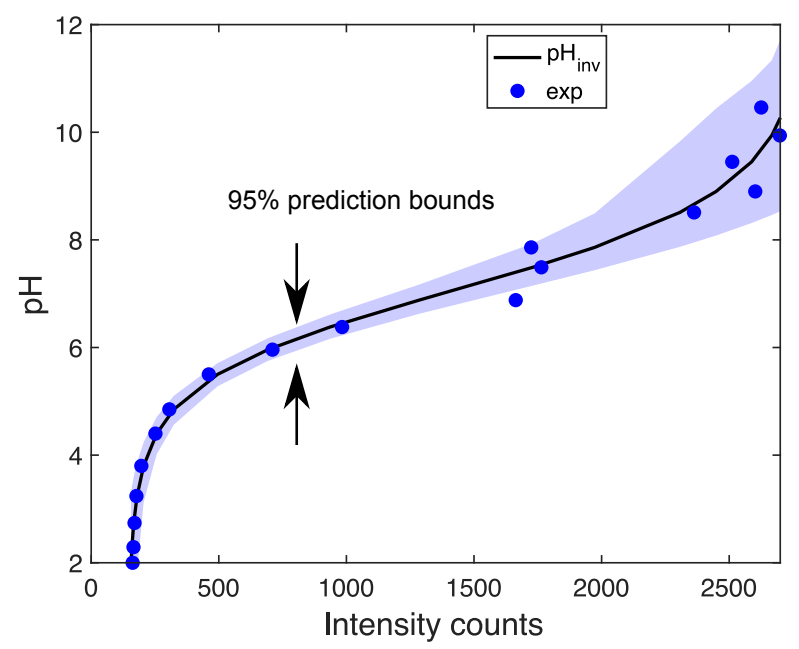

Figure 2.8: The inverse function based on calibration measurements presented in the main text. At a given $\mathrm{pH}$, the mean of three separate intensity measurements is shown here, since the error bars are small.

2.1(b)). The inverse function is therefore:

$$
p H_{\text {inv }}=-\ln \left(\frac{\beta}{\ln \left(I_{f, \max }\right)-\alpha}-1\right)+\gamma .
$$

The prediction interval for the non-linear fit (based on the measured calibration data) presented in Fig. 2.8 is calculated based on Guthrie et al. [74 and shows that at the higher ends of our $\mathrm{pH}$-sensitive range, the error in measurement can be close to $\pm 1 \mathrm{pH}$ unit.

All remaining fits presented here use the 'fit' function in MATLAB (R2019b).

\subsubsection{Dye migration effects: limits to supporting electrolyte concentration}

Since Fl is charged in solution, an electric field induced inhomogeneity in the dye distribution will make it difficult to decouple intensity changes due to migration from a $\mathrm{pH}$ change. An anionic $[75] \mathrm{pH}$ insensitive dye, namely Sulforhodamine B (Sigma Aldrich, Molecular weight: $580.65 \mathrm{~g} / \mathrm{mol}, 8 \mu \mathrm{M}$, henceforth $\mathrm{SRb}$ ) was therefore used to indicate the presence of dye migration. Although unlike Fl, SRb has a single negative charge in solution, due to their similar molecular weight it still serves as a good qualitative indicator 


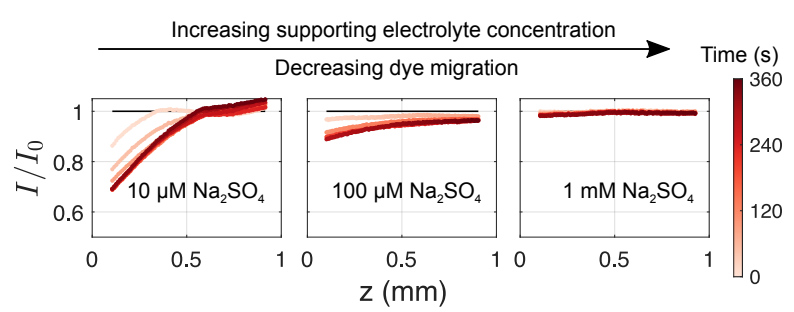

Figure 2.9: Migration effect for different supporting electrolyte concentrations. The emission intensity $(I)$ is normalized with the intensity profile before applying the current $\left(I_{0}\right)$. The measurement of fluorescence intensity is restricted to $z>0.1 \mathrm{~mm}$ due to limitations of the optical setup (see Fig. 2.6 and related discussion for details). The measurements were performed with a solution containing $8 \mu \mathrm{M}$ SRb. $\mathrm{pH}$ was adjusted to $\mathrm{pH} 5$ by addition of $\mathrm{H}_{2} \mathrm{SO}_{4}$. The color code reflects the time at which the concentrations were measured. $|i|=$ $5.59 \mu \mathrm{A} / \mathrm{cm}^{2}$.

of dye migration. SRb is also mildly temperature sensitive (intensity decrease $\approx 1.2 \%$ per $\mathrm{K}[76]$ ), but for the current densities considered in this work the temperature change is estimated (even when using resistivity of pure water) to be negligible. The measured fluorescent intensity for the highest current density $\left(5.59 \mu \mathrm{A} / \mathrm{cm}^{2}\right)$ in this work is presented in Fig. 2.9(c). For low supporting electrolyte concentration, i.e. $=10 \mu \mathrm{M}$, the fluorescence intensity of the dye near the electrode surface and up to a distance of $\approx 0.75 \mathrm{~mm}$ above the electrode decreased by up to $30 \%$. However, this migration effect reduces significantly for increased concentration of the supporting electrolyte, and is almost negligible for $\mathrm{Na}_{2} \mathrm{SO}_{4}$ concentrations $\geq 1 \mathrm{mM}$. A concentration of the supporting electrolyte much greater than this is therefore used in the experiments performed in this study.

\subsubsection{Details of the numerical model}

For each ion species $k$, we have a related dimensional concentration diffusion equation of the type shown in equation (2.1) in the main text. Scaling the spatial $z$ and temporal $t$ coordinates with their respective diffusive scales such that $z^{*}=z / L$ and $t^{*}=t /\left(L^{2} / D_{H^{+}}\right)$. Here $L=5 \mathrm{~mm}$ is the extent of the numerical domain such that at $z=L$ the concentration of all ions is kept equal to its initial value. Assuming that the concentration of water is large and therefore essentially constant during the experiment the differential equations 


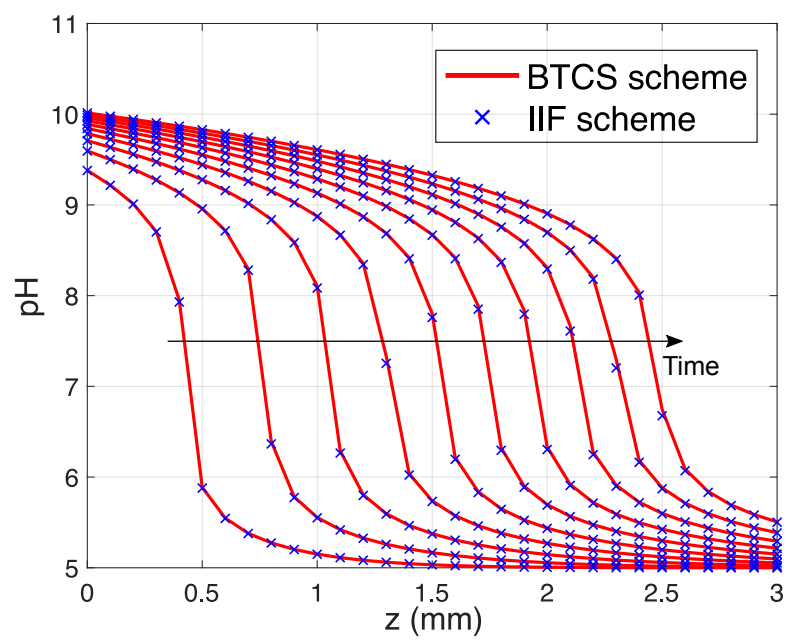

Figure 2.10: Comparison of results using BTCS and IIF numerical schemes. Note: only the $\mathrm{H}^{+}$and $\mathrm{OH}^{-}$ions were considered for this comparison. The relatively small effect of $\mathrm{HFl}^{-}$on the $\mathrm{pH}$ profiles is consequently also absent.

simplify to:

$$
\begin{aligned}
\frac{\partial c_{H^{+}}^{*}}{\partial t^{*}} & =\frac{\partial^{2} c_{H^{+}}^{*}}{\partial z^{* 2}}-D a_{1}\left(c_{H^{+}}^{*} c_{O H^{-}}^{*}-1\right) \\
& -D a_{2}\left(c_{H^{+}}^{*} c_{F l^{2-}}^{*}-\frac{K_{f, e q}}{c_{H^{+}}^{0}}\left(1-c_{F l^{2-}}^{*}\right)\right) \\
\frac{\partial c_{O H^{-}}^{*}}{\partial t^{*}} & =D_{r, 1} \frac{\partial^{2} c_{O H^{-}}^{*}}{\partial z^{* 2}} \\
& -\frac{D a_{1} c_{H+}^{0}}{c_{O H^{-}}^{0}}\left(c_{H^{+}}^{*} c_{O H^{-}}^{*}-1\right) \\
\frac{\partial c_{F l^{2-}}^{*}}{\partial t^{*}} & =D_{r, 2} \frac{\partial^{2} c_{F l^{-}}^{*}}{\partial z^{* 2}} \\
& -\frac{D a_{2} c_{H+}^{0}}{T}\left(c_{H^{+}}^{*} c_{F l^{2-}}^{*}-\frac{K_{f, e q}}{c_{H^{+}}^{0}}\left(1-c_{F l^{2-}}^{*}\right)\right)
\end{aligned}
$$

Here, the concentration of ions $c_{H^{+}}^{*}$ and $c_{O H^{-}}^{*}$ is normalized with its initial value $c_{H^{+}}^{0}$ and $c_{\mathrm{OH}^{-}}^{0}$ respectively. Further $T$ is the total initial concentration of fluorescein $\left(c_{\mathrm{HFl}^{-}}+c_{\mathrm{Fl}^{2-}}\right)$ which is used to non-dimensionalize the diffusion equation for $c_{F l^{2-}}$. The resulting Damköhler numbers $D a^{\prime} s$ are defined as 


$$
\begin{gathered}
D a_{1}=\frac{k_{f} c_{O H-}^{0} L^{2}}{D_{H+}}, \quad D a_{2}=\frac{k_{f, F l} T L^{2}}{D_{H^{+}}}, \\
D_{r, 1}=\frac{D_{O H^{-}}}{D_{H^{+}}}, \quad D_{r, 2}=\frac{D_{F l^{2-}}}{D_{H^{+}}} .
\end{gathered}
$$

Flux boundary conditions are employed at the electrode surface. In particular, the consumption flux of $\mathrm{H}^{+}$is set by the Faradaic current density $i_{f}$ as $\frac{\partial c_{\mathrm{H}}^{*}}{\partial z^{*}}=$ $\frac{-\left|i_{f}\right| L}{F D_{H^{+}} c_{H^{+}}^{0}}$, with $F$ denoting the Faraday constant, while all other fluxes are zero at $z=0$. It is important to note that $i_{f}$ is not the applied current density $i$, but has been modified to take the contribution of a capacitive current into account. This is achieved by using a constant capacitance similarly as done by Bonnefont et al. [77. Assuming a Stern layer thickness $\lambda_{S}=1 \mathrm{~nm}$, a permittivity 10 times the vacuum permittivity [78] $\epsilon_{0}$, and that the whole potential drop occurs within the Stern layer, the capacitance $C$ is estimated to be about $C \approx 88 \mu \mathrm{F} / \mathrm{cm}^{2}$. The double layer capacitance of platinum (measured in $\left.0.1 \mathrm{M} \mathrm{KClO}_{4}\right)$ was found to be in a similar range $\left(20-120 \mu \mathrm{F} / \mathrm{cm}^{2}\right)$ [9]. $i_{f}$ is then related to the measured time-dependent potential $(\phi)$ change by $i_{f}=i-C \frac{d \phi}{d t}$. Since the exact value of $\mathrm{C}$ in our measurements is not known, results for $0 \leq C \leq 120 \mu \mathrm{F} / \mathrm{cm}^{2}$ have also been presented in Fig. 2.3(c) in the main text.

The large reaction rate constants and the associated large Damköhler numbers $\left(D a \gtrsim 10^{6}\right)$ render the system of equations very stiff. To nonetheless numerically handle them efficiently, an implicit integrating factor formulation was adopted 82,83$]$.

A second order central difference scheme is used to discretize spatial gradients. The numerical domain of length $L$ is divided into $N+1$ grid points such that

\begin{tabular}{|c|c|c|c|}
\hline Parameter & Value (units) & Parameter & Value (units) \\
\hline$D_{H^{+}}$ & $9.3 \times 10^{-9}\left(\mathrm{~m}^{2} / \mathrm{s}\right) 47$ & $\mathrm{~T}$ & $8 \times 10^{-6}(M)$ \\
\hline$D_{\mathrm{OH}^{-}}$ & $4.62 \times 10^{-9}\left(\mathrm{~m}^{2} / \mathrm{s}\right) 47$ & $k_{f, F l}$ & $k_{f}$ \\
\hline$D_{F l^{2-}}$ & $0.42 \times 10^{-9}\left(\mathrm{~m}^{2} / \mathrm{s}\right)$ & $K_{f_{e q}}$ & $4.36 \times 10^{-7}\left(M^{-1}\right) 56$ \\
\hline$k_{f}$ & $1.4 \times 10^{11}\left(M^{-1} s^{-1}\right) 81$ & Area & $4 \pi \times 10^{-4}\left(m^{2}\right)$ \\
\hline$k_{b}$ & $2.6 \times 10^{-5}\left(s^{-1}\right) 81$ & $C_{S}=10 \epsilon_{0} / \lambda_{s}$ & $88\left(\mu \mathrm{F} / \mathrm{cm}^{2}\right)[77]$ \\
\hline
\end{tabular}

Table 2.1: Parameters and associated used in the model 
$\Delta z=\frac{L}{N}$. We then obtain a set of equations of the form:

$$
\begin{aligned}
& \underset{\partial \boldsymbol{c}_{k}^{*}}{\partial t^{*}}=\frac{D_{r, k}}{\Delta z^{2}}\left(\left[\begin{array}{cccc}
-2 & 2 & 0 \cdots & \\
1 & -2 & 1 & \cdots \\
\vdots & \vdots & \ddots & \vdots \\
0 & \cdots & 1 & -2
\end{array}\right]\left[\begin{array}{c}
c_{k}^{*}(1) \\
\vdots \\
c_{k}^{*}(N)
\end{array}\right]+\left[\begin{array}{c} 
\pm J_{k} \Delta z \\
0 \\
\vdots \\
\\
c_{k}^{*}(N+1)
\end{array}\right]\right) \\
& \pm D a \times f\left(\boldsymbol{c}^{*}\right)
\end{aligned}
$$

Here $\boldsymbol{c}_{\boldsymbol{k}}^{*}=c_{k}(m)$ is the (non-dimensional) spatially discretized concentration $\left(1 \leq m \leq N+1\right.$, but continuous in time) of ions and $J_{k}$ is the constant flux of the ions at the electrode surface. In our simulations:

$$
\begin{aligned}
c_{H^{+}}^{*}(N+1) & =1 \\
c_{O H^{-}}^{*}(N+1) & =1 \\
c_{F l^{2-}}^{*}(N+1) & =\frac{c_{F l^{2-}}}{T}
\end{aligned}
$$

and,

$$
\begin{aligned}
J_{H^{+}} & = \\
& \begin{cases}0, & \text { if }\left|i_{C a p}\right|>|i| \\
\frac{\left(-|i|+\left|i_{C a p}\right|\right) L}{F D_{H^{+}} c_{H^{+}}^{0}}, & \text { otherwise }\end{cases} \\
J_{O H^{-}} & =0 \\
J_{F l^{2-}} & =0
\end{aligned}
$$

where $i_{C a p}$ is the time dependent capacitive current density as described in the main text.

The above set of equations are stiff due to large reaction rate constants (and related $D a$ ) for the non-linear reaction terms $f(c)$. Using an implicit scheme such as Backward-Time-Central-Space (BTCS), would therefore require very small time steps and consequently a large run-time. We instead integrate in time according to the implicit integrating factor (IIF) scheme presented in Nie et al. 82. A second order approximation of the $f(c)$-term is used, while employing the trapezoid rule to approximate the integration of the time dependent $i_{C a p}$. The set of non-linear equations are then solved at each time step using the fsolve function in MATLAB (R2019b). The numerical scheme 
was validated, first with the analytical solution of the linear reaction-diffusion equation used in Nie et al. 82]. We further compared the results of the IIF with the BTCS scheme (for our system) for the highest current density used in this work $\left(|i|=5.59 \mu \mathrm{A} / \mathrm{cm}^{2}\right)$. The results compare well as shown in Fig. 2.10, confirming the proper implementation of the numerical scheme.

\subsubsection{Repeat experiments}

Fig. 2.11 shows the measured $\mathrm{pH}$ profiles in a repeated experiment has been provided to highlight the reliability of the measurement method. A comparison of the $\mathrm{pH}$ front with the model results is also shown. Similar to the results presented in the main text, the experimental profiles are in good agreement at the two lower current densities and deviate from the 1D diffusion model at the two highest current densities.

\subsubsection{Sulfates comparison}

To account for the buffering capacity of sulfates $\left(\mathrm{Na}_{2} \mathrm{SO}_{4} / \mathrm{H}_{2} \mathrm{SO}_{4}\right)$ we adjusted the model to include the following reaction couples:

$$
\begin{aligned}
& \mathrm{H}^{+}+\mathrm{SO}_{4}{ }^{2-} \underset{k_{f, S}}{\stackrel{k_{b, S}}{\rightleftharpoons}} \mathrm{HSO}_{4}{ }^{-} \\
& \mathrm{Na}^{+}+\mathrm{SO}_{4}^{2-} \underset{k_{f, N a}}{\stackrel{k_{b, N a}}{\rightleftharpoons}} \mathrm{NaSO}_{4}{ }^{-}
\end{aligned}
$$

There is an extra bulk reaction term due to $\mathrm{HSO}_{4}{ }^{-}$ionization in the $\mathrm{H}^{+}$ equation. Furthermore, additional reaction diffusion equations $\left(\mathrm{SO}_{4}{ }^{2-}\right.$ and $\mathrm{NaSO}_{4}{ }^{-}$here) and have to be taken into account. The initial concentrations of the ions are estimated based on the total dissolved $\mathrm{Na}_{2} \mathrm{SO}_{4}$ and $\mathrm{pH}$ of the solution. The dissociation constants of $\mathrm{HSO}_{4}$ [65 67] and $\mathrm{NaSO}_{4}{ }^{-}$[84, 85] are taken from the literature $\left(K_{\mathrm{HSO}}=0.0103\right.$ and $\left.K_{\mathrm{NaSO} 4}=0.5\right)$. Also for the forward rate constants $k_{f, N a}=k_{f} \times 0.1$ and $k_{f, S} 86=k_{f} \times 5$ are taken. Fig. 2.12 shows a comparison of the full $\mathrm{pH}$ profiles for the 4 different current densities considered. The buffer effect at the two lower current densities is captured well by the model, although the profiles do not match exactly at all times. Finally, the two highest current densities have been presented here only for the sake of completeness, as (discussed in the main text) experiments at these values of $|i|$ are marked by the appearance of inhomogeneous fluorescein intensity in a plane and therefore do not follow a 1D diffusion approximation. 

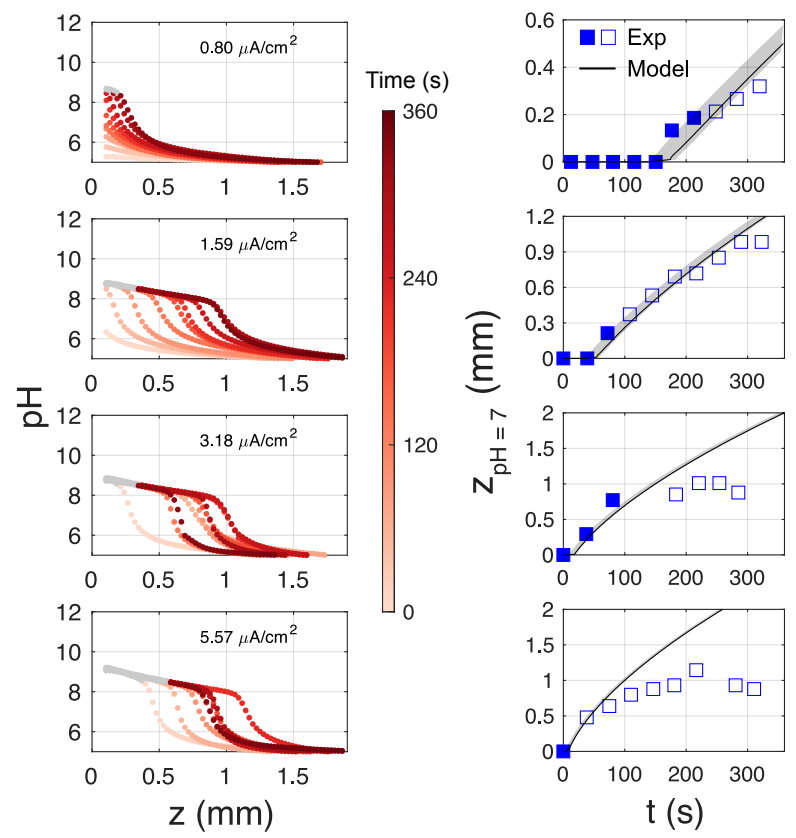

Figure 2.11: Experimental repeats for all $|i|$ presented in the main text. Left: $\mathrm{pH}$ profile measured. $\mathrm{pH}>8.5$ has been grayed out due to the uncertainty in measurement described in the main text. Right: Comparison of depletion length, $z_{p H=7}$, of experiment versus model. The shaded region indicates the model results over a range of capacitance $0 \leq C \leq 120 \mu \mathrm{F} / \mathrm{cm}^{2}$ (solid line with $\mathrm{C}=88 \mu \mathrm{F} / \mathrm{cm}^{2}$ ). Open squares show $\mathrm{pH}$ front after the first appearance of inhomogeneity described in the main text. 
(a) Exp

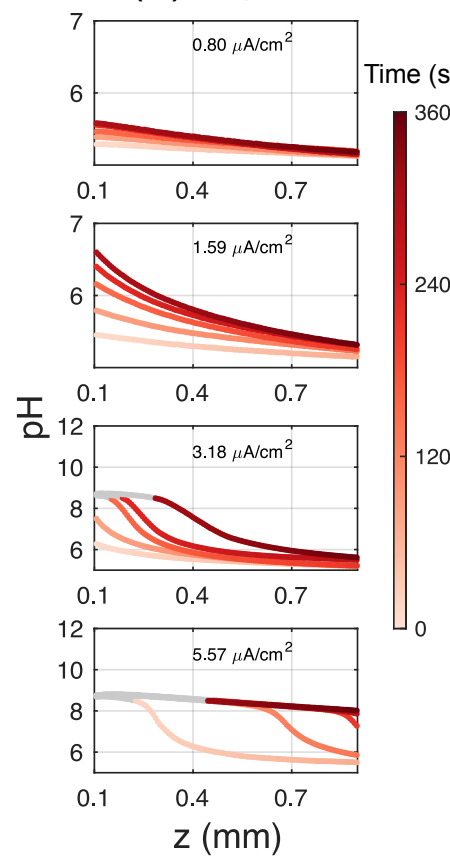

(b) Model
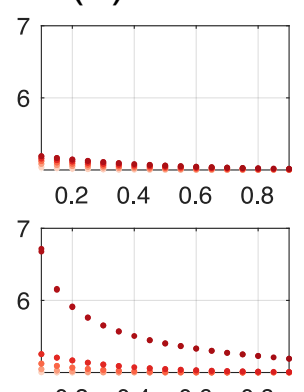

T

$\begin{array}{llll}0.2 & 0.4 & 0.6 & 0.8\end{array}$
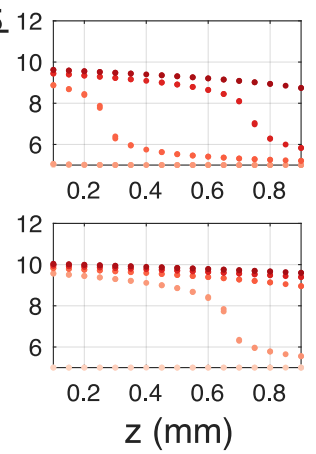

Figure 2.12: pH versus Depth for the case with sulfates: Experiments versus Simulations. (a) The experimental profiles for all $|i|$ values. (b) Numerical pH profiles based on values discussed in the text. 
Chapter 3

\section{The effect of buoyancy driven convection and bubble clusters on the growth and dissolution of bubbles}




\subsection{Introduction}

The formation of gas bubbles in supersaturated liquids is common in both everyday situations [87] and industrial processes. Particularly, chemical processes that result in the evolution of gas in a liquid such as catalytic decomposition of hydrogen peroxide [33] and electrolysis are prone to nucleation and growth of the gas bubbles on the reaction surface. In electrochemical cells, these bubbles may substantially increase the cell resistance by blocking electrode surface and reducing contact with the electrolyte. Since these bubbles are non-conducting, they can further influence the cell resistance by affecting the potential distribution in solution 12,13 .

However, bubbles can also enhance the electrode reaction rate by contributing to the removal of dissolved gas from the vicinity of the electrode [13]. This enhancement in rate is particularly significant for fast reactions (where the kinetic exchange current is large), such as hydrogen evolution on platinum. Here the reaction at large currents is limited by mass transport and the Nernst equation is valid [6]. The current on $\mathrm{a}_{2}$ evolving platinum electrode therefore depends on the concentration of dissolved $\mathrm{H}_{2}$ near the electrode surface, a measure of which is the bubble growth/dissolution rate [6]. Since bubbles grow and dissolve in response to the concentration gradient of dissolved $\mathrm{H}_{2}$ at their boundary, they serve as indicators for the neighbouring dissolved gas concentration. Measurements of bubble dissolution have been previously reported by Karnbach et al. 88] to explain the relaxation of the open-circuit potential at their micro-electrode. Given the small size of their electrode (compared to the final bubble size) the dissolve gas distribution is controlled by the single attached bubble [23]. In contrast, our measurements represent the other extreme i.e. bubble dissolution on an "infinite electrode" (electrode size $\gg$ bubble). Thus, the measurement bubble growth/dissolution rates serves as a proxy to the dissolved gas concentration which in principle can also be used in combination with the measurement of $\mathrm{pH}$ (Chapter 2) to understand the measured electrochemical response.

In this chapter, we image hydrogen bubbles on a platinum electrode in an acidic electrolyte in response to a well defined voltage pulse, with the aim of measuring dissolved gas concentration in solution. Experimental bubble size is compared to a numerical model assuming purely diffusive gas transport. We observe that by including in the numerical model the effect of buoyancy due to the requirement of electroneutrality in the bulk solution, and the bubble clustering, we are able to correctly predict the growth and dissolution behavior 
of the bubbles. The analysis reveals the importance of convective phenomenon in the transport dynamics of electrochemical systems.

\subsection{Experimental setup}

Fig. 3.1(a) shows the experimental setup. The electrochemical cell is made of Teflon. The cell is used in a 3-electrode configuration with a transparent platinum working electrode, a $\mathrm{Pt}$ mesh counter electrode placed as a ring at a distance of $\approx 4 \mathrm{~cm}$ from the working electrode, and a $\mathrm{Ag} / \mathrm{AgCl}$ (in $3 \mathrm{M} \mathrm{NaCl}$; BasiR) reference electrode. The electrochemical cell was mounted on the stage of a Nikon A1R confocal microscope. The working electrode was illuminated from below with a $532 \mathrm{~nm}$ laser. Partial transparency of the working electrode was achieved by evaporating $10 \mathrm{~nm}$ Pt on glass, with a $3 \mathrm{~nm}$ Chromimum underlayer $(10 \mathrm{~nm} \mathrm{Pt}$ roughly $\approx 30 \%$ transmittance 89 . A camera above the electrochemical cell detected the transmitted images. The laser and the camera (transmission detector) are part of the confocal microscope assembly. A VersaStat (PAR) potentiostat was used for the electrochemical measurements with a recording frequency of $100 \mathrm{~Hz} .0 .1 \mathrm{M} \mathrm{H}_{2} \mathrm{SO}_{4}$ (Sigma Aldrich) was used as the electrolyte. Supporting electrolyte was purposely avoided, so that a binary electrolyte approximation could be used.

Simultaneous electrochemical and optical measurements were performed with the following experimental protocol. First, a negative (reduction) potential pulse was applied for a short time $(60-360 \mathrm{~s}$ depending on the experiment) to the working electrode. During this time, the microscope stage was slowly moved (about the electrode center) until a growing bubble was encountered in the field of view of the camera. Overall, we tried to ensure that measured bubble was the first bubble growing at that location, so that there were no history effects due to depletion of the gas concentration and bubble detachment [90]. After the potential was stopped, the microscope imaging was continued for approximately $10 \mathrm{~min}$. The open-circuit potential was measured simultaneously. Fresh electrolyte was used for each individual experiment.

An example image is shown in Fig. 3.1(b). The bubbles appear as a shadow on the electrode surface. We track the bubble size (red circle) over time for all the experiments. Note that the bubbles are not isolated as can be seen from Fig. 3.1(b)(here with center-to-center distance $\approx 0.6 \mathrm{~mm}$ ) and that we only track the size of the 'main' bubble in the field of view. 


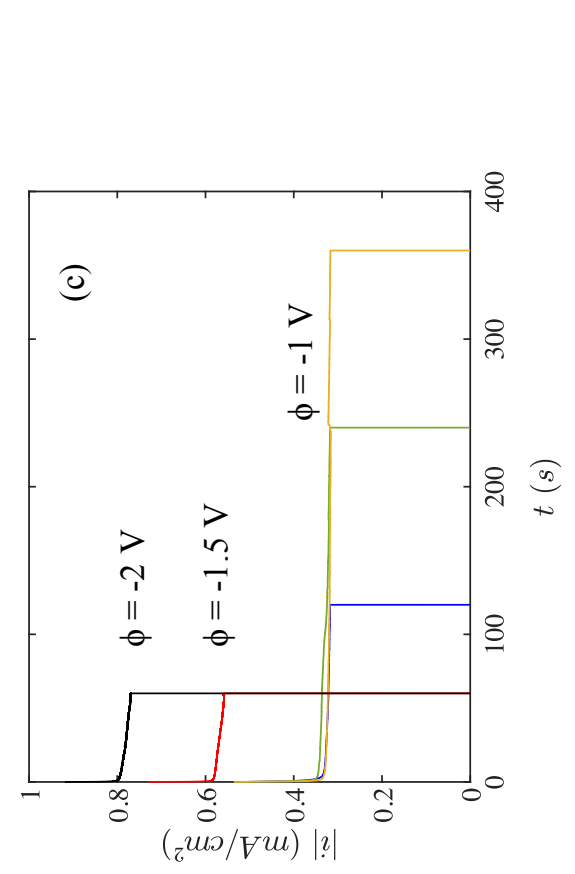

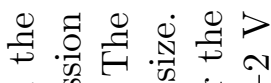

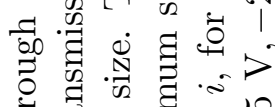

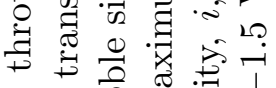

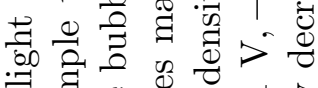

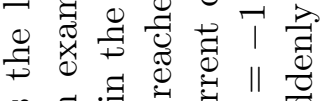

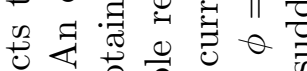

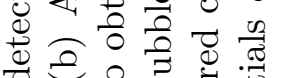

웅

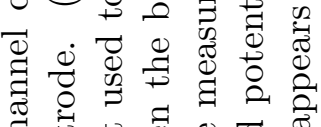

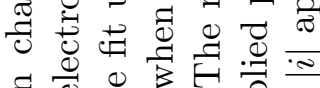

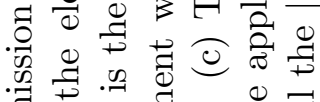

坖

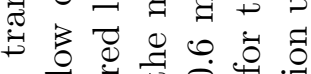

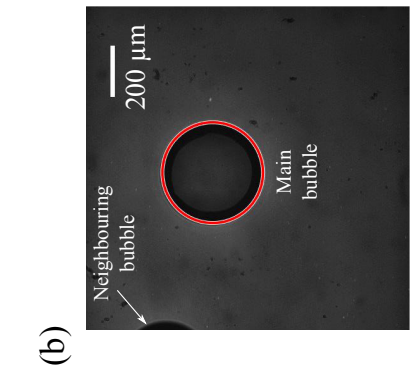

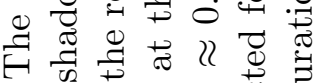

. $\approx \dot{0} \stackrel{0}{0}$

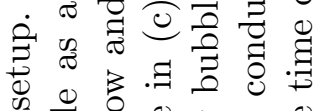

क 000 o 000

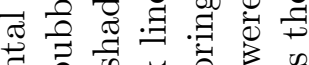

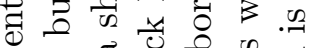

苟

की

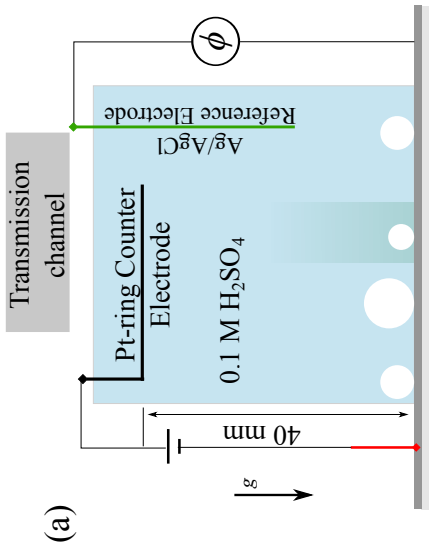

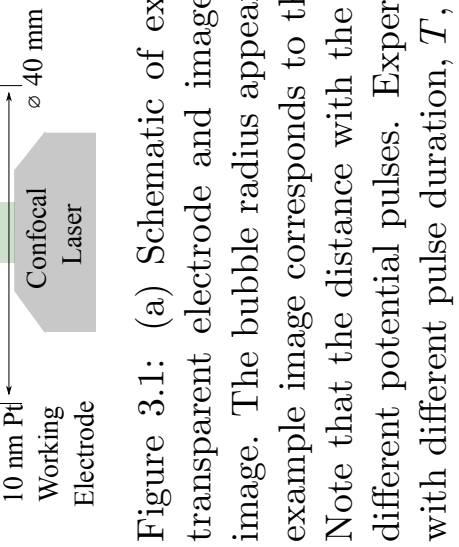




\subsection{Numerical setup}

To model bubble growth/dissolution dynamics the concentration field of the dissolved gases in solution, here $\mathrm{H}_{2}$, was solved. The bubble is taken as a spherical boundary tangent to the electrode surface as shown in Fig. 3.2. To solve for the concentration field of the gases, the advection-diffusion equation was used in combination with fluid continuity and Navier-Stokes equations. Although there is no imposed flow in the problem, the change in concentration of dissolved gaseous product and the ions in solution can result in gradients in the density, $\rho$, in the solution which can cause overturning and onset of flow. The transport equations for all dissolved species therefore involves an advection term.

The ion concentration in solution can be calculated using the Nernst-Planck equations, together with the Poisson equation for the electrostatic potential. However, beyond the Debye layer, i.e. distances $\gtrsim 10 \mathrm{~nm}$, the electroneutrality approximation applies, and for a binary electrolyte, the Nernst-Planck equations reduce to an advection-diffusion one with an effective diffusion coefficient (harmonic mean of the cation and anion) 91, 92]. The reactant $\mathrm{H}^{+}$ ion is therefore transported in solution as a single uncharged species $\mathrm{H}_{2} \mathrm{SO}_{4}$. The overall system of equations solved are:

Concentration

$$
\frac{\partial C_{j}}{\partial t}+(\mathbf{u} . \nabla) C_{j}=D_{j} \nabla^{2} C_{j}
$$

Here, $C_{j}(\mathbf{x}, t)$, is the concentration field of dissolved species, where subscript $j$ indicates the species, i.e. reactant $\mathrm{H}_{2} \mathrm{SO}_{4}$ or product $\mathrm{H}_{2}$. $D_{j}$ is the respective diffusion coefficients of the dissolved species $\left(\mathrm{H}_{2}\right.$ and $\left.\mathrm{H}_{2} \mathrm{SO}_{4}\right)$.

$\underline{\text { Velocity }}$

$$
\begin{aligned}
\boldsymbol{\nabla} \cdot \mathbf{u} & =0, \\
\rho_{0} \frac{\partial \mathbf{u}}{\partial t}+\rho_{0}(\mathbf{u} \cdot \boldsymbol{\nabla}) \mathbf{u} & =-\nabla p+\mu \nabla^{2} \mathbf{u}+\mathbf{F}, \\
\text { where, } & \\
\mathbf{F}=\left(\rho-\rho_{0}\right) \mathbf{g} & =\rho_{0} \sum_{\forall i} \beta_{j}\left(C_{j}-C_{j, 0}\right) \mathbf{g}, \\
\beta_{j} & =-\frac{1}{\rho_{0}}\left(\frac{\partial \rho}{\partial C_{j}}\right)_{T, p} .
\end{aligned}
$$

The velocity field $\mathbf{u}(\mathbf{x}, t)$ and the (kinematic) pressure field $p(\mathbf{x}, t)$ are solved 
simultaneously with the concentration. $\mu, \mathbf{g}$ and $T$ are symbols for the viscosity of water, acceleration due to gravity and temperature respectively. The Boussinesq approximation [93, which is widely used in the study of natural convection, has been invoked in the equations $(2 \mathrm{a})$ and $(2 \mathrm{~b})$. This approximation is valid in systems with small density fluctuations $\left(\Delta \rho / \rho_{0} \ll 1\right)$ and accordingly, a constant value of density $\rho_{0}$ has been used in all terms in equations (2a) and (2b). The effect of density change $\Delta \rho=\rho-\rho_{0}$ then only appears as the body force term, $\mathbf{F} . \beta_{j}$ in equation $(2 \mathrm{~d})$ refers to the change in density brought about by the addition of $\mathrm{H}_{2}$ and depletion of $\mathrm{H}_{2} \mathrm{SO}_{4}$.

The evolution of the bubble radius, $R$, is linked to the diffusive mass transfer of hydrogen through the bubble interface [94]:

$$
\frac{d N}{d t}=D_{\mathrm{H}_{2}} \int_{S} \nabla C_{\mathrm{H}_{2}} \cdot \hat{\mathbf{n}} d S,
$$

where,

$$
N=\frac{4}{3 \mathbb{R T}_{\infty}} \pi R^{3} P_{0}
$$

Here the $\mathbb{R}, P_{0}, T_{\infty}$ are the ideal gas constant, ambient pressure and temperature respectively. $N$ represents the total moles of gaseous phase and has been related to the instantaneous bubble radius using the ideal gas approximation in equation (3b). Note that the Laplace pressure is neglected due the relatively large bubble sizes studied here $(R \gtrsim 3 \mu \mathrm{m}$ i.e. the bubble radius corresponding to 1 bar Laplace pressure)

The following boundary conditions have been used along with the above equations to solve for species transport in solution:

Domain boundary conditions

$$
\begin{aligned}
\nabla C_{\mathrm{H}_{2} \mathrm{SO}_{4}} \cdot \hat{\mathbf{n}} & =\frac{-|i| / D_{\mathrm{H}_{2} \mathrm{SO}_{4}}}{F}, \\
\nabla C_{\mathrm{H}_{2}} \cdot \hat{\mathbf{n}} & =\frac{|i| / D_{\mathrm{H}_{2}}}{2 F}, \\
\mathbf{u}(z=0) & =0
\end{aligned}
$$

Here $|i|$ is the absolute current density, $F=96485 \mathrm{C} / \mathrm{mol}$ is Faraday's constant and $\hat{\mathbf{n}}$ is the unit normal vector at the boundary. The prefactor to $F$ indicates the number of moles of electrons consumed per molar consumption/production of reactant/product respectively. Additionally, periodic boundary conditions are imposed for the velocity components and scalar fields at side walls of the 
Cartesian domain in the $\mathbf{x}$ and $\mathbf{y}$ directions. Outflow boundary condition is applied on top wall by making sure that the diffusive and advective fluxes of both momentum and concentration fields are conserved through the top boundary.

At bubble boundary

$$
\begin{aligned}
\nabla C_{\mathrm{H}_{2} \mathrm{SO}_{4}} \cdot \hat{\mathbf{n}} & =0 \\
\mathbf{u} & =\frac{d R}{d t} \hat{\mathbf{n}}+\frac{d \mathbf{r}_{b}}{d t} \\
C_{\mathrm{H}_{2}}(t) & =k_{H} P_{0}
\end{aligned}
$$

Here $\mathbf{r}_{b}$ is the location of the bubble center and $k_{H, k}$ is Henry's constant for $\mathrm{H}_{2}$.

It should be noted that while the no-slip boundary condition at the bubble surface (tangential component of (5b) ) is not an ideal assumption, it can be realistic in many cases where the interface is contaminated or surfactants are used 95. Furthermore, preliminary simulations indicate that in the considered range of current densities the velocities (and advective transport) near the bubble boundary are around two order of magnitudes smaller than the velocity of plumes induced by the density gradients in the bulk solution. Accordingly, choice of a no-slip boundary condition instead of free-shear has helped avoid
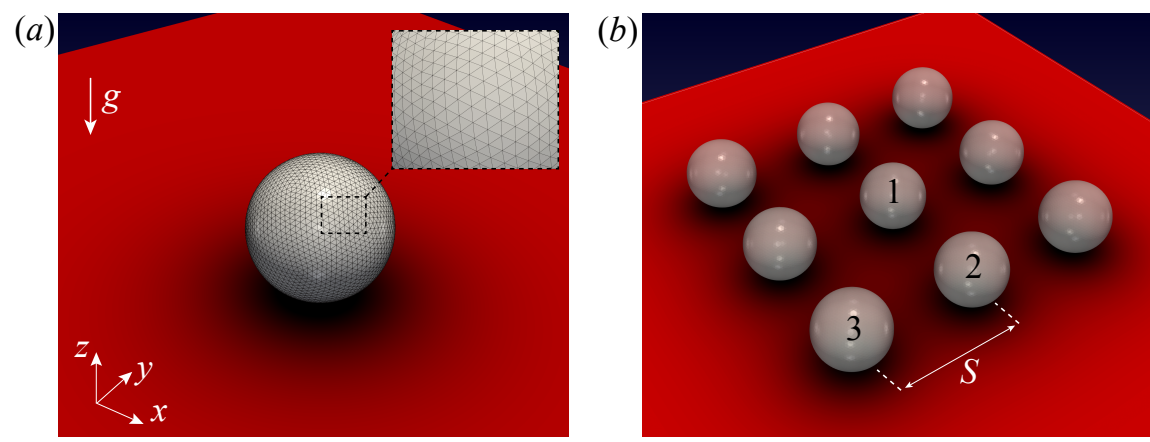

Figure 3.2: (a) Schematic for the simulation setup, with a single bubble attached to the center of the electrode. The colormap represents the gas-depleted diffusion layer in the proximity of the bubble. (b) The setup for the simulation of bubble clusters. A $3 \times 3$ bubble cluster is simulated with spacing $S$. The growth of bubbles 1, 2 and 3 (center, mid-edge and diagonal bubbles) is presented in the Results section. 
significant numerical complexities and computational cost without having the accuracy of flow physics significantly influenced.

The above equations are solved for two different domains: for a single bubble and a $3 \times 3$ bubble cluster as shown in Fig. 3.2 (a) and (b) respectively. Further details of the numerical scheme have been provided in the Appendix.

\subsection{Results and discussion}

Fig. 3.1(c) shows the measured values of the current density $|i|$ for different applied potentials $\phi$ and pulse duration $T$. The measured current densities for $\phi=-1 \mathrm{~V}$, for different values of pulse $T$ are similar indicating the reliability of the electrochemical measurement. From the microscope images, we extract the bubble radius, by fitting a circle to the bubble shadow (using the Hough transform in MATLAB). The radius of the bubbles for the different experiments is plotted in Fig. 3.3(a). Due to experimental limitations (see experimental protocol in Section 4.2 , we're unable to measure both the growth and dissolution phase of the bubbles in all the experiments. Nevertheless, the curves for the evolution of the bubble radius for all experiments appear qualitatively similar and we take the black line in Fig. 3.3(a) as a representative case for all the measurements

In Fig. 3.3(a) we note that that the bubbles start to dissolve soon $(\sim 10 \mathrm{~s})$ after the potential is stopped, with an initial fast dissolution rate as evident from the sharp change in slope of $R$. The black solid line in Fig. 3.3(a) shows the experimental measurement for a particular case $(\phi=-2 V$, see Fig. 1.1(c) solid black line) where, both, the bubble growth and dissolution phases were measured. A numerical simulation of purely diffusive gas transport however reveals that bubble growth continues for much longer, dashed black line in Fig. 3.3(a) (same current density as experiment). This discrepancy indicates that a diffusive transport model does not capture all the physical processes present in the measurement.

The change in dissolution rate in experiments is better indicated by the rate of change of bubble radius, $d R / d t$ for all the experiments, beginning at the instant $t_{\text {peak }}$ when the maximum bubble radius is measured. Fig. 3.3(b) reveals that the bubbles indeed dissolve with a faster rate initially. Furthermore, since the dissolution rate appears to be dependent on the maximum bubble radius $R_{0}$ (direction of arrow in the figure), we also present in the inset of Fig. 3.3 (b) the variation of dimensionless dissolution rate, $d \bar{R} / d \bar{t}$, which has been obtained by normalizing the dimensional dissolution rate with $J a_{m} \frac{R_{0}}{R_{0}^{2} / D_{H}}$, 

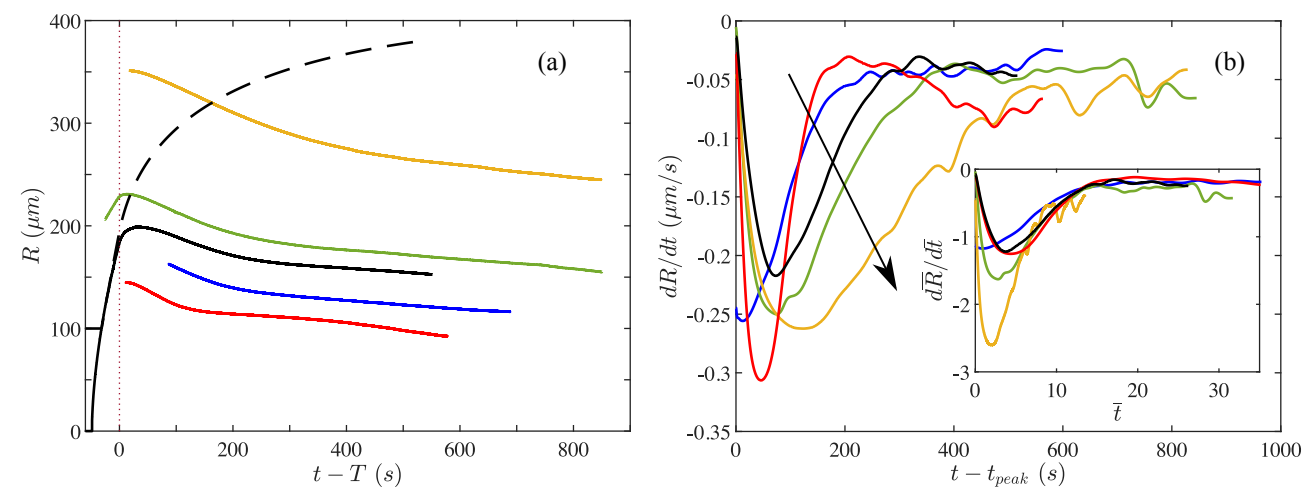

Figure 3.3: (a) Bubble radius obtained from the experiments. The line color indicates different experiments and relates to the color code in Fig. 3.1(c). The dashed black line is the numerically calculated bubble evolution for purely diffusive transport for the current density corresponding to the black line in Fig. 3.1(c). (b) Bubble dissolution rate starting at the time, $t_{\text {peak }}$, when the maximum bubble radius is measured. The direction of arrow shows the increasing bubble size. The inset shows the non-dimensionalized bubble dissolution rate.

where $J a_{m}=\frac{M_{H} C_{H s}}{\rho_{H}}$ is the mass transfer Jakob number [96], and $M_{H}, \rho_{H}$ and $D_{H} C_{H s}$ are the molar mass, density, diffusion coefficient and saturation concentration (based on $1 \mathrm{~atm}$. pressure respectively) of hydrogen gas. This normalization comes directly from the application of Fick's law at the bubble boundary, i.e. equation $3 \mathrm{a}$ and $3 \mathrm{~b}$. The time-axes has further been normalized by a diffusion time based on the maximum size of the bubble $D_{H} / R_{0}^{2}$, i.e. $\bar{t}=\frac{t-t_{\text {peak }}}{R_{0}^{2} / D_{H}}$

In the inset of Fig. $3.3(\mathrm{~b})$, we observe that at large times $(\bar{t} \gtrsim 10)$, the dissolution rate for all the experiments is similar. Moreover, the peak value of $d \bar{R} / d \bar{t} \sim \mathcal{O}(1)$ which indicates that the bubbles dissolves due to a concentration gradient at its boundary $\nabla C_{H} \sim \frac{C_{H s}-0}{R_{0}}$, and therefore effectively in an unsaturated ambient. These results along with the prediction from the numerical model for purely diffusive transport suggest that there is likely an additional physical mechanism which depletes the dissolve gas in solution around a bubble. 

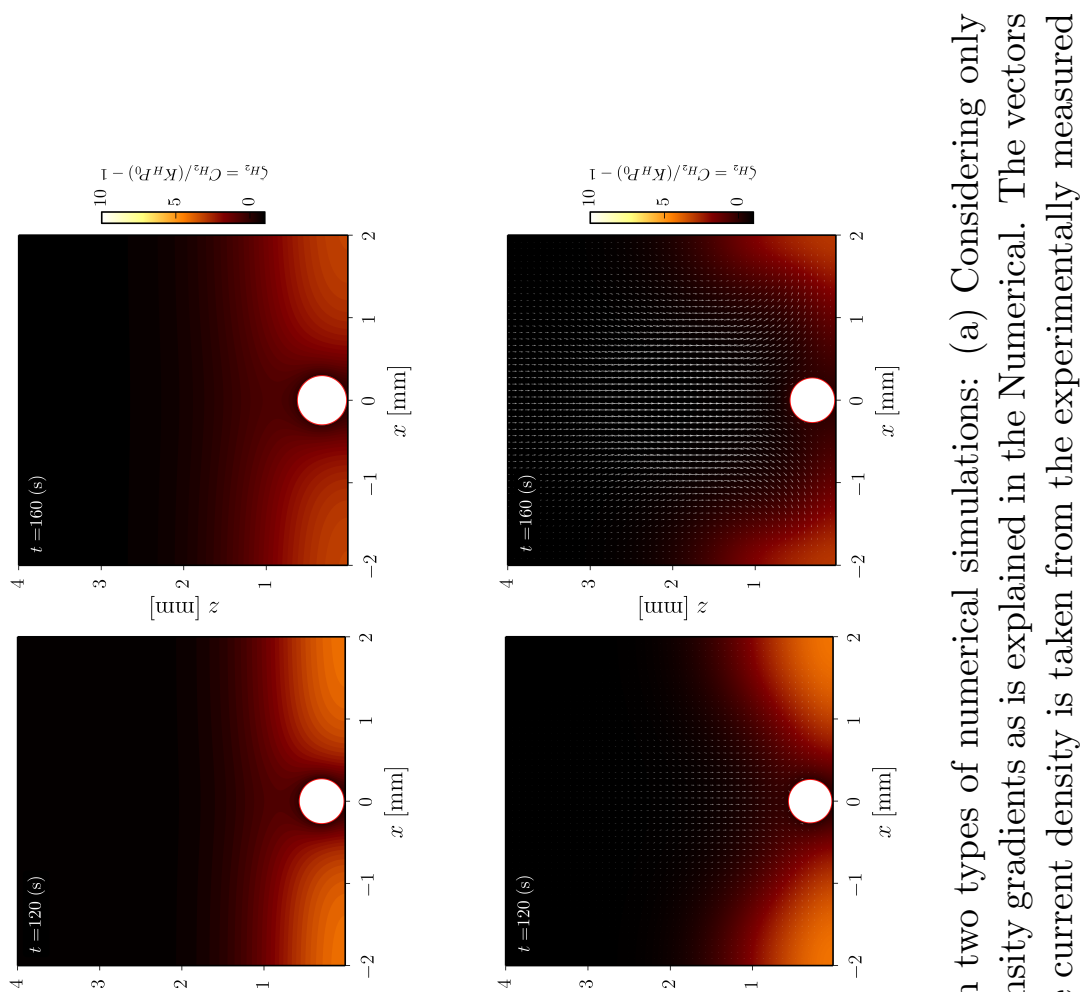

త্টে

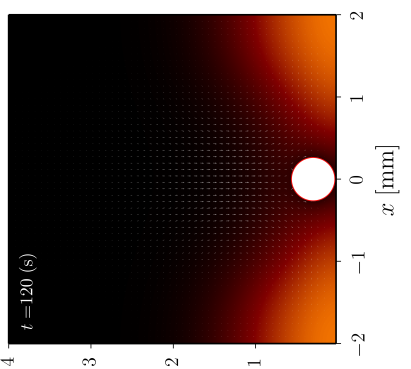

兽

当

廿 胥承

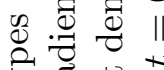

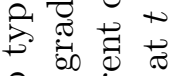

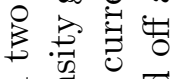

[ü] z

[uய]

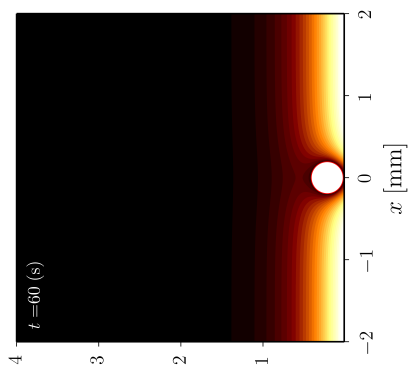

[uu] z
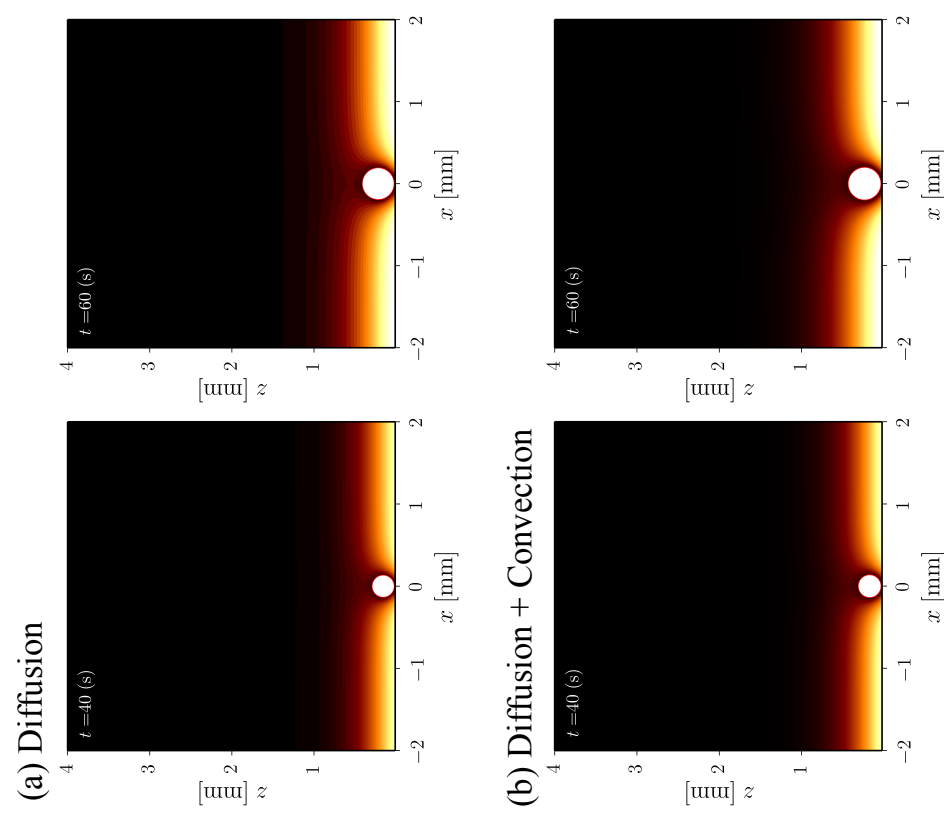

키웡워

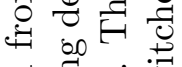

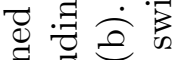

.

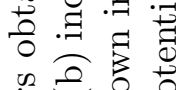

을 定

○్등

苛

요욤

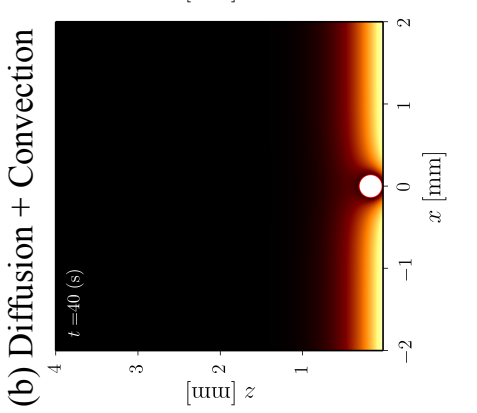

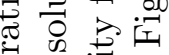

Э

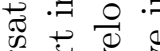

ஹू:

$1 \%$

$\ddot{\forall}$

๑ 0

농

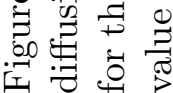




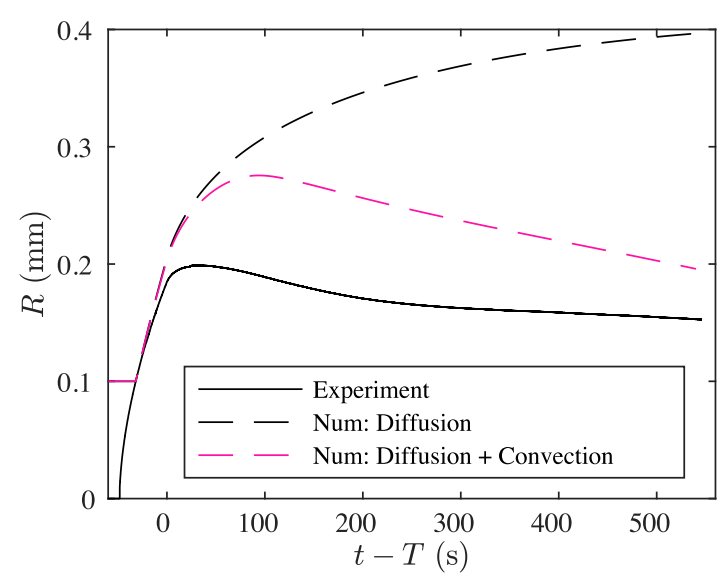

Figure 3.5: Comparison of experimentally measured bubble radius with those obtained from numerical simulations of a single bubble with and without convection.

To explain the experimental observation, we first consider convective transport in solution as the additional mechanism that reduces the dissolved gas in the bubble neighbourhood. On including the effect of density gradients due to dissolved $\mathrm{H}_{2}$ and the depleted reactant $\mathrm{H}_{2} \mathrm{SO}_{4}$, numerical simulations reveal that the onset of convection is brought on some time after the potential is switched off. Fig. 3.4 contrasts the contours for hydrogen oversaturation, $\zeta_{\mathrm{H}_{2}}=\frac{C_{\mathrm{H}}-C_{H s}}{C_{H s}}$ for the model with (a) only diffusion and with (b) the addition of density gradient driven convection. The velocity field has also been shown for the latter case. A positive or negative value of $\zeta_{\mathrm{H}_{2}}$ represents an over or under saturated solution respectively. It can be seen by Fig. 3.4 (a) and (b) that the $\mathrm{H}_{2}$ boundary layer near the electrode evolves differently in the two cases. The inclusion of density gradients in the model in fact results in a jet (downward plume) of fresh gas-unsaturated electrolyte which impinges on the bubble, and exposes it to an unsaturated ambient. As a consequence, the bubble begins to dissolve soon after the reaction is terminated, no external applied potential, as shown in Fig. 3.5 .

While it is clear that density-driven convection brings about bubble dissolution, the bubble sizes measured in the experiments and the numerical model are different. A possible reason could be that the numerical model solves for a relatively isolated bubble (distance between bubbles $=4 \mathrm{~mm}$, because of periodic boundary conditions), which is not the case for the experiments as 

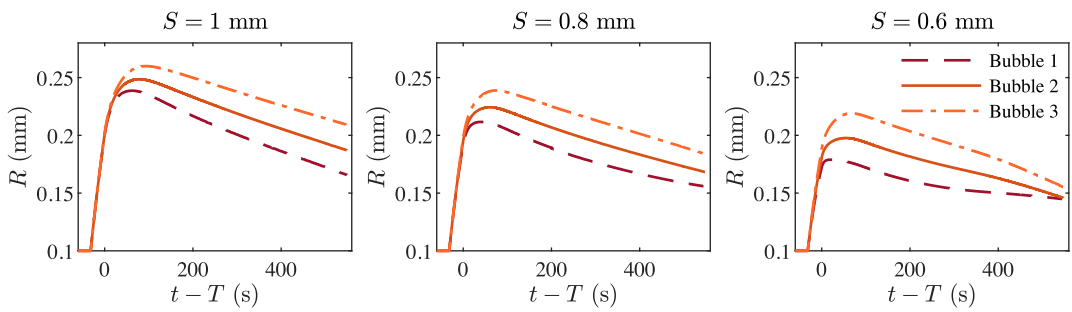

Figure 3.6: The evolution of the bubble radius for three different values of bubble spacing $S$. For each plot, the radius evolution of the center, mid-edge and diagonal bubbles (Bubbles 1,2 and 3 see Fig. 3.2 is shown.

is evident from Fig. 3.1(b) where the neighbouring bubble is at a distance $\approx 6 \mathrm{~mm}$. Since it is also more likely that bubbles grow in clusters, the numerical model is solved instead for a $3 \times 3$ bubble grid as shown in Fig. 3.2(b).

Fig. 3.6 shows the different dissolution rates for bubbles based for three different spacings $S$. In all cases, the central bubble (Bubble 1) grows to a smaller size compared to the mid-edge (Bubble 2) or the diagonal (Bubble 3) bubble, since due to its neighbouring bubbles, it is exposed to a less (gas) saturated ambient liquid. Moreover, for $S=0.6 \mathrm{~mm}$, Bubble 1 appears to dissolve slowly after $t=200 \mathrm{~s}$ while Bubble 2 and 3 dissolve at a faster rate. On examining the $\mathrm{H}_{2}$ oversaturation contours presented in Fig. 3.7(a) we find that for $S=0.6$ $\mathrm{mm}$, the bubble clusters behave as a single gas-oversaturated cloud. The central bubble, compared to the bubbles on the edge, is thereby shielded from the unsaturated ambient. Furthermore, at later times, the gas-supersaturated cloud forms a convective plume which dissolves the edge bubbles at an even faster rate. A similar behavior for the dissolution of droplets within clusters was seen recently by Chong et al. [97]. The size of the central bubble is therefore dependent on the parameter $S$, and so, in Fig. 3.7(b) we plot the radius for different $S$ values. The numerical result for $S=0.7 \mathrm{~mm}$ (which is close to the distance of $\approx 6 \mathrm{~mm}$ that is seen in experiments) is thus found to be in reasonable agreement with the experimental value. Note that in the above, besides the distance $S$ between bubbles within a cluster there is an additional length scale involved i.e. the distance between clusters $=4 \mathrm{~mm}$. 

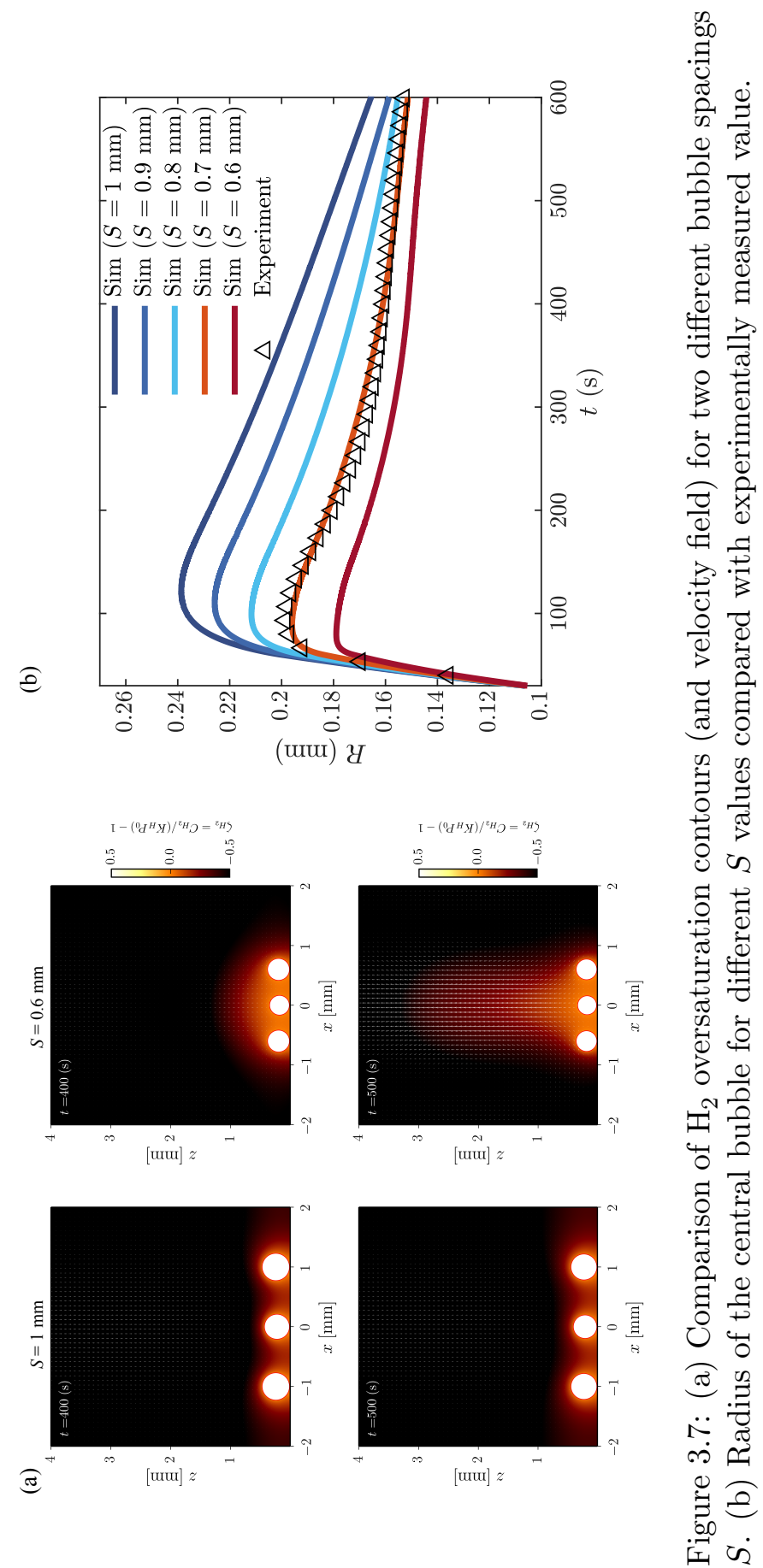


\subsection{Conclusion}

To summarize, we have measured bubble growth and dissolution rates during electrochemical hydrogen evolution in an attempt to estimate the concentration field of the dissolved gas in solution. To accomplish this, we image the hydrogen bubbles formed in response to a well defined potential pulse applied to a platinum electrode. We compare experimentally measured bubble radius with results from two different numerical simulations: one that involves only diffusive transport, and another including the effect of density-driven convection. We highlight that the density driven convection, which is driven by proton consumption at the electrode (primarily proton consumption since $\left|\beta_{\mathrm{H}_{2} \mathrm{SO}_{4}}\right|>\left|\beta_{\mathrm{H}_{2}}\right|$ ) combined with requirement of electroneutrality in the bulk solution, causes fresh, gas-free ambient electrolyte to impinge on the bubble resulting in its sudden dissolution. Finally, the role of bubble clusters is shown to significantly influence the dissolved gas concentration and transport in the electrolyte.

While it is clear that buoyancy convection likely exists in the present experimental system, bubble clusters and their spacing are used as an effective fitting parameter to model the experimental results; in particular the slowdown in the dissolution rate. Another reason for this reduction in dissolution rate could however be the presence of dissolved air in the electrolyte which Karnbach et al. [88 have used to explain their measurements. In the presence of additional gases in solution, the gas concentration at a bubble interface is related to the overall molar gas content, instead of equation (5c) [88, 98]. So, in [88], while hydrogen diffuses from the bubble to the solution, air diffuses from the solution to the bubble and thereby reduces the bubble dissolution rate.

Thus, to correctly estimate the dissolved $\mathrm{H}_{2}$ concentration in solution using the bubble size, the role of buoyancy driven convection, bubble distribution on the electrode and dissolved air, all have to be separately investigated. We have shown here how the former two cases may impact the dissolution rate. Moreover, it is shown that despite the small size of bubbles, they likely affect the current or voltage at the electrode because of their impact on transport in solution, an instance of which is shown here. Even in realistic electrolytic systems, where there is excess supporting electrolyte, there will be density gradients caused by gradients in the supporting electrolyte concentration due to the electroneutrality requirement. Here bubbles will no doubt impact the transport in solution, at least in a similar way, by providing the initial perturbation to the adverse density gradients. 


\subsection{Appendix}

\subsubsection{Numerical scheme}

Spatial terms are discretized using a second-order accurate finite difference method on a staggered grid. A fractional-step third-order Runge-Kutta (RK3) scheme, in combination with a Crank-Nicolson scheme for the viscous terms are employed to perform the time marching [99]. The solver is coupled with a versatile moving least squares (MLS) based immersed boundary method (IBM) (100, 101]) which uses a triangulated grid network called Lagrangian markers (figure $3.2(\mathrm{~b})$ ) to enforce the gas-liquid interfacial boundary conditions and transfer the flow and concentration quantities to the underlying Eulerian mesh. The location of Lagrangian markers is updated in time based on equation (3). The concentration gradient $\left.\left(\boldsymbol{\nabla} C_{k} \cdot \hat{\mathbf{n}}\right)\right|_{S}$ on bubble interface is calculated through extending a probe normal to the barycentre of each triangulated Lagrangian face and measuring the intended scalar at the tip of the probe by an additional MLS interpolation.

The data regarding physical properties of the analyzed electrochemical system compiled in the simulations are tabulated in table 3.1. The diffusion coefficients and molar volume expansion coefficients have been taken from 102 The numerical parameters using which the simulations have been carried out are listed in table 3.2 . The computational domain has been chosen specifically with equal height, width and depth of $4 \mathrm{~mm}$. Using the periodic boundary conditions in $\mathbf{x}$ and $\mathbf{y}$ directions, we effectively model an electrochemical system with an infinite electrode surface area on which the bubbles are spaced $4 \mathrm{~mm}$ from each other in an array configuration. The time steps are adapted automatically in such a way that Courant-Friedrichs-Lewy (CFL) number never surpasses the preassigned value of 0.2 .

A limitation of this model, is the initial diameter of the bubble with which it is injected into the computational domain. The initial bubble size is chosen based on the computational capacity to resolve the smallest possible bubble with respect to the computational domain. Here, we choose the initial diameter of the bubble to be one-twentieth of the computational domain and use 256 grid points in each direction, i.e. 13 grid points are present per diameter of the initialized bubble. The time when the bubble is initialized (here $28.21 \mathrm{~s}$ ) with diameter of $0.2 \mathrm{~mm}$ has been taken from the experimental data. 
Table 3.1: Physical properties of the analyzed system

\begin{tabular}{ll}
\hline Properties & Unit \\
\hline$\left(C_{\left.\mathrm{H}_{2} \mathrm{SO}_{4}\right)_{0}=100}\right.$ & $\mathrm{mol} \mathrm{m}^{-3}$ \\
$T_{\infty}=298$ & $\mathrm{~K}$ \\
$P_{0}=1$ & $\mathrm{bar}$ \\
$\rho_{L}=1030$ & $\mathrm{~kg} \mathrm{~m}^{-3}$ \\
$\nu_{L}=0.94 \times 10^{-6}$ & $\mathrm{~m}^{2} \mathrm{~s}^{-1}$ \\
$D_{\mathrm{H}_{2} \mathrm{SO}_{4}}=1.8 \times 10^{-9}$ & $\mathrm{~m}^{2} \mathrm{~s}^{-1}$ \\
$D_{\mathrm{H}_{2}}=3.7 \times 10^{-9}$ & $\mathrm{~m}^{2} \mathrm{~s}^{-1}$ \\
$\beta_{\mathrm{H}_{2}}=+13.4 \times 10^{-6}$ & $\mathrm{~m}^{3} \mathrm{~mol}^{-1}$ \\
$\beta_{\mathrm{H}_{2} \mathrm{SO}_{4}}=-62 \times 10^{-6}$ & $\mathrm{~m}^{3} \mathrm{~mol}^{-1}$ \\
\hline
\end{tabular}

Table 3.2: Numerical setup information

\begin{tabular}{lll}
\hline Parameter & Value & Unit \\
\hline Domain size & $4 \times 4 \times 4$ & $\mathrm{~mm}$ \\
Initial bubble diameter & 0.2 & $\mathrm{~mm}$ \\
Grid resolution & $256^{3}$ & \\
No. of grids per initial diameter & 13 & \\
Time step & $0.005-0.05$ & $\mathrm{~s}$ \\
Bubble injection time & 28.21 & $\mathrm{~s}$ \\
\hline
\end{tabular}




\section{Chapter 4}

\section{Electroconvective patterns in water electrolysis}

In electrochemical systems, an understanding of the underlying transport processes is required to aid in their better design. This includes knowledge of possible near-electrode convective mixing that can enhance measured currents. Here, we provide first evidence of electroconvective instability during electrocatalytic proton reduction using a binary acidic electrolyte in contact with a platinum electrode. The current-voltage characteristics confirm that electroconvection, visualized via a fluorescent dye, drives current densities larger than the diffusion transport limit. The onset characteristics of the instability are discussed in detail. Specifically, the onset and transition times of the instability do not follow the expected inverse-square dependence on the current density for all values, Instead, they are delayed by the water dissociation reaction above a bulk-reaction-limited current density. The dominant size of the electroconvective patterns is also measured and found to vary as the diffusion length scale, confirming previous predictions on the size selection of electroconvective vortices. 


\subsection{Introduction}

Electrolysis is projected to be a core-technology for a sustainable society [103], with applications in energy storage (lithium-ion batteries, water electrolysis), climate change mitigation $\left(\mathrm{CO}_{2}\right.$ reduction), and production of useful chemicals $\left(\mathrm{N}_{2}\right.$ reduction to $\left.\mathrm{NH}_{3}\right)$. Economical considerations typically require electrolyzers for these processes to operate at large current densities [43, 104], at which mostly transport processes are rate-limiting. This triggers special interest into convective phenomena as a possible driver of 'overlimiting currents', i.e. beyond the diffusive ion-transport limit. In the absence of external mixing, such convection may be induced by buoyancy [36, 105], but can interestingly also originate from electrohydrodynamic forces. The latter, known as electroconvection, is generally associated with the instability at ion-selective interfaces (membranes or electrodes) of the formed space-charge layer [64, 106, 107]. Electroconvection has been studied extensively on ion-exchange membranes (IEM) in the context of water desalination [108 111] and on electrodes for metal electrodeposition 112 115. Particularly, it has been shown 112 114 that electroconvection leads to a change in the morphology of the metal deposit and dendrite formation, which may result in short-circuiting in lithium-ion batteries and has implications on their design [115. However, the electrocatalytic processes of water electrolysis, $\mathrm{CO}_{2}$ and $\mathrm{N}_{2}$ reduction additionally involve non-linear bulk reactions. Their presence is known to drastically affect the $\mathrm{pH}$ distribution [50, 116] and fluid properties [36, 117, 118], but how this impacts the electroconvective phenomenon in these important systems remains unclear.

In this chapter we present measurements of electroconvective patterns in water electrolysis. Details on the experimental setup employed are provided in Section 4.2. In Section 4.3.1 and Section 4.3.2, we show the results of linear sweep voltammetric and chronopotentiometric experiments respectively. An effective reaction-diffusion model derived in Appendix 4.5.1 is used to explain the experimental transition times. Finally, we summarize our findings in Section 4.4.

\subsection{Experimental Setup}

A schematic of the employed setup with relevant dimensions is shown in Fig. 4.1(a). We use a cylindrical electrochemical cell made of Teflon with a transparent platinum working electrode and a Pt-ring mesh counter electrode (dis- 

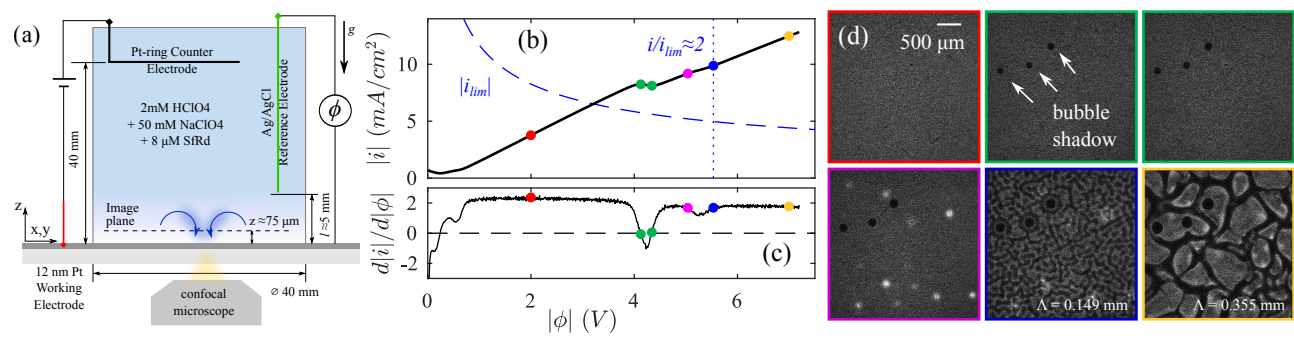

Figure 4.1: (a) Schematic of the experimental setup. (b) Linear sweep voltammograms at a rate $|d \phi / d t|=0.1 \mathrm{~V} / \mathrm{s}$. The limiting current based on the Cottrell equation $i_{\text {lim }}(t)$ has been plotted as a dashed blue line. The green $\left(d|i| / d|\phi|=0\right.$ ), magenta and blue markers (both $d^{2}|i| / d|\phi|^{2}=0$ ) have been placed at locations of the respective transitions in $|i|$ as shown in (c). The fluorescence images in (d) are measured simultaneously with the linear sweep, and the color code corresponds to the markers in (b). The dominant wavelength, $\Lambda$, of the patterns in (d) is calculated as described in the supplementary information.

tance between working and counter electrode $\approx 4 \mathrm{~cm}$ ) for the measurements. The transparency of the platinum electrode was obtained by sputtering a 12 $\mathrm{nm}$ platinum layer on a $170 \mu \mathrm{m}$ glass slide. A $3 \mathrm{~nm}$ chromium under-layer was used for better adhesion. Electrical contact to the thin film platinum electrode was made using a platinum contact pressed onto the electrode. The electrical measurements were made with a VersaStat potentiostat using a $\mathrm{Ag} / \mathrm{AgCl}$ (BasiR) reference electrode. Overall, the experimental design allows for a quasi 1-D and unrestricted progression of the depletion front, unlike previous thin-cell measurements in electrolysis 119, 120.

The electrochemical cell is mounted on an inverted laser scanning confocal fluorescent microscope (Nikon confocal microscope A1 system, Nikon Corporation, Tokyo, Japan) with a $4 \mathrm{x}$ dry objective (CFI Plan Fluor $4 \mathrm{x} / 0.13$ ) which was used to measure a $3.17 \mathrm{~mm} \times 3.17 \mathrm{~mm}$ region $\left(512 \times 512\right.$ pixel $\left.^{2}\right)$ chosen close to the center of the electrode. A $561 \mathrm{~nm}$ excitation laser was used to excite the chosen fluorescent dye (Sulforhodamine 101), while the emission was collected in a $545-645 \mathrm{~nm}$ wavelength window with a pinhole size of 28.1 $\mu \mathrm{m}$. The fluorescence measurements were made at the z-location of maximum fluorescence intensity which was $z \approx 75 \mu \mathrm{m}$ above the electrode surface. The electrode surface was in turn found by the maxima of the reflected light intensity 116. Sulforhodamine 101 was chosen for measurements since it is a 
$\mathrm{pH}$ and temperature insensitive dye [76]. A relatively small concentration of $8 \mu \mathrm{M}$ ensured that self-quenching of its fluorescence signal, which is observed at dye concentrations $\approx 100 \mathrm{mM}[121$, was avoided. We further assume electrochemical stability of the dye during the (reductive) measurement. For all the measurements, the electrolyte was composed of $2 \mathrm{mM} \mathrm{HClO}_{4}, 8 \mu \mathrm{M}$ of Sulforhodamine 101, and $50 \mu \mathrm{M}$ of supporting salt $\mathrm{NaClO}_{4}$. All chemicals were obtained from Sigma-Aldrich. Note that the supporting or indifferent salt affects the conductivity of the electrolyte (electrical migration effects in solution), and was purposely avoided to create conditions suitable for the onset of electroconvection. However, the application of the largest current density considered in this work $\left(\approx 10 \mathrm{~mA} / \mathrm{cm}^{2}\right)$ required the addition of at least 50 $\mu \mathrm{M}$ of $\mathrm{NaClO}_{4}$. Nevertheless, the concentration of the supporting $\mathrm{Na}^{+}$ions, $c_{\mathrm{Na}}$ is much smaller than that of the reacting $\mathrm{H}^{+}$ion, $c_{\mathrm{H}}$, i.e. $c_{\mathrm{Na}}<<c_{\mathrm{H}}$ such that a binary electrolyte approximation can be used.

\subsection{Results and Discussion}

\subsubsection{Linear sweep voltammetry}

We first measure the current-voltage relationship, since the onset of electroconvection at IEM's is typically associated with a characteristic shape of the current-potential curve $108,110,122$. To examine this behavior for electrocatalytic proton reduction, we sweep the potential (at a rate of $0.1 \mathrm{~V} / \mathrm{s}$ starting at $0 \mathrm{~V}$ ), as is common practice in electrochemistry $[6]$. The derived voltagedependent current density, $|i(\phi)|$ is plotted in Fig. 4.1(b). A small decrease in $|i|$, associated with a transient capacitive current $[6]$ (due to sudden potential change from the open circuit potential, $\sim 400 \mathrm{mV}$, to start potential of the sweep) is followed by a continuous increase up to $|\phi| \lesssim 4 \mathrm{~V}$. After an additional decrease in $|i|$, the current resumes its increasing trend with increasing $|\phi|$. This behavior is similar to that encountered on IEM's. In that case, the transient levelling-off is associated with reaching the diffusion limit and the subsequent recovery of an increasing slope in the $|i(\phi)|$ curve is linked to the driving of overlimiting currents due to electroconvective transport [108, 110. This analogy suggests that the transition indicated by the green markers in Fig. 4.1(b) is related to the diffusion limit of proton reduction at the electrode surface and electroconvection setting in for $\phi>4 \mathrm{~V}$. The latter is confirmed by the results of the fluorescence imaging in Fig. 4.1(d). These images were measured simultaneously with the voltammogram and the corresponding times 
are indicated with markers of same colors in Fig. 4.1(b) and 4.1(c). Specifically, green markers are placed at $d|i| / d|\phi|=0$ and magenta and blue markers indicate points at which $d^{2}|i| / d|\phi|^{2}=0$ (see Fig. 4.1 (c)). Since the fluorescent dye molecules are charged, the lateral electric-field gradients associated with electroconvection, i.e. due to the instability of the polarized layers near the electrode [107], lead to inhomogeneities in the image plane. Initially (red marker), the dye distrbution is homogeneous and besides the appearance of bubble shadows the image remains unchanged even as the potential is increased. At $\phi \approx 5 \mathrm{~V}$, the first inhomogeneity in the dye distribution appears (magenta marker), and eventually a very distinct pattern emerges over the entire imaged area (blue marker). At later times and even higher potentials (yellow), the typical pattern size is significantly larger, indicating an increase in size of the electroconvective vortices.

Determining the ratio of the measured and the limiting currents reveals to what extent the emergence of convective structures is associated with overlimiting currents. The diffusion-limited current density $i_{\text {lim }}$, is given by the Cottrell equation [6],

$$
i_{\text {lim }}(t)=-F A D_{s} \frac{c_{0}}{\left(1-\tau_{\mathrm{H}}\right) \sqrt{\pi D_{s} t}},
$$

where $F$ is Faraday's constant, $A$ is the electrode area, $D_{s}=\frac{2 D_{\mathrm{H}} D_{\mathrm{ClO}}}{D_{\mathrm{H}}+D_{\mathrm{ClO}}}$ is the effective salt diffusivity, $\tau_{\mathrm{H}}=\frac{D_{\mathrm{H}}}{D_{\mathrm{H}}+D_{\mathrm{ClO}}}$ is the ion transport number for the $\mathrm{H}^{+}$ion and $c_{0}$ the bulk concentration of the $\mathrm{H}^{+}$ion. $D_{\mathrm{H}}$ and $D_{\mathrm{ClO}}$ are the diffusivities of the $\mathrm{H}^{+}$and $\mathrm{ClO}_{4}^{-}$ions respectively. Specifically, $i_{\text {lim }}(t)$ is a time-dependent function obtained by solving the transient diffusion equation in a semi-infinite domain with a zero concentration boundary condition, for a binary electrolyte. It is shown in Fig. 4.1(b) that pattern formation occurs at $i / i_{\text {lim }} \approx 2$, confirming that the pattern formation observed in Fig. $4.1 \mathrm{~d}$ occurs at overlimiting currents. Note that the analysis presented here does not include the second Wien effect, i.e. the increase in the rate of production of $\mathrm{H}^{+}$ions due to an enhancement of the dissociation constant $k_{b}$ for water at high electric-fields 123, 124] (for chronopotentiometric measurements an estimate of this effect is provided in Appendix 4.5.1). This will likely also play a role here and might be one of the reasons why electroconvection only sets in for $i / i_{\text {lim }}>1$. 

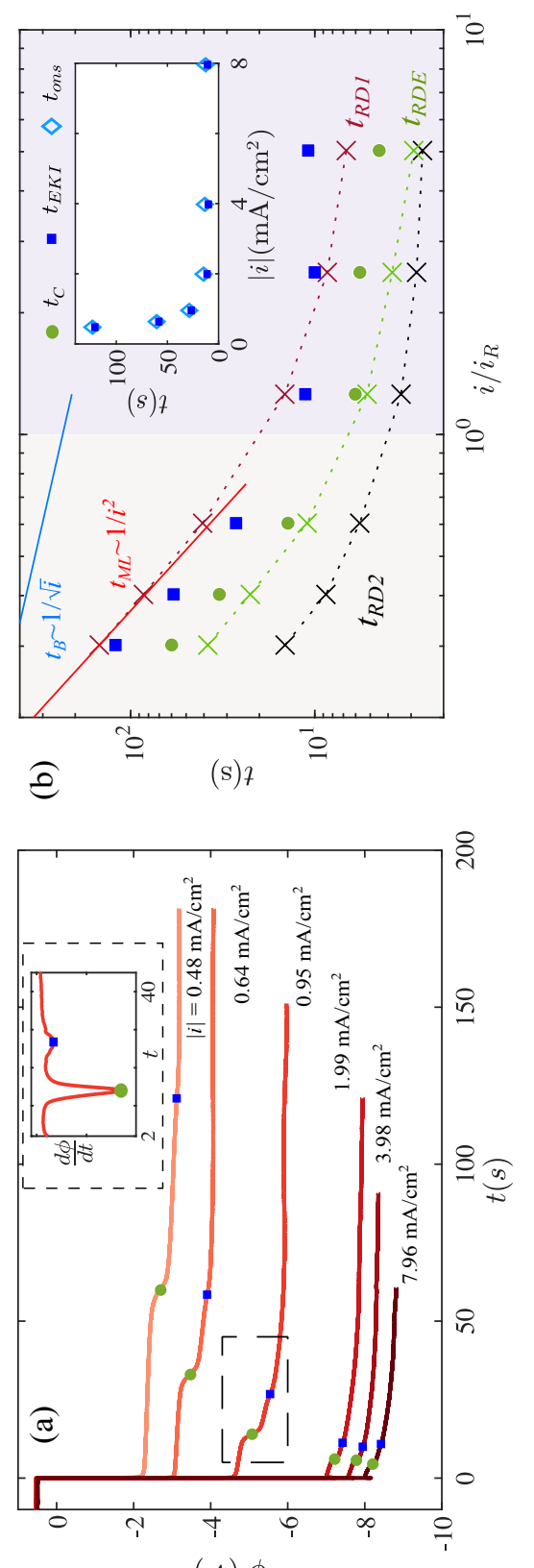

(1) $\phi$

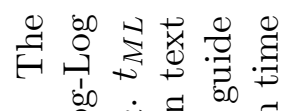

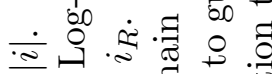

\& 0 . द्व

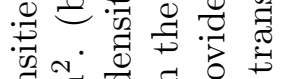

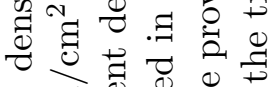

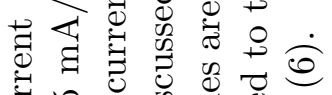

హె

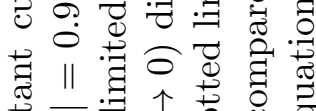

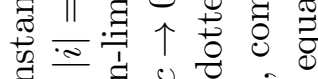

ठ․

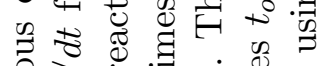

芯

$>$ n 3 ق

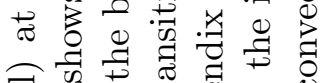

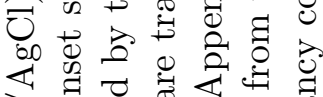

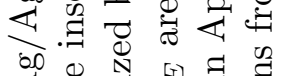

य

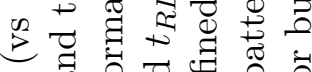

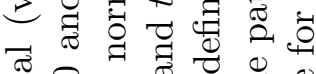

㺃 0 .

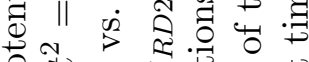

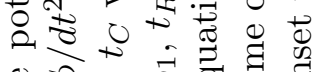

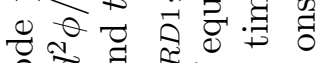

ఫٓ

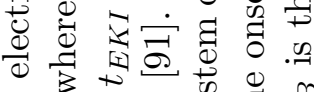

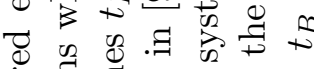

苛

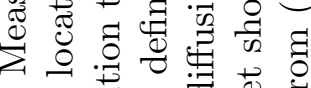

ఠ

ఠ

ㄱ.

氙

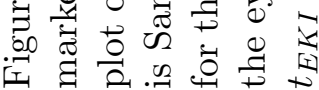




\subsubsection{Chronopotentiometric measurements}

While voltammetric experiments provided clear evidence for the existence of electroconvection, detailed analysis is complicated given that both $i$ and $\phi$ vary in time. To correlate the onset of electroconvection to changes in the measured potential [125, 126], we therefore performed experiments at constant current densities. For such configurations, the transition to electroconvection has further been linked to Sand's time, i.e. the time at which the electrolyte concentration vanishes at the boundary [6]. Thus, using constant-current experiments the transition times in $\phi$, the pattern onset time $t_{\text {ons }}$, and Sand's time can be correlated.

\section{Characteristic times}

The potentials recorded during the constant-current experiments are presented in Fig. 4.2(a). All considered values of the current density $|i|$ are at least a 100 times greater in magnitude than the steady-state diffusion limited current density, $i_{\text {lim }}=-F D_{S} c_{0} / L=-2.89 \mu \mathrm{A} / \mathrm{cm}^{2}$, where $L=20 \mathrm{~mm}$ is half the distance between the working and counter electrode (see Fig. 4.1(a)). The fluorescence images (see Appendix, Fig. 4.8) confirm that pattern formation is observed in all experiments. From the potential curves, we identify two distinct times, which correspond to local minima in $d \phi / d t$ as shown in the inset of Fig. 4.2(a). From Fig. 4.2(b), the later of the two times (blue square) is found to be in very good agreement with the onset time of pattern formation, $t_{\text {ons }}$, (obtained by visual inspection of the dye images), at all $|i|$. This connects the second (less pronounced) minimum in $d \phi / d t$ to the onset of electrokinetic instability which is therefore referred to as $t_{E K I}$ in the following. The first minimum in $d \phi / d t$, named $t_{C}$, is not observed on IEM's [126] and is likely related to a change in the reaction at the electrode due to transport limitations as will be shown later.

Before doing so, it is useful to consider the dependence of $t_{E K I}$ and $t_{C}$ on $|i|$. First, we compare our experimental observations in Fig. 4.2(b) to an estimate for Sand's time given by Morris and Lingane [91, $t_{M L}=\frac{\pi D_{s}}{4}\left(\frac{c_{0} F}{\left(1-\tau_{\mathrm{H}}\right) i}\right)^{2}($ red line), which applies in the absence of a bulk reaction and for a binary electrolyte assuming electroneutrality. For small current densities, $t_{E K I}$ is found to be in good agreement with $t_{M L}$. Moreover, both $t_{C}$ and $t_{E K I}$ follow the classical $1 / i^{2}$ relationship implied by the expression for $t_{M L}$. With increasing $|i|$ however, the decrease of $t_{C}$ and $t_{E K I}$ is significantly slower. In fact, we find that the deviation occurs around a "bulk reaction-limited" current 
density $i_{R}$, which reflects the maximum current (or proton flux) that can be sustained at the electrode by the bulk-reaction term when the concentration at the electrode reaches diffusion limitation. In particular, $i_{R}=-F D_{\mathrm{H}} c_{0} / \delta_{R}=$ $-F k_{b} c_{W} \delta_{R}$, where, $\delta_{R}=\sqrt{\frac{D_{\mathrm{H}} c_{0}}{k_{b} c_{W}}}$ is the size of the reaction-diffusion boundary layer for dissociation of water, based on a balance between diffusive flux $\sim D_{H} \frac{c_{0}}{\delta_{R}^{2}}$ and production due to water dissociation $\sim k_{b} c_{W}$, where $k_{b}$ and $c_{W}$ are the dissociation constant and water concentration respectively (values of constants can be found in Appendix 4.5.1.

To explore the reason for the change in scaling behavior for $t_{C}$ and $t_{E K I}$ at $i / i_{R} \approx 1$ (see Fig. 4.2(b)), we consider the ion transport equations for the different components of the acidic electrolyte. As shown in Appendix 4.5.1. assuming electroneutrality, the corresponding system of equations is reduced to a reaction-diffusion one in the limit of two extreme cases: 1 ) in the absence of supporting salt, called $R D 1$ henceforth (RD for Reaction-Diffusion), and 2) with excess supporting electrolyte $(R D 2)$. The key difference between the two models is the electrical migration term in the ion transport equations which is absent in $R D 2$. For both cases, we integrate the transport equations numerically and obtain the respective Sand's times, $t_{R D 1}$ and $t_{R D 2}$, which are presented in Fig. 4.2(b). $t_{R D 1}$ and $t_{R D 2}$, provide an envelope for both the experimental transition times, i.e. $t_{R D 2}<t_{C}, t_{E K I}<t_{R D 1}$. Moreover, $t_{R D 1}$, which is an estimate of Sand's time in the case of negligible supporting electrolyte, approximates $t_{E K I}$ reasonably well. Importantly, $t_{R D 1}$ approaches $t_{M L}$ (see previous paragraph for definition) at $i / i_{R} \ll 1$, and differs significantly from $t_{M L}$ for $i / i_{R} \gtrsim 1$, revealing the increasing importance of the bulk-reaction at higher current densities, which causes the deviation from the classical scaling.

The preceding discussion has shown that the time of the second (electroconvective) transition in $\phi$ is approximated reasonably well by Sand's time $t_{R D 1}$. The small but distinct potential change at $t_{E K I}$ is therefore related to the vanishing conductivity at the boundary (see equation (14)). Here, we provide a possible explanation for the additional transition at $t_{C}$ in terms of a change in the reaction at the electrode at the moment when diffusion limitation i.e. $c_{\mathrm{H}} \approx 0$ is encountered at the electrode surface.

To do so, we consider the kinetic boundary condition at the reaction plane which can be expressed as the generalized Frumkin-Butler-Volmer equation 
[77, 127 129] for the Faradaic current $\left(i_{F}\right)$ at the boundary.

$$
i_{F}=k_{-} c_{\mathrm{H}} \Gamma(1-\theta) e^{-\alpha \Delta \phi_{S} / \phi_{T}}-k_{+} \Gamma \theta e^{\alpha \Delta \phi_{S} / \phi_{T}}
$$

where,

$$
i_{F}=\left.D_{\mathrm{H}}\left(\frac{\partial c_{\mathrm{H}}}{\partial z}+\frac{c_{\mathrm{H}}}{\phi_{T}} \frac{\partial \phi}{\partial z}\right)\right|_{z=0}
$$

Here, $k_{-}$is the rate constant for the reduction reaction (formation of $\mathrm{PtH}_{a d s}$ ), $k_{+}$for the corresponding oxidation reaction, $\alpha=0.5, \Gamma$ the total number of available sites for reaction, $\theta$ the fractional coverage, $\Delta \phi_{S}$ the potential drop across the Stern layer driving the reaction and $\phi_{T}=R T / F$ the thermal voltage ( $R$ is the ideal gas constant, $T=298 \mathrm{~K}$ ).

We rewrite equation 2a as:

$$
\begin{aligned}
i_{F} & =i_{k i n}\left(1-\frac{k_{+} \theta}{k_{-}(1-\theta) c_{\mathrm{H}}} e^{2 \alpha \Delta \phi_{S} / \phi_{T}}\right) \\
i_{k i n} & =k_{-} c_{\mathrm{H}} \Gamma(1-\theta) e^{-\alpha \Delta \phi_{S} / \phi_{T}}
\end{aligned}
$$

where $i_{k i n}$ is the kinetic current. For fast reversible reactions, such as proton reduction on platinum, $i_{F} / i_{k i n}<<1$ [130] and quasi-equilibrium is maintained (right hand side of equation $3 \mathrm{a}=0$ ). Thus, equation $(2 \mathrm{a})$ reduces to the Nernst equation and the potential drop across the stern layer $\Delta \phi_{S}$ can be estimated using:

$$
\frac{\Delta \phi_{S}}{\phi_{T}}=\frac{1}{2 \alpha} \ln \frac{k_{-}(1-\theta) c_{\mathrm{H}}}{k_{+} \theta}
$$

Finally, it can be seen that $c_{\mathrm{H}} \rightarrow 0$ is equivalent to $\theta \rightarrow 1$ at the reaction boundary, i.e. a change from the underpotential to overpotential hydrogen deposition at the electrode [131.

To estimate the time of this transition from the transport equations, we heuristically assume that the potential gradient vanishes at the reaction plane, $\left.\frac{\partial \phi}{\partial z}\right|_{z=0}=0$, and solve the electroneutrality equations with a modified flux boundary condition at the electrode, $D_{\mathrm{H}} \frac{\partial c_{\mathrm{H}}}{\partial z}=\frac{i}{F}$ (instead of equation (19a)). This is similar to the "zero-field approximation" that has been used to model electrode reactions in the absence of a supporting electrolyte for fast electron transfer reactions [132, 133], but with the added simplification of electroneutrality. The "zero-field approximation" inherently assumes that the Stern layer adsorbs ions that screen the surface charge 129. Since electro-catalytic proton 
reduction on platinum is a fast reaction and proceeds first by an (underpotential) adsorption of protons at the boundary, this approximation appears justified in the present system.

The transition time within this approximation, $t_{R D E}$, is the moment when the flux of protons at the electrode becomes diffusion limited i.e. when $c(z=0)=$ 0 . Model results for $t_{R D E}$ are compared to $t_{C}$ in Fig. 4.2(b). The values are close and the small difference between the two is indeed expected since $t_{R D E}$ actually predicts the time at the base of the spike in $d \phi / d t$ (inset Fig. 4.2(a)), whereas $t_{C}$ corresponds to the inflection point in $\phi$.

\section{Role of Buoyancy}

Previous studies have shown that buoyancy may influence electroconvection [126, 134] and here we briefly discuss the role of buoyancy forcing in the present system. The relevant dimensionless parameter in this context is the Rayleigh number $R a$, which relates buoyancy and viscous forces. For our configuration, we define

$$
R a=\frac{g \beta d^{4}}{D_{S} \eta} \frac{\partial c}{\partial z}
$$

where $g$ is the acceleration due to gravity, $d \approx \sqrt{D_{S} t}$ is the length scale over which the gradient is applied and $\eta=10^{-3} \mathrm{~Pa} s$ is the dynamic viscosity of water. The density gradient can be estimated by using the concentration flux at the boundary $\frac{\partial c}{\partial z}=i\left(1-\tau_{\mathrm{H}}\right) /\left(F D_{S}\right)$ in the electroneutrality limit 91, and the coefficient $\beta \approx \frac{\Delta \rho}{\Delta c}=0.0575 \mathrm{~kg} / \mathrm{mol} 135$ ] for density change with depletion of $\mathrm{HClO}_{4}$ at the electrode. We estimate an onset time for buoyancy driven convection by taking a critical Rayleigh number $R a_{c}=817$ [136, 137]. With a critical value for the onset for buoyancy driven convection of $R a_{c}=817 \quad 136$, 137] we obtain the relation

$$
i t_{B}^{2}=R a_{c} F \eta /\left(g \beta\left(1-\tau_{\mathrm{H}}\right)\right)
$$

for the variation of the onset time for buoyancy convection, $t_{B}$. The implied dependence $t_{B} \sim 1 / \sqrt{i}$ is compared to the other transition times in Fig. 4.2(b). However, Tan and Thorpe [137] have shown that the choice of the diffusion length scale (here $\sqrt{D_{S} t}$ ) may under-predict the Rayleigh number and hence over-estimate $t_{B}$. To get a better estimate, we alternatively evaluate $R a$ based on the numerical concentration profiles, similar to what was done by Valença et al. 126. In Fig. 4.3(a), we present the time evolution of the concentration profiles $c$ normalized with the initial/bulk concentration $c_{0}$ for the smallest 

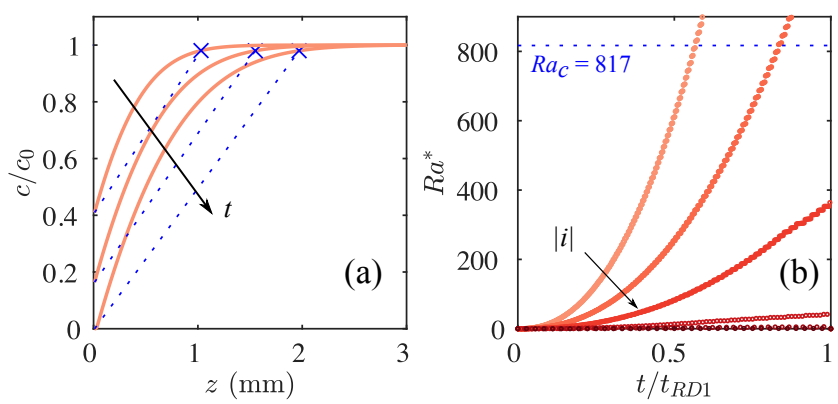

Figure 4.3: (a) Solid lines represent concentration profiles of $\mathrm{HClO}_{4}$ at times $t=51 \mathrm{~s}, 103 \mathrm{~s}$ and $153 \mathrm{~s}$ obtained from the numerical model $R D 1$ for the smallest current density $|i|=0.48 \mathrm{~mA} / \mathrm{cm}^{2}$. The dotted line shows the effective diffusion layer which is used to calculate $R a^{*}$ (b) The evolution of $R a^{*}$ for all current densities. $R a_{c}$ is an estimate of the critical Rayleigh number for the present configuration.

applied $|i|$. The effective diffusion layer thickness $\delta_{B}(t)$ is taken as the distance from the boundary where $c=0.98 c_{0}$. As a result, we redefine the Rayleigh number based on this quasi-steady length scale as

$$
R a^{*}=\frac{g \beta \Delta c \delta_{B}^{3}}{D_{S} \eta}
$$

where $\Delta c=c_{0}-c(0, t)$ is the effective concentration depletion in the diffusion layer. The dotted line in Fig. 4.3(a) indicates the estimated diffusion layer for numerical concentration profiles at three representative times.

The time evolution of $R a^{*}$ at different $|i|$ is presented in Fig. 4.3(b). Note that we have normalized the time-axis with Sand's time $t_{R D 1}$ (which is an estimate of electroconvection onset time from the model) to indicate whether buoyancy driven convection occurs before electroconvection. When $R a^{*}>$ $R a_{c}$, the onset of buoyancy driven convection is expected. From Fig. 4.3(b), we conclude that for the lower two current densities, the onset of buoyancy-mixing may be expected before electroconvection. This would explain the sudden smoothing of the pattern after its onset for the smallest current density (Fig. 4.8) which is most likely caused by large-scale buoyant mixing. For the rest however, we observe that electroconvection precedes any density-driven mixing $\left(R a\left(t_{R D 1}\right) \ll R a_{c}\right)$. It therefore appears unlikely that the different scaling of the transition times for the three largest current densities, at $i / i_{R} \gtrsim 1$ in Fig. 4.2 (b), is a buoyancy effect. Nevertheless, since electroconvection can 
(a)

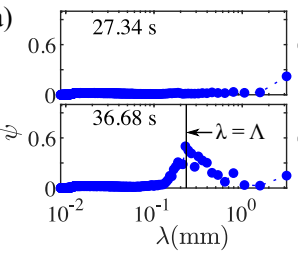

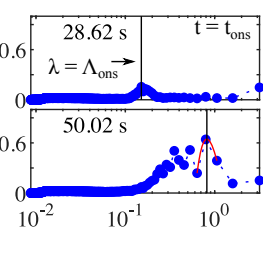

(b)

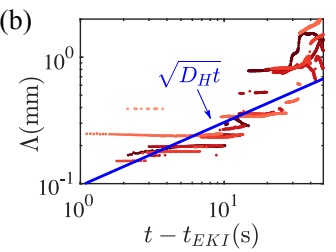

(c)

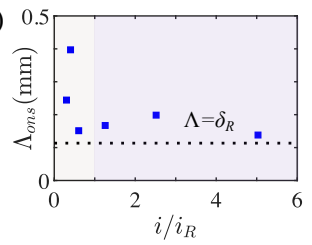

Figure 4.4: (a) Radially averaged power spectrum $\psi$, plotted against wavelength $\lambda$ at different times for $|i|=0.95 \mathrm{~mA} / \mathrm{cm}^{2}$. The dotted line is provided to guide the eye. A parabola (red curve) is fit about the maximum value and two adjacent points to obtain the wavelength of instability $\Lambda$. (b) The peak wavelength of the pattern $\Lambda$ is plotted as function of time, for all current densities after their onset. The color scheme is the same as used in Fig. 4.2(a). The solid blue line shows the diffusion length scale $\sqrt{D_{\mathrm{H}} t}$. (b) Structure size at onset $\Lambda\left(t_{\text {ons }}\right)=\Lambda_{\text {ons }}$ as a function of the current density, where $\delta_{R}$ is the size of the bulk reaction-diffusion boundary layer.

accelerate the onset of buoyancy driven convection [134], it may drive mixing at later times.

\section{Structure size and evolution}

In addition to the transition times, we can also determine a typical length scale of the patterns as a measure of the size of the electroconvective vortices [109]. We find the dominant wavelength of the patterns $\Lambda$ from the maximum in the radially averaged one-sided power spectrum $\psi$ of the mean subtracted fluorescence intensity of the images. In Fig. 4.4(a) we present the time evolution of $\psi$ for a particular current density $|i|=0.95 \mathrm{~mA} / \mathrm{cm}^{2}$. There is indeed a clear dominant wavelength of the pattern which increases with time. At each time, $\Lambda$ is taken as the vertex of the parabola (red line) that is fit to the three points adjacent to the peak.

Fig. 4.4(a) shows that when shifted by their respective instability time $t_{E K I}$, the growth of $\Lambda$ consistently follows a diffusive behavior with $\Lambda \approx \sqrt{D_{\mathrm{H}} t}$ across all $|i|$. The similarity in the pattern evolution at different current densities is also evident from fluorescence images directly (see Appendix 4.5.3). This result is in line with the numerical prediction of Rubinstein and Zaltzman [106] who showed that the size of electroconvective vortices in steady-state (which evolves through the merging of smaller vortices) is equal to length scale of the diffusion domain. The agreement with the steady-state prediction, 

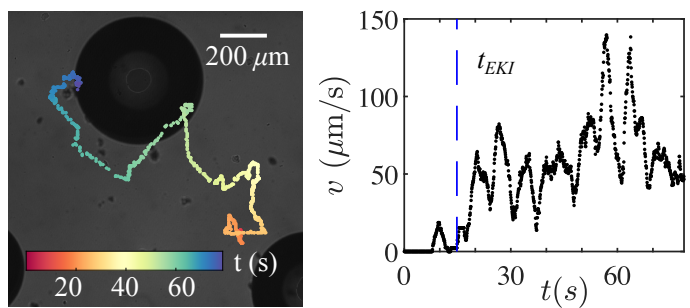

Figure 4.5: Measurements for $|i| \approx 2.3 \mathrm{~mA} / \mathrm{cm}^{2}=1.5 i_{R}$. Left: Time trace of the motion of a particulate impurity in solution. The particle path has been overlaid on the final (backlit) image taken of the electrode. The dark circle represents the bubble shadow. Right: In-plane velocity of the particle. $t_{E K I}$ has been measured from the fluorescence images.

moreover, indicates that in our system, the vortices grow in a quasi-steady manner despite the transient evolution of the diffusion layer. Note that with $\sqrt{D_{\mathrm{H}} t}$ being an estimate of the vertical propagation of the diffusive front, or findings imply a typical aspect ratio (lateral wavelength over height of the structures) of 1. Lastly, in Fig. 4.4(b) we plot the initial wavelength of the patterns $\Lambda_{\text {ons }}=\Lambda\left(t_{\text {ons }}\right)$ (taken at the empirical threshold value $\psi=0.15$, see Fig. 4.4(a) at $t=28.62 \mathrm{~s})$. The value of $\Lambda_{\text {ons }}$ saturates at the reactiondiffusion boundary layer thickness $\Lambda=\delta_{R}$ for $i / i_{R}>1$, which is another manifestation of the limiting behavior observed for the pattern onset time.

\section{Convective motion}

In addition to the dye images and the footprint in the potential curves at $t_{E K I}$, we also obtain direct evidence of convective motion in the fluid by tracking the motion of a particulate impurity (size $\hat{a} \approx 40 \mu \mathrm{m}$ ). The time trace of motion and the in-plane velocity are shown in Fig. 4.5. We find that the particle, initially at rest, moves vigorously only after $t=t_{E K I}$, with velocities, $v \sim 100 \mu \mathrm{m} / \mathrm{s}$, comparable to electroconvective velocities measured by [126]. It should be noted that measurement with fluorescent tracer particles (Thermo Scientific, Fluoro-Max Red 36-2B, $6 \mu \mathrm{m}$ ) failed since, presumably due to electrophoretic effects, these quickly disappeared from the measurement plane once the patterns emerged. The particulate impurity is apparently charged to a lesser extent compared to the tracers. Yet it is still conceivable that also in this case the velocity $v_{E P}=\mu_{p} E_{b}$ induced by the bulk electric field $E_{b}$ may be significant. To test this, we estimate the electrophoretic mobility 
$\mu_{p}$ using the relation for a spherical colloidal particle [138]: $\mu=\frac{2 \varepsilon_{r} \varepsilon_{0} \zeta_{p}}{3 \eta f\left(a / \lambda_{D}\right)}$, where $\varepsilon_{0}$ is the permittivity of vacuum, $\varepsilon_{r}=80$ is the relative permittivity of water, $f\left(\hat{a} / \lambda_{d}\right)$ is Henry's function which depends on the ratio of the particle size to the diffuse layer thickness $\lambda_{D}=\sqrt{\varepsilon_{0} \varepsilon_{r} R T /\left(2 F^{2} c_{0}\right)}=6.8 \mathrm{~nm}$ (for $\hat{a} / \lambda_{d} \gg 1, f=1.5$ ) and $\zeta_{p} \approx 0.1 \mathrm{~V}$ is the assumed zeta-potential of the particle. We approximate $E_{b}$, based on the steady-state diffusion of counter ions as $E_{b}=\frac{R T / F}{c} \frac{\partial c}{\partial z} \approx \frac{R T / F}{\delta_{R}}=226 \mathrm{~V} / \mathrm{m}$, where diffusion length is taken to be its limiting value $\delta_{R}$. The electrophoretic velocity is therefore calculated to be $v_{E P} \approx 16 \mu \mathrm{m} / \mathrm{s}$. This value is smaller than the particle velocity that is measured soon after pattern onset $(\approx 50 \mu \mathrm{m} / \mathrm{s})$, and moreover an order of magnitude smaller than the maximum particle velocity. Thus, we conclude that the particle motion must be driven by the surrounding flow.

A final remark is regarding the roles of the bubbles that can be seen to nucleate occasionally (see Fig. 4.1) and can cause bending of electric-field lines around them (the case of a dielectric sphere in an electric-field [139]). The presence of such a perturbation, however, does not appear to influence the transition times significantly as evidenced by the good agreement between experimental results and those from the 1-D ion transport model. Further, the pattern formation does not necessarily initiate from bubble locations and the structures generally appeared unaffected by the bubbles except in their immediate vicinity.

\subsection{Conclusion}

In summary, conclusive evidence for the the existence of electroconvective pattern formation in water electrolysis is provided. We additionally reveal pattern formation up to a supporting electrolyte concentration $c_{\text {sup }}=1 \mathrm{mM}$, i.e for $c_{\text {sup }} / c_{\mathrm{H}} \leq 0.5$ (see Appendix 4.5.2). While electroconvection is unlikely in commercial electrolyzers where $c_{\text {sup }} / c_{\mathrm{H}} \gg 1$, These findings are relevant to laboratory electrochemical studies which are frequently performed in the absence of supporting electrolyte [140, 141]. For instance, electroconvection could be the possible driving mechanism for the so-called "spontaneous convection" (different from buoyancy driven convection) which is assumed by Amatore et al. [142] to fit experimentally measured currents. Amatore et al. 142] have described the mixing as an extension of Levich's idea of turbulent diffusivity, however the origin of the mixing appears to be unclear [36]. 


\subsection{Appendices}

\subsubsection{Numerical model}

A simplified numerical model is derived here primarily to calculate Sand's time for the present system.

The general form of the Nernst-Planck-Poisson equations with a bulk reaction is:

$$
\begin{aligned}
\frac{\partial c_{k}}{\partial t} & =\frac{\partial J_{k}}{\partial z}+\mathrm{R}_{k} \\
J_{k} & =D_{k}\left(\frac{\partial c_{k}}{\partial z}+\frac{z_{k} F c_{k}}{R T} \frac{\partial \phi}{\partial z}\right) \\
\varepsilon \nabla^{2} \phi & =-\Sigma z_{k} F c_{k}
\end{aligned}
$$

where $c_{k}$ is the concentration, $J_{k}$ is the mass flux, $z_{k}$ is the sign of the charge of ionic species ' $k$ '. $\mathrm{R}_{k}$ is the bulk reaction for each equation, $\phi$ is the electrostatic potential in solution and $\varepsilon$ is the absolute permittivity of water. More specifically, taking an acid with anion $\mathrm{ClO}_{4}^{-}$and a supporting salt with cation $\mathrm{Na}^{+}$and anion $\mathrm{ClO}_{4}^{-}$, we have:

$$
\begin{aligned}
& \frac{\partial c_{\mathrm{H}}}{\partial t}=D_{\mathrm{H}} \frac{\partial}{\partial z}\left(\frac{\partial c_{\mathrm{H}}}{\partial z}+\frac{F c_{\mathrm{H}}}{R T} \frac{\partial \phi}{\partial z}\right)+R \\
& \frac{\partial c_{\mathrm{ClO}}}{\partial t}=D_{\mathrm{ClO}} \frac{\partial}{\partial z}\left(\frac{\partial c_{\mathrm{ClO}}}{\partial z}-\frac{F c_{\mathrm{ClO}}}{R T} \frac{\partial \phi}{\partial z}\right) \\
& \frac{\partial c_{O H}}{\partial t}=D_{O H} \frac{\partial}{\partial z}\left(\frac{\partial c_{O H}}{\partial z}-\frac{F c_{O H}}{R T} \frac{\partial \phi}{\partial z}\right)+R \\
& \frac{\partial c_{\mathrm{Na}}}{\partial t}=D_{\mathrm{Na}} \frac{\partial}{\partial z}\left(\frac{\partial c_{\mathrm{Na}}}{\partial z}+\frac{F c_{\mathrm{Na}}}{R T} \frac{\partial \phi}{\partial z}\right)
\end{aligned}
$$

Here, $R=k_{b} c_{W}-k_{f} c_{\mathrm{H}} c_{\mathrm{OH}}$ is the bulk dissociation of water for the reaction,

$$
\mathrm{H}^{+}+\mathrm{OH}^{-} \underset{k_{b}}{\stackrel{k_{f}}{\rightleftharpoons}} \mathrm{H}_{2} \mathrm{O}
$$

where, $k_{b}=2.6 \times 10^{-5} s^{-1}$ is the water dissociation rate constant, and $k_{f}=$ $1.4 \times 10^{-11} \mathrm{M}^{-1} s^{-1}$ the rate constant for $\mathrm{H}^{+}$and $\mathrm{OH}^{-}$association 81 . Note that the concentration of water, $c_{W}=55.55 \mathrm{M}$, is assumed to be large and unchanging. 


\section{(acidic) Binary electrolyte (RD1)}

Assuming electroneutrality, we get continuity of the current i.e the current (or charge flux) is constant in the system and equal to the value at the boundary. In other words,

$$
\begin{gathered}
\sum z_{k} J_{k}=\frac{\partial}{\partial z}\left(D_{\mathrm{H}} c_{\mathrm{H}}-D_{\mathrm{ClO}} c_{\mathrm{ClO}}-D_{\mathrm{OH}} c_{\mathrm{OH}}+D_{\mathrm{Na}} c_{\mathrm{Na}}\right) \\
+\frac{F}{R T} \frac{\partial \phi}{\partial z}\left(D_{\mathrm{H}} c_{\mathrm{H}}+D_{\mathrm{ClO}} c_{\mathrm{ClO}}+D_{\mathrm{OH}} c_{\mathrm{OH}}+D_{\mathrm{Na}} c_{\mathrm{Na}}\right) \\
=\frac{i}{F}
\end{gathered}
$$

Since electroneutrality implies that $c_{\mathrm{H}}+c_{\mathrm{Na}}=c_{\mathrm{ClO}}+c_{\mathrm{OH}}=c$, the above equations can be rewritten as

$$
\begin{array}{r}
\frac{\partial}{\partial z}\left(\left(D_{\mathrm{H}}-D_{\mathrm{OH}}\right) c-\left(D_{\mathrm{H}}-D_{\mathrm{Na}}\right) c_{\mathrm{Na}}+\left(D_{\mathrm{OH}}-D_{\mathrm{ClO}}\right) c_{\mathrm{ClO}}\right) \\
+\frac{F}{R T} \frac{\partial \phi}{\partial z}\left(\left(D_{\mathrm{H}}+D_{\mathrm{OH}}\right) c-\left(D_{\mathrm{H}}-D_{\mathrm{Na}}\right) c_{\mathrm{Na}}-\left(D_{\mathrm{OH}}-D_{\mathrm{ClO}}\right) c_{\mathrm{ClO}}\right)=\frac{i}{F}
\end{array}
$$

Consider the case where $c_{\mathrm{Na}}, c_{\mathrm{OH}} \ll c_{\mathrm{H}}=c_{\mathrm{ClO}}=c$, i.e. the (initial) concentration of $\mathrm{OH}^{-}$is very small and there is close to no supporting electrolyte in solution. The gradient in the potential in this case is given by

$$
\frac{\partial \phi}{\partial z}=\frac{R T}{F c} \frac{1}{\left(D_{\mathrm{H}}+D_{\mathrm{ClO}}\right)}\left(\frac{i}{F}-\left(D_{\mathrm{H}}-D_{\mathrm{ClO}}\right) \frac{\partial c}{\partial z}\right)
$$

Furthermore, note that in equation 2 the contribution of the potential gradient term is of the form

$$
\begin{aligned}
& D_{k} \frac{\partial}{\partial z}\left(c_{k} \frac{\partial \phi}{\partial z}\right)= \\
& D_{k} \frac{\partial}{\partial z}\left(\frac{c_{k}}{c} \frac{R T}{F\left(D_{\mathrm{H}}+D_{\mathrm{ClO}}\right)}\left(i-\left(D_{\mathrm{H}}-D_{\mathrm{ClO}}\right) \frac{\partial c}{\partial z}\right)\right)
\end{aligned}
$$

Since $c_{\mathrm{OH}} / c \sim c_{\mathrm{Na}} / c \sim 0$, the contribution of the potential gradient term to the transport of $\mathrm{OH}^{-}$and the salt cation is negligible. Equation $9 \mathrm{c}$ and $9 \mathrm{~d}$ can now be written as:

$$
\begin{aligned}
\frac{\partial c_{\mathrm{OH}}}{\partial t} & =D_{\mathrm{OH}} \frac{\partial}{\partial z}\left(\frac{\partial c_{\mathrm{OH}}}{\partial z}\right)+\mathrm{R} \\
\frac{\partial c_{\mathrm{Na}}}{\partial t} & =D_{\mathrm{Na}} \frac{\partial}{\partial z}\left(\frac{\partial c_{\mathrm{Na}}}{\partial z}\right)
\end{aligned}
$$


with boundary conditions:

$$
\left.c_{k}\right|_{z \rightarrow \infty}=c_{k, \text { initial }}
$$

and,

$$
\begin{gathered}
\left.D_{\mathrm{OH}}\left(\frac{\partial c_{\mathrm{OH}}}{\partial z}\right)\right|_{z=0}=0 \\
\left.D_{\mathrm{Na}}\left(\frac{\partial c_{\mathrm{Na}}}{\partial z}\right)\right|_{z=0}=0
\end{gathered}
$$

Also, equation $9 \mathrm{a}$ and $9 \mathrm{~b}$ and related boundary conditions,

$$
\begin{aligned}
&\left.D_{\mathrm{H}}\left(\frac{\partial c}{\partial z}+\frac{F c}{R T} \frac{\partial \phi}{\partial z}\right)\right|_{z=0}=\frac{i}{F} \\
&\left.D_{\mathrm{ClO}}\left(\frac{\partial c}{\partial z}-\frac{F c}{R T} \frac{\partial \phi}{\partial z}\right)\right|_{z=0}=0
\end{aligned}
$$

, can further be reduced to the diffusion equation, with the additional reaction term, for an effective salt species $c_{S}$, following the procedure for a binary electrolyte by 91,92$]$.

The final set of equations that are solved are:

$$
\begin{aligned}
\frac{\partial c_{S}}{\partial t} & =D_{S} \frac{\partial^{2} c}{\partial z^{2}}+\frac{D_{\mathrm{ClO}}}{D_{\mathrm{H}}+D_{\mathrm{ClO}}} \mathrm{R} \\
\frac{\partial c_{\mathrm{OH}}}{\partial t} & =D_{\mathrm{OH}} \frac{\partial^{2} c_{\mathrm{OH}}}{\partial z^{2}}+\mathrm{R}
\end{aligned}
$$

with boundary conditions

$$
\begin{gathered}
\left.c_{S}\right|_{z=l}=c_{0} \\
\left.c_{\mathrm{OH}}\right|_{z=l}=\frac{k_{b} c_{W}}{k_{f} c_{0}}
\end{gathered}
$$

and,

$$
\begin{array}{r}
\left.\frac{D_{S}}{1-t_{H}} \frac{\partial c_{S}}{\partial z}\right|_{z=0}=\frac{i}{F} \\
\left.D_{\mathrm{OH}}\left(\frac{\partial c_{\mathrm{OH}}}{\partial z}\right)\right|_{z=0}=0
\end{array}
$$

where, $D_{S}=2 D_{\mathrm{H}} D_{\mathrm{ClO}} /\left(D_{\mathrm{H}}+D_{\mathrm{ClO}}\right)$ and $\tau_{\mathrm{H}}=D_{\mathrm{H}} /\left(D_{\mathrm{H}}+D_{\mathrm{ClO}}\right)$. 

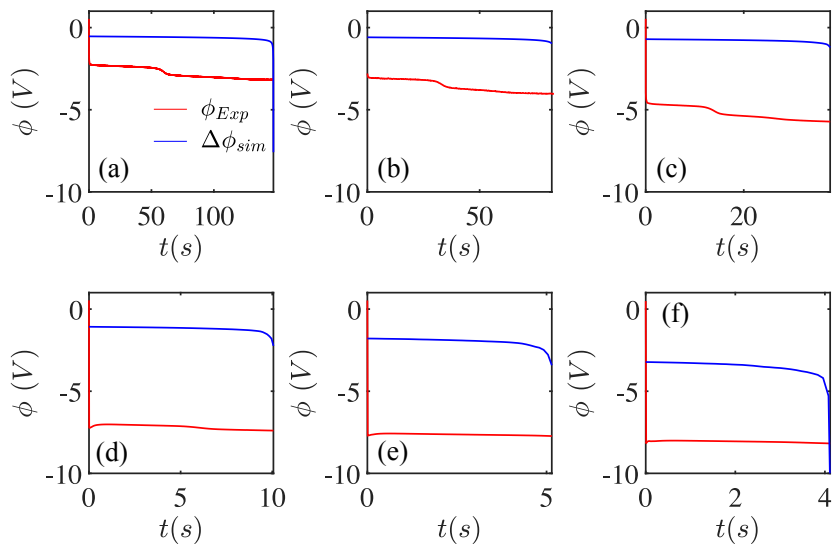

Figure 4.6: The measured electrode potential $\phi_{E x p}$ compared with that calculated from the electroneutral numerical model $\Delta \phi_{s i m}$. The difference indicates the potential drop in the diffuse layer.

\section{Excess supporting electrolyte (RD2)}

We can also derive a simplified model for ion transport for the case when the electrolyte solution contains excess supporting electrolyte. While not directly applicable to the present experimental system, it helps provide a lower limit for the measured transition times. Here, besides assuming electroneutrality, we also have $c_{\mathrm{H}}, c_{\mathrm{OH}}<<c_{\mathrm{Na}}=c_{\mathrm{ClO}}=c$. Similarly, the potential gradient is given by

$$
\frac{\partial \phi}{\partial z}=\frac{R T}{F c} \frac{1}{\left(D_{\mathrm{Na}}+D_{\mathrm{ClO}}\right)}\left(\frac{i}{F}-\left(D_{\mathrm{Na}}-D_{\mathrm{ClO}}\right) \frac{\partial c}{\partial z}\right)
$$

Here, instead $c_{\mathrm{OH}} / c \sim c_{\mathrm{H}} / c \sim 0$, and the contribution of the potential gradient term to the transport of $\mathrm{H}^{+}$and $\mathrm{OH}^{-}$is negligible. The equations reduce to a reaction-diffusion system

$$
\begin{aligned}
\frac{\partial c_{\mathrm{H}}}{\partial t} & =D_{\mathrm{H}} \frac{\partial c_{\mathrm{H}}}{\partial z^{2}}+\mathrm{R} \\
\frac{\partial c_{\mathrm{OH}}}{\partial t} & =D_{\mathrm{OH}} \frac{\partial c_{\mathrm{OH}}}{\partial z^{2}}+\mathrm{R}
\end{aligned}
$$




\begin{tabular}{|c|c|}
\hline$D_{\mathrm{H}}=9.3 \times 10^{-9} \mathrm{~m}^{2} / \mathrm{s}[143]$ & $D_{\mathrm{OH}}=4.5 \times 10^{-9} \mathrm{~m}^{2} / \mathrm{s} \quad 144$ \\
\hline$k_{b}=2.6 \times 10^{-5} \mathrm{~s}^{-1} 81$ & $k_{f}=1.4 \times 10^{11} \mathrm{~s}^{-1} \mathrm{M}^{-1} 81$ \\
\hline$D_{\mathrm{ClO}}=1.792 \times 10^{-}$ & $55 \mathrm{M}$ \\
\hline
\end{tabular}

Table 4.1: Values of the used constants

with boundary conditions,

$$
\begin{aligned}
c_{\mathrm{H}}(l) & =c_{0} \\
c_{\mathrm{OH}}(l) & =\frac{k_{b} c_{W}}{k_{f} c_{0}}
\end{aligned}
$$

at $z=l$ (where $c_{0}$ is the initial $\mathrm{H}^{+}$concentration) and,

$$
\begin{aligned}
\frac{\partial c_{\mathrm{H}}}{\partial z} & =\frac{i_{F}}{D_{\mathrm{H}} F} \\
\frac{\partial c_{\mathrm{OH}}}{\partial z} & =0
\end{aligned}
$$

at the electrode surface. Note that in this case, the potential gradient in solution is obtained by solving the transport equations for the supporting electrolyte.

We use a second order finite difference approximation with the integrating factor (IIF) numerical scheme presented in Nie et al. [82] to solve the reactiondiffusion models above (as done in in our recent work [116]). For the calculation, we use a time resolution of $\Delta t=0.03 \mathrm{~s}$ and a spatial resolution of $\Delta z=10 \mu \mathrm{m}$ for the calculations. Values of the constants used in presented in Table 4.1. The corresponding Sand's time for the above two models, $t_{R D 1}$ and $t_{R D 2}$, is the time when the concentration of the reacting ion $c=0$ at the boundary.

\section{Estimating Potential drop in the double layer}

For the chronopotentiometric experiments, the measured potential $\phi_{E x p}$ is the total potential drop between the working and the reference electrode, i.e. $\phi_{E x p}=\Delta \phi_{S}+\Delta \phi_{D}+\Delta \phi_{b u l k}$, where $\Delta \phi_{S}$ and $\Delta \phi_{D}$ are the potential drop in Stern and diffuse layer respectively, and $\Delta \phi_{b u l k}$ is the potential drop in the bulk electroneutral solution. $\Delta \phi_{S}$ is the potential difference that drives the reaction, and is assumed to be equal to the reversible potential for hydrogen evolution ( $0 \mathrm{~V}$ vs RHE). Measured on the $\mathrm{Ag} / \mathrm{AgCl}$ reference electrode scale, 
this value is $\phi_{\text {rev }}=0-0.059 \mathrm{pH}-\phi_{A g / A g C l}^{0}=0.3792 \mathrm{~V}$ where $\phi_{A g / A g C l}^{0}=0.22 \mathrm{~V}$ is the standard potential for the reference electrode 146. Furthermore, the results of the numerical model $R D 1$ can be used to calculate $\Delta \phi_{\text {bulk }}$ by integrating equation (14). This combined numerical value $\Delta \phi_{\text {sim }}=\Delta \phi_{\text {bulk }}+\phi_{\text {rev }}$ is presented along with the $\phi_{E x p}$ in Fig. 4.6 (a)-(e) for increasing $|i|$ respectively. The difference is an estimate of $\Delta \phi_{D}$, where for all current densities $\Delta \phi_{D}>1 \mathrm{~V}$. This implies that within the diffuse double layer which has a thickness of $\lambda_{D}=6.8 \mathrm{~nm}$, the electric field $E_{D} \gtrsim 1 / \lambda_{D} \mathrm{~V} / \mathrm{m}=1 \mathrm{MV} / \mathrm{cm}$. This is sufficiently large to increase the dissociation rate of water [123, 124 beyond its bulk value $k_{b}$. For $E_{D}=1 \mathrm{MV} / \mathrm{cm}$ the increased dissociation constant is calculated to be $\approx 3 k_{b}$ (using equation (38) in [124]). Thus the water dissociation rate is at least three times as fast in the double layer than in the bulk solution and will definitely contribute additional protons for the reaction at the electrode.

\subsubsection{Patterns at different supporting salt concentrations}

In Fig. 4.7 we show additional images of patterns at onset (visual inspection), at different supporting salt concentrations (here $\mathrm{NaClO}_{4} ; c_{\text {sup }}$ ), for the highest current density considered in our work $i=7.96 \mathrm{~mA} / \mathrm{cm}^{2}\left(i \approx 5 i_{R}\right)$. In each of the case, $c_{\mathrm{Na}}<c_{\mathrm{H}}$. The images show the pattern at the moment of onset, and the time of onset is mentioned in the right bottom corner of the image. A general observation is that with increasing supporting salt concentration, the onset time of the pattern as well as the initial wavelength of the pattern (wavelength of fluorescence intensity variation) increases. There appears to be, in fact, a sudden increase in initial pattern wavelength between $200 \mu \mathrm{M}<$ $c_{\text {sup }}<400 \mu \mathrm{M}$.

\subsubsection{Panels of pattern images for all current densities}

In Fig. 4.8 we present the images of the pattern at equal intervals (10 s) after their onset $t_{E K I} \approx t_{\text {ons }}$. The pattern images for almost all the current densities appears to grow in a similar manner as shown quantitatively in Fig. $2(\mathrm{~d})$ in the main text. For the lowest current density however the smoothing of the pattern could be brought about by large scale buoyant convection. 

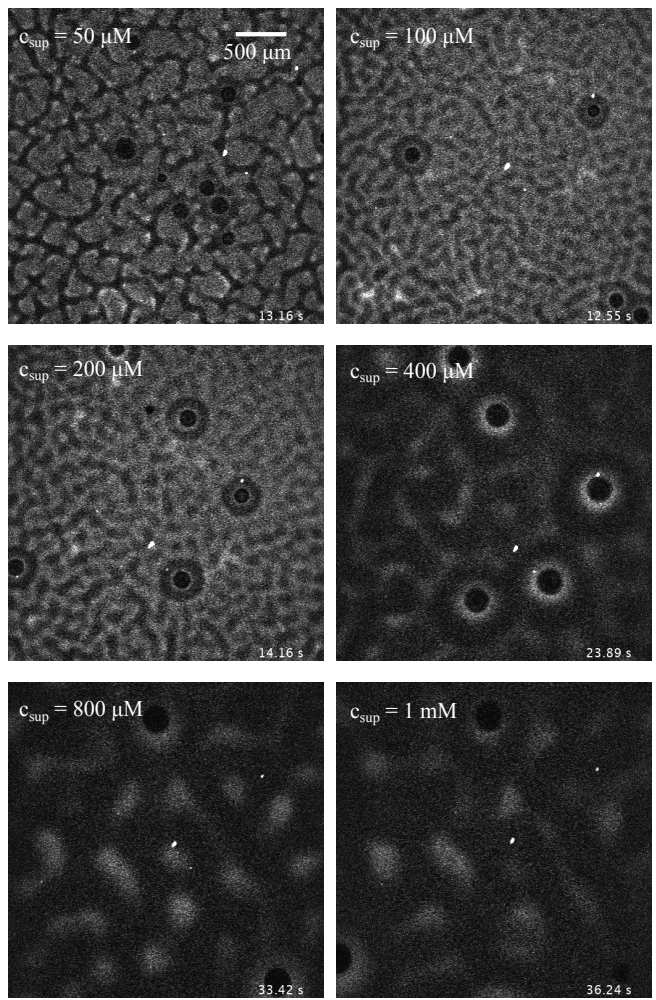

Figure 4.7: Panel showing the patterns formed for different supporting electrolyte concentration for $|i|=7.96 \mathrm{~mA} / \mathrm{cm}^{2}$ at their onset. The time of onset of the pattern, after the current is applied, is listed in the bottom right corner. 

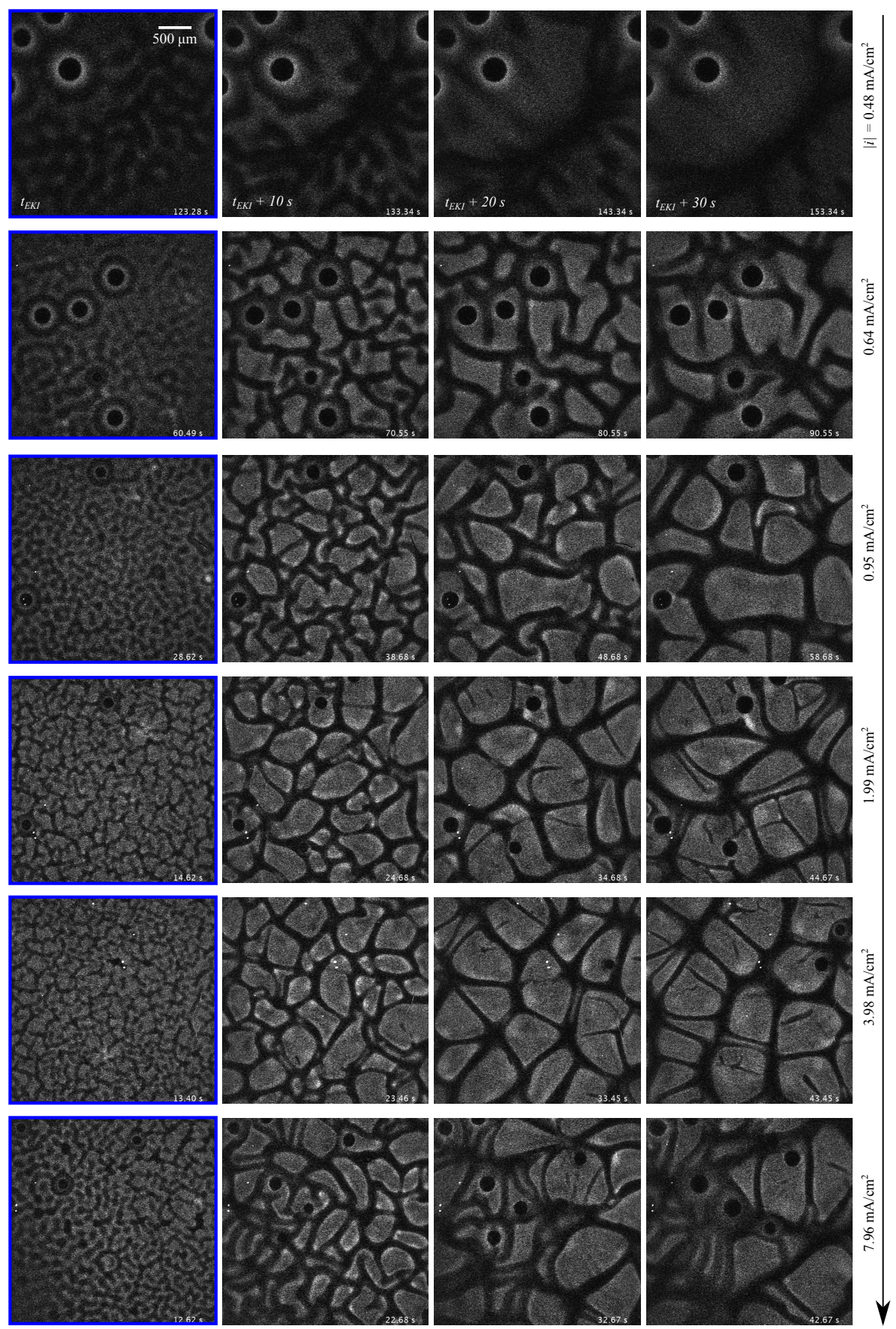

Figure 4.8: Panel showing the patterns formed for different applied currents at $\approx 10 \mathrm{~s}$ intervals after onset $t_{\text {ons }} \approx t_{E K I}$. The time of onset of the pattern (after the current is applied) is listed in the bottom right corner. 
Chapter 5

\section{Future research directions}


(a) Fluorescein Intensity

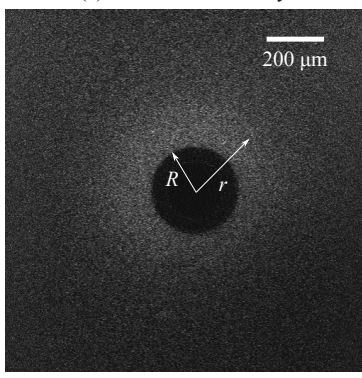

(b) Bubble shadow

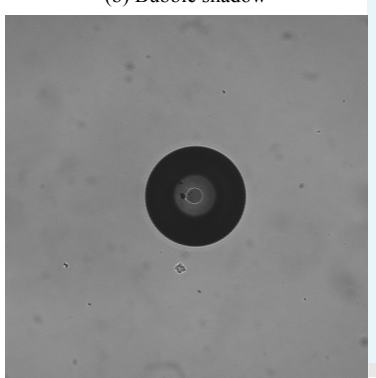

(c) Fluorescein Intensity vs distance from electrode
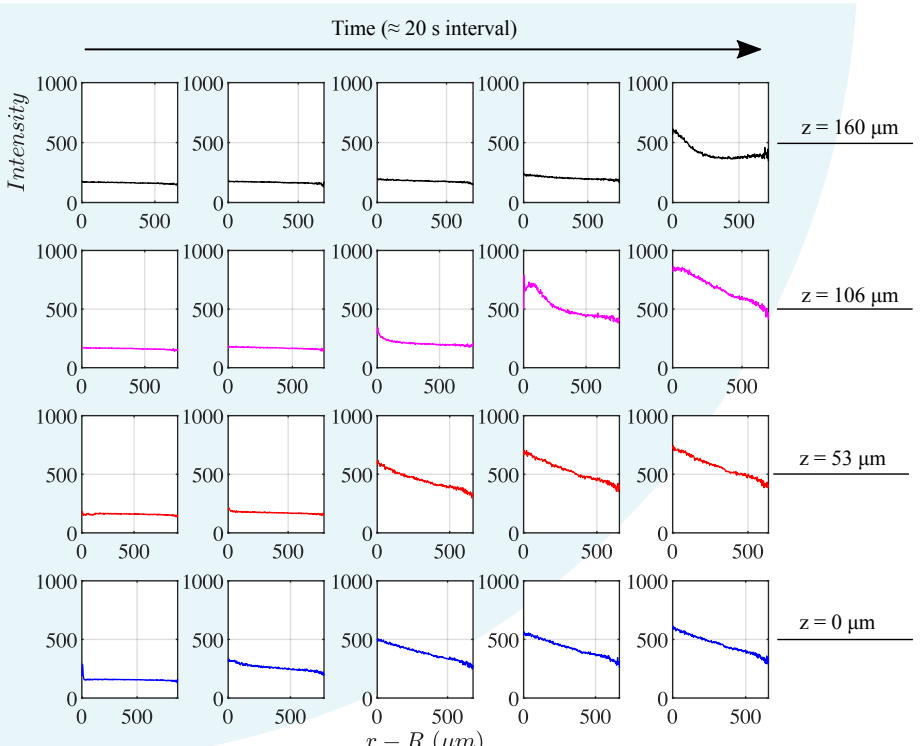

Figure 5.1: (a) Snapshot of Fluorescein intensity around a bubble at $z=$ $53 \mu \mathrm{m}$ from the electrode surface when $i \approx-0.4 \mathrm{~mA} / \mathrm{cm}^{2}$ is applied to the electrode. (b) Bubble shadow showing the diameter of the bubble. (c) The radially averaged Fluorescein intensity as a function of distance from the bubble surface $r-R$ for different distances $z$ from the electrode.

\subsection{Immediate Research projects}

The work presented in the previous chapters leads most directly to the following research questions and direction.

\subsection{1 pH change around a bubble}

It was hypothesized that the current increase observed in Chapter 1 was due to higher electrode reaction rate around a bubble. Measuring the $\mathrm{pH}$ around a bubble was thought to be an indirect way of establishing this effect. A higher reaction rate (proton reduction) around the bubble would result in a higher $\mathrm{pH}$ in the bubble vicinity. A pH measurement technique was therefore first established which involves using a $\mathrm{pH}$-sensitive dye Fluorescein whose intensity increases with $\mathrm{pH}$ (Chapter 2).

Preliminary measurements of $\mathrm{pH}$ around a bubble were performed on an trans- 
parent platinum electrode (same setup as Chapter 2-4). The Fluorescein intensity was measured around a pre-existing bubble, when a current density $i \approx-0.4 \mathrm{~mA} / \mathrm{cm}^{2}$ was applied to the platinum electrode with $3 \gtrsim \mathrm{pH} \lesssim 4$ $\mathrm{HClO}_{4}$ (with $0.5 \mathrm{M} \mathrm{NaClO}_{4}+8 \mu \mathrm{M}$ Fluorescein) 1 . The Fluorescein intensity is uniformly dark before the experiment indicating that the $\mathrm{pH}$ is below the Fluorescein measuring range $5<\mathrm{pH}<9$ in the entire image plane. When the current is applied, the Fluorescein becomes bright first close to the bubble as shown in Fig. 5.1(a). An image of the bubble shadow during the experiment is shown in Fig. 5.1(b). This indicates that Fluorescein exists in its free Fluorescent form $\mathrm{Fl}^{2-}$ (and therefore lesser protons and higher $\mathrm{pH}$ see Fig. 2.1(b)) first in the vicinity of the bubble.

Additionally, the $\mathrm{pH}$ was measured at different depths (different $z$ locations, same axes definition as in Chapter 2) from the electrode. In Fig. 5.1(c) the radially averaged Fluorescein Intensity is presented over time. The Fluorescein intensity (and therefore $\mathrm{pH}$ ) increases first near the electrode (as expected) and is consistently higher near the bubble than further away from it. A likely reason for this could be that protons are consumed faster near the bubble than further away from it.

However, electrolytic bubbles can also be charged [20] and this effect has to be discounted before drawing any conclusions. Recently, Vogel et al. 147. have suggested that bubbles have a corona of high $\mathrm{pH}$ around them (although in oxidative conditions) since they adsorb $\mathrm{OH}^{-}$ions on their surface. Thus, additional control measurements are required to understand the reason for this apparent high $\mathrm{pH}$ around the bubble.

\footnotetext{
${ }^{1}$ The precise $\mathrm{H}^{+}$concentration is not known since the present results were obtained after a few test experiments in an electrolyte with an initial concentration of $1 \mathrm{mM} \mathrm{HClO}_{4}(\mathrm{pH} 3)$
} 


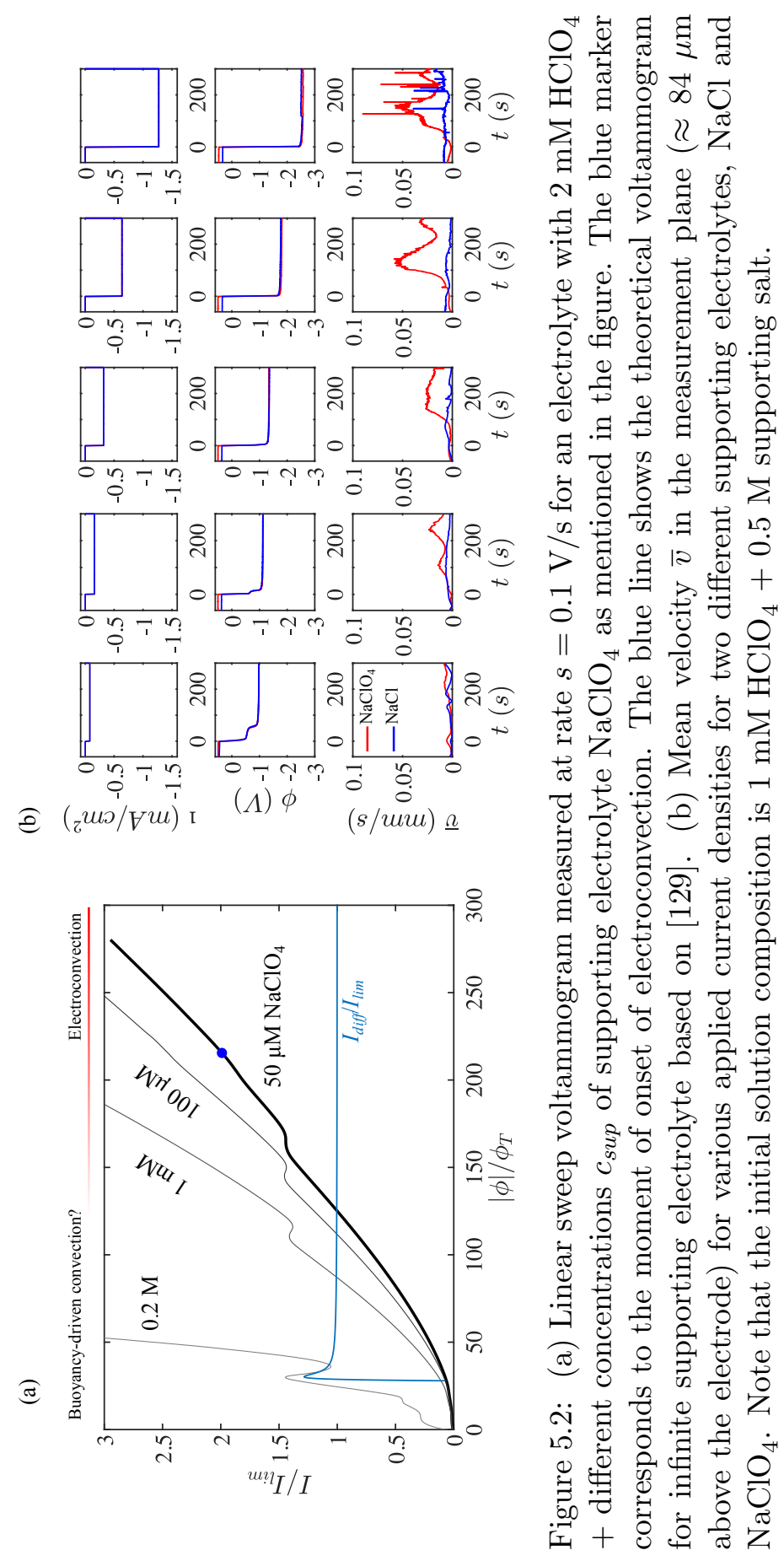




\subsubsection{Currents above the diffusion transport limit}

In Chapter 4, a particular (simple) case of a binary electrolyte was examined and it was shown that (electro) convective instability can drive overlimiting currents in electrocatalytic systems. Overlimiting currents are best presented in a current-potential phase diagram as shown in Fig. 5.2(a) (here with starting concentration of $2 \mathrm{mM} \mathrm{HClO}_{4}$ ) where we present the results for an approximate binary electrolyte $(50 \mu \mathrm{M} \mathrm{NaClO}$, electroconvective instability is observed at the blue marker), and also with solutions containing different concentrations of supporting electrolyte $\mathrm{NaClO}_{4}$ as indicated in the figure. The potential is normalized with the thermal voltage $\phi_{T}$ and the current with the limiting current $I_{\text {lim }}$ as defined by the Cottrell equation [6]. Simultaneously we present the theoretical voltammogram (blue line) for the case with infinite amount of supporting electrolyte (no potential drop in the bulk solution) based on Yan et al. (equation (28) and equation (33) in 129]) 2. The theoretical diffusion limited current $I_{d i f f}$ is calculated for the experimental voltage sweep rate $s=0.1 \mathrm{~V} / \mathrm{s}$ and is also normalized by the $I_{\text {lim }}$.

It is evident from Fig. 5.2(a) that with increasing electrolyte concentration, the current-potential behavior below the limiting current approaches the theoretical diffusion-limited voltammogram. Moreover, it can be seen that overlimiting currents can be driven for all supporting electrolyte concentrations $c_{\text {sup }}$ and therefore must be a feature of the electrocatalytic hydrogen evolution reaction on platinum. Particularly, for $\mathrm{NaClO}_{4}$ concentration $c_{\text {sup }}=0.2 \mathrm{M}$, since there is no electroconvection because of the large concentration of the supporting electrolyte, $\left(c_{\text {sup }} / c_{\mathrm{H}} \gg 1\right.$ and therefore small differences in potential gradient in the bulk solution [107]), the driver for overlimiting currents must then be an additional ion-transport mechanism. Buoyancy driven convection is a possibility whose role was briefly discussed for binary electrolytes in Chapter 4. For the case of excess supporting salt, gradients in density are likely caused by differences in supporting salt concentration due to electroneutrality in the bulk solution. The degree of convective motion must then depend on the Rayleigh number $R a$ of the system which depends on the density coefficient $\beta$, as $R a \propto \beta$ (see equation (7) in Chapter 4) and consequently the molar mass of the supporting electrolyte. This hypothesis was tested by mea-

\footnotetext{
${ }^{2}$ To obtain the theoretical voltammogram, the voltage has been shifted by the open circuit potential $\phi_{O C}=400 \mathrm{mV}$ and $\phi_{A g / A g C l}^{0}=210 \mathrm{mV}$ which gives the blue curve its intercept on the x-axis $\left(\phi_{O C}+\phi_{A g / A g C l}^{0}\right) / \phi_{T} \approx 25$. Also, the peak in the blue curve is due to the fast potential sweep rate $\frac{s}{\phi_{T} /\left(l^{2} / D_{H}\right)}$, where $l \gtrsim 5 \mathrm{~mm}$ is the distance between the working and the reference electrode
} 
suring convective motion (with fluorescent tracer particles Thermo Scientific, Fluoro-Max Red 36-2B, $6 \mu \mathrm{m}$ ) in a plane close to the electrode surface for different supporting salts, $\mathrm{NaClO}_{4}$ and $\mathrm{NaCl}$ (lower Molar Mass). Particle Image Velocimetry (PIVlab $32 \times 32$ interrogation window, $50 \%$ overlap) was used to determine the velocity field in a plane $\approx 84 \mu \mathrm{m}$ above the electrode surface. In Fig. 5.2(b), the mean velocity in the plane $\bar{v}$ is presented along with the applied current density $i$ and measured potential $\phi$ for an initial solution with $1 \mathrm{mM} \mathrm{HClO}_{4}+0.5 \mathrm{M}$ supporting electrolyte $\left(\mathrm{NaCl}\right.$ or $\left.\mathrm{NaClO}_{4}\right)$. For both supporting electrolytes, while the measured electrode potential is similar, $\bar{v}$ is smaller for the solution with $\mathrm{NaCl}$ indicating that the supporting electrolyte affects the degree of mixing in solution.

Therefore buoyancy driven convection appears relevant to the driving of overlimiting currents in electrocatalytic systems. This is especially relevant for near-neutral $\mathrm{pH}$ solutions $\left(\mathrm{pH} \sim 7\right.$ ), where a high $\mathrm{pH}$ region (large $\mathrm{OH}^{-}$concentration) is formed near the electrode which propagates into the solution as a fast reaction-diffusion front of thickness $\delta$ (presented in Fig. 2.3 as $z_{p H=7}$ ). This allows for the possibility of density driven convection since $R a \propto \delta^{3}$. Lastly, a related issue is ion transport within the diffuse double layer with thickness $\sim 1 \mathrm{~nm}$. The potential drop within the diffuse layer can be $\sim$ $\mathcal{O}(1 \mathrm{MV} / \mathrm{cm})$ as shown in Chapter 4 . These potentials are sufficiently large to increase the dissociation rate of water, but may also influence other dissolved ionic species and affect their reaction at the electrode.

\subsection{Additional Recommendations}

It may be useful to pursue the following research directions to better understand gas evolving electrochemical systems:

- Measurement of bubble contact area: Since gas-electrode contact creates additional resistance for the electrochemical cell, the measurement of the bubble contact area and its dependence on experimental parameters (current-potential and supporting electrolyte type) is required. A related direction would be to investigate the movement of the three-phase contact line and its relationship to the potential drop at the electrode surface.

- Bubble nucleation location: It would be interesting to see how the bubble distribution on an electrode is influenced by the potential distribution 
in solution, i.e by playing with the distance and shape of the counter electrode.

- Bubble nucleation instant: German et al. [148] have shown that $\mathrm{H}_{2}$ bubble nucleation on Platinum occurs for a minimum surface concentration of $c=0.21 \mathrm{M}$. It might be interesting to find this value for different concentration (of both reactant and product) and potential. This would be similar to mapping out a phase diagram for the present reaction where besides pressure, temperature and volume/density (for single phase, for two-phase also concentration) bubble nucleation would also depend on the electrochemical potential. 


\section{Bibliography}

${ }^{1}$ S. E. Renfrew, D. E. Starr, and P. Strasser, "Electrochemical Approaches toward CO2 Capture and Concentration", ACS Catalysis 10, 13058-13074 $(2020)$.

${ }^{2}$ R. Sharifian, M. Wagterveld, I. A. Digdaya, C. Xiang, and D. A. Vermaas, "Electrochemical carbon dioxide capture to close the carbon cycle", Energy Environ. Sci. 10, 147-154 (2021).

${ }^{3}$ J.-P. Jones, G. K. S. Prakash, and G. A. Olah, "Electrochemical CO2 Reduction: Recent Advances and Current Trends", Israel J. Chem.. 54, 14511466 (2014)

${ }^{4}$ E. Bakker and M. Telting-Diaz, "Electrochemical Sensors", Anal. Chem. 74, 2781-2800 (2002).

${ }^{5}$ J. Radjenovic and D. L. Sedlak, "Challenges and Opportunities for Electrochemical Processes as Next-Generation Technologies for the Treatment of Contaminated Water", Energy Environ. Sci. 49, 11292-11302 (2015).

${ }^{6}$ A. J. Bard and L. R. Faulkner, Electrochemical Methods: Fundamentals and Applications, 2nd Ed. Vol. 38, 12 (Wiley, 2002).

${ }^{7}$ UNFCCC, Paris Agreement 2015, 2015.

${ }^{8}$ E. C. Secretariat-General, Communication from the commission to the European Parliament, The European Council, The European Economic and Social Committee and the Committee of the regions The European Green Deal.

${ }^{9}$ Hydrogen Council, "Hydrogen scaling up : A sustainable pathway for the global energy transition. www.hydrogencouncil.com", Hydrogen scaling up: A sustainable pathway for the global energy transition, 80 (2017). 
${ }^{10}$ IRENA, Hydrogen : a Renewable Energy Perspective - Report prepared for the 2nd Hydrogen Energy Ministerial Meeting in Tokyo, Japan, September (2019), p. 52.

${ }^{11}$ A. A. Dahlkild, "Modelling the two-phase flow and current distribution along a vertical gas-evolving electrode", J. Fluid Mech. 428, 249-272 (2001).

${ }^{12}$ P. J. Sides and C. W. Tobias, "Primary Potential and Current Distribution Around a Bubble on an Electrode", J. Electrochem. Soc. 127, 288 (1980).

${ }^{13}$ J. Dukovic and C. W. Tobias, "The Influence of Attached Bubbles on Potential Drop and Current Distribution at Gas-Evolving Electrodes", J. Electrochem. Soc. 134, 331 (1987).

${ }^{14} \mathrm{~K}$. Zeng and D. Zhang, "Recent progress in alkaline water electrolysis for hydrogen production and applications", Prog. Energy Combust. Sci. 36, 307-326 (2010).

${ }^{15}$ M. Wang, Z. Wang, X. Gong, and Z. Guo, "The intensification technologies to water electrolysis for hydrogen production - A review", Renew. Sustain. Energy Rev. 29, 573-588 (2014).

${ }^{16}$ C. Gabrielli, F. Huet, M. Keddam, A. Macias, and A. Sahar, "Potential drops due to an attached bubble on a gas-evolving electrode", J. Appl. Electrochem. 19, 617-629 (1989).

${ }^{17} \mathrm{H}$. Vogt, "The incremental ohmic resistance caused by bubbles adhering to an electrode", Journal of Applied Electrochemistry 13, 87-88 (1983).

${ }^{18} \mathrm{~S}$. Ardo, D. Fernandez Rivas, M. A. Modestino, V. Schulze Greiving, F. F. Abdi, E. Alarcon Llado, V. Artero, K. Ayers, C. Battaglia, J.-P. Becker, D. Bederak, A. Berger, F. Buda, E. Chinello, B. Dam, V. Di Palma, T. Edvinsson, K. Fujii, H. Gardeniers, H. Geerlings, S. M. H. Hashemi, S. Haussener, F. Houle, J. Huskens, B. D. James, K. Konrad, A. Kudo, P. P. Kunturu, D. Lohse, B. Mei, E. L. Miller, G. F. Moore, J. Muller, K. L. Orchard, T. E. Rosser, F. H. Saadi, J.-W. Schüttauf, B. Seger, S. W. Sheehan, W. A. Smith, J. Spurgeon, M. H. Tang, R. van de Krol, P. C. K. Vesborg, and P. Westerik, "Pathways to electrochemical solar-hydrogen technologies", Energy Environ. Sci. 11, 2768-2783 (2018).

${ }^{19}$ J. P. Glas and J. W. Westwater, "Measurements of the growth of electrolytic bubbles", Int. J. Heat Mass Transfer. 7, 1427-1443 (1964).

${ }^{20}$ N. P. Brandon and G. H. Kelsall, "Growth kinetics of bubbles electrogenerated at microelectrodes", J. Appl. Electrochem. 15, 475-484 (1985). 
${ }^{21}$ Y. Wang, X. Hu, Z. Cao, and L. Guo, "Investigations on bubble growth mechanism during photoelectrochemical and electrochemical conversions", Colloids and Surfaces A 505, 86-92 (2016).

${ }^{22} \mathrm{P}$. van der Linde, Á. Moreno Soto, P. Peñas-López, J. Rodríguez-Rodríguez, D. Lohse, H. Gardeniers, D. van der Meer, and D. Fernández Rivas, "ElectrolysisDriven and Pressure-Controlled Diffusive Growth of Successive Bubbles on Microstructured Surfaces", Langmuir 33, 12873-12886 (2017).

${ }^{23}$ X. Yang, F. Karnbach, M. Uhlemann, S. Odenbach, and K. Eckert, "Dynamics of Single Hydrogen Bubbles at a Platinum Microelectrode", Langmuir 31, 8184-8193 (2015).

${ }^{24}$ D. Fernández, P. Maurer, M. Martine, J. M. D. Coey, and M. E. Möbius, "Bubble Formation at a Gas-Evolving Microelectrode", Langmuir 30, 13065 13074 (2014)

${ }^{25}$ C. Gabrielli, F. Huet, and R. Nogueira, "Fluctuations of concentration overpotential generated at gas-evolving electrodes", Electrochim. Acta 50, $3726-3736$ (2005).

${ }^{26}$ D. Lohse and X. Zhang, "Surface nanobubbles and nanodroplets", Rev. Mod. Phys. 87, 981-1035 (2015)

${ }^{27}$ L. Zhang, Y. Zhang, X. Zhang, Z. Li, G. Shen, M. Ye, C. Fan, H. Fang, and J. Hu, "Electrochemically Controlled Formation and Growth of Hydrogen Nanobubbles", Langmuir 22, 8109-8113 (2006).

${ }^{28}$ S. Yang, P. Tsai, E. S. Kooij, A. Prosperetti, H. J. W. Zandvliet, and D. Lohse, "Electrolytically Generated Nanobubbles on Highly Orientated Pyrolytic Graphite Surfaces", Langmuir 25, 1466-1474 (2009).

${ }^{29}$ S. Yang, P. Tsai, E. S. Kooij, A. Prosperetti, H. J. W. Zandvliet, and D. Lohse, "Correction to Electrolytically Generated Nanobubbles on Highly Orientated Pyrolytic Graphite Surfaces", Langmuir 29, 5937-5937 (2013).

${ }^{30}$ Q. Chen, H. S. Wiedenroth, S. R. German, and H. S. White, "Electrochemical Nucleation of Stable N2 Nanobubbles at Pt Nanoelectrodes", J. Am. Chem. Soc. 137, 12064-12069 (2015).

${ }^{31}$ O. R. Enríquez, C. Sun, D. Lohse, A. Prosperetti, and D. van der Meer, "The quasi-static growth of CO 2 bubbles", J. Fluid Mech. 741, R1 (2014).

32 Á. Moreno Soto, T. Maddalena, A. Fraters, D. van der Meer, and D. Lohse, "Coalescence of diffusively growing gas bubbles", J. Fluid Mech. 846, 143165 (2018). 
${ }^{33}$ P. Lv, H. Le The, J. Eijkel, A. Van den Berg, X. Zhang, and D. Lohse, "Growth and Detachment of Oxygen Bubbles Induced by Gold-Catalyzed Decomposition of Hydrogen Peroxide", J. Phys. Chem. C 121, 20769-20776 (2017).

${ }^{34}$ T. Kadyk, D. Bruce, and M. Eikerling, "How to Enhance Gas Removal from Porous Electrodes?", Sci. Rep. 6, 38780 (2016).

${ }^{35}$ P. van der Linde, P. Peñas-López, Á. Moreno Soto, D. van der Meer, D. Lohse, H. Gardeniers, and D. Fernández Rivas, "Gas bubble evolution on microstructured silicon substrates", Energy Environ. Sci. 11, 3452-3462 (2018).

${ }^{36}$ K. Ngamchuea, S. Eloul, K. Tschulik, and R. G. Compton, "Advancing from Rules of Thumb: Quantifying the Effects of Small Density Changes in Mass Transport to Electrodes. Understanding Natural Convection", Anal. Chem. 87, 7226-7234 (2015).

${ }^{37}$ J. A. Leistra and P. J. Sides, "Voltage Components at Gas Evolving Electrodes", J. Electrochem. Soc. 134, 2442-2446 (1987).

${ }^{38}$ M. Cooper and A. Lloyd, "The microlayer in nucleate pool boiling", International Journal of Heat and Mass Transfer 12, 895-913 (1969).

${ }^{39}$ V. K. Dhir, "Boiling Heat Transfer", Ann. Rev. Fluid Mech. 30, 365-401 (1998).

${ }^{40}$ M. Pourbaix, H. Zhang, and A. Pourbaix, "Presentation of an Atlas of Chemical and Electrochemical Equilibria in the Precence of a Gaseous Phase", Materials Science Forum 251-254, 143-148 (1997).

${ }^{41}$ R. Kas, R. Kortlever, H. Yılmaz, M. T. M. Koper, and G. Mul, "Manipulating the Hydrocarbon Selectivity of Copper Nanoparticles in CO 2 Electroreduction by Process Conditions", ChemElectroChem 2, 354-358 (2015).

${ }^{42}$ K. Yang, R. Kas, and W. A. Smith, "Tenacious Mass Transfer Limitations Drive Catalytic Selectivity during Electrochemical Carbon Dioxide Reduction", 1-26 (2019).

${ }^{43}$ T. Burdyny and W. A. Smith, "CO2 reduction on gas-diffusion electrodes and why catalytic performance must be assessed at commercially-relevant conditions", Energy Environ. Sci. 12, 1442-1453 (2019).

${ }^{44}$ M. C. O. Monteiro, L. Jacobse, T. Touzalin, and M. T. M. Koper, "MediatorFree SECM for Probing the Diffusion Layer $\mathrm{pH}$ with Functionalized Gold Ultramicroelectrodes", Anal. Chem. 92, 2237-2243 (2020). 
${ }^{45} \mathrm{~L}$. Bouffier and T. Doneux, "Coupling electrochemistry with in situ fluorescence (confocal) microscopy", Curr. Opin. Electrochem. 6, 31-37 (2017).

${ }^{46}$ S. Cannan, I. Douglas Macklam, and P. R. Unwin, "Three-dimensional imaging of proton gradients at microelectrode surfaces using confocal laser scanning microscopy", Electrochemistry Communications 4, 886-892 (2002).

${ }^{47}$ N. C. Rudd, S. Cannan, E. Bitziou, I. Ciani, A. L. Whitworth, and P. R. Unwin, "Fluorescence confocal laser scanning microscopy as a probe of $\mathrm{pH}$ gradients in electrode reactions and surface activity", Anal. Chem. 77, 62056217 (2005)

${ }^{48}$ A. J. Leenheer and H. A. Atwater, "Imaging Water-Splitting Electrocatalysts with pH-Sensing Confocal Fluorescence Microscopy", J. Electrochem. Soc. 159, H752-H757 (2012).

${ }^{49}$ J. Mai, H. Miller, and A. V. Hatch, "Spatiotemporal Mapping of Concentration Polarization Induced pH Changes at Nanoconstrictions", ACS Nano 6, 10206-10215 (2012)

${ }^{50}$ M. B. Andersen, D. M. Rogers, J. Mai, B. Schudel, A. V. Hatch, S. B. Rempe, and A. Mani, "Spatiotemporal pH Dynamics in Concentration Polarization near Ion-Selective Membranes", Langmuir 30, 7902-7912 (2014).

${ }^{51}$ N. Pande, G. Mul, D. Lohse, and B. Mei, "Correlating the Short-Time Current Response of a Hydrogen Evolving Nickel Electrode to Bubble Growth", J. Electrochem. Soc. 166, E280-E285 (2019)

${ }^{52}$ A. Angulo, P. van der Linde, H. Gardeniers, M. Modestino, and D. Fernández Rivas, "Influence of Bubbles on the Energy Conversion Efficiency of Electrochemical Reactors", Joule 4, 555-579 (2020).

${ }^{53}$ W. J. Bowyer, J. Xie, and R. C. Engstrom, "Fluorescence Imaging of the Heterogeneous Reduction of Oxygen", Anal. Chem. 68, 2005-2009 (1996).

${ }^{54}$ B. Tassy, A. L. Dauphin, H. M. Man, H. Le Guenno, E. Lojou, L. Bouffier, and A. de Poulpiquet, "In Situ Fluorescence Tomography Enables a 3D Mapping of Enzymatic O 2 Reduction at the Electrochemical Interface", Anal. Chem. 92, 7249-7256 (2020).

${ }^{55}$ H. Diehl and R. Markuszewski, "Studies on fluorescein II: The solubility and acid dissociation constants of fluorescein in water solution", Talanta 32, 159-165 (1985)

${ }^{56} \mathrm{H}$. Diehl and R. Markuszewski, "Studies on fluorescein VII: The fluorescence of fluorescein as a function of pH", Talanta 36, 416-418 (1989) 
${ }^{57}$ R. Sjöback, J. Nygren, and M. Kubista, "Absorption and fluorescence properties of fluorescein", Spectrochim. Acta Part A: Mol. Biomol. Spectrosc. 51, L7-L21 (1995).

${ }^{58}$ M. F. Li, L. W. Liao, D. F. Yuan, D. Mei, and Y.-X. Chen, "pH effect on oxygen reduction reaction at $\mathrm{Pt}(111)$ electrode", Electrochim. Acta 110, 780-789 (2013).

${ }^{59}$ F. Si, Y. Zhang, L. Yan, J. Zhu, M. Xiao, C. Liu, W. Xing, and J. Zhang, "Electrochemical Oxygen Reduction Reaction", in Rotating electrode methods and oxygen reduction electrocatalysts (Elsevier, 2014), pp. 133-170.

${ }^{60}$ D. Pletcher and S. Sotiropoulos, "A study of cathodic oxygen reduction at platinum using microelectrodes", J. Electroanal. Chem. 356, 109-119 (1993).

${ }^{61}$ R. G. Compton, P. J. Daly, P. R. Unwin, and A. M. Waller, "In-situ electrochemical ESR: ECE versus dispi", J. Electroanal. Chem. Interfacial Electrochem. 191, 15-29 (1985).

${ }^{62}$ R. G. Compton, R. G. Harland, P. R. Unwin, and A. M. Waller, "Rotatingdisc electrodes. ECE and DISP1 processes", J. Chem. Soc., Faraday Trans. 1 83, 1261 (1987).

${ }^{63}$ R. G. Compton, D. Mason, and P. R. Unwin, "The reduction of fluorescein in aqueous solution (at $\mathrm{pH}$ 6). A new DISP2 reaction", J. Chem. Soc., Faraday Trans. 1 84, 483 (1988).

${ }^{64}$ A. Mani and K. M. Wang, "Electroconvection Near Electrochemical Interfaces: Experiments, Modeling, and Computation", Ann. Rev. Fluid Mech. 52, 509-529 (2020).

${ }^{65}$ W. J. Hamer, "The Ionization Constant and Heat of Ionization of the Bisulfate Ion from Electromotive Force Measurements 1", J. Am. Chem. Soc. 56, 860-864 (1934).

${ }^{66}$ A. K. Covington, J. V. Dobson, and L. Wynne-Jones, "Dissociation constant of the bisulphate ion at $25^{\circ} \mathrm{C}$ ", Trans. Faraday Soc. 61, 2057-2062 (1965).

${ }^{67}$ Y. C. Wu and D. Feng, "The second dissociation constant of sulfuric acid at various temperatures by the conductometric method", Journal of Solution Chemistry 24, 133-144 (1995).

${ }^{68}$ S. Paddock, "Confocal Reflection Microscopy: The "Other" Confocal Mode", BioImaging 32, 274-277 (2002). 
${ }^{69}$ N. S. Claxton, T. J. Fellers, and M. W. Davidson, "Microscopy, Confocal", in Encyclopedia of medical devices and instrumentation (John Wiley \& Sons, Inc., Hoboken, NJ, USA, Apr. 2006).

${ }^{70}$ T. D. Visser and J. L. Oud, "Volume measurements in three-dimensional microscopy", Scanning 16, 198-200 (2008).

${ }^{71}$ M. J. Doughty, "pH dependent spectral properties of sodium fluorescein ophthalmic solutions revisited", Opth. Physio. Optics 30, 167-174 (2010).

${ }^{72}$ J. Ohser, P. Haas, F. Farbach, P. Menstell, A. Schwämmle, O. S., and D. Dobrovolskij, "Attenuation correction for confocal laser scanning microscopy and its application in chromatography", J. Microsc. 00, jmi.12888 (2020).

${ }^{73}$ T. D. Visser, F. C. Groen, and G. J. Brakenhoff, "Absorption and scattering correction in fluorescence confocal microscopy", J. Microsc. 163, 189-200 (1991).

${ }^{74} \mathrm{~W}$. Guthrie, J. Filliben, and A. Heckert, NIST/SEMATECH e-Handbook of Statistical Methods, edited by W. Guthrie (2020).

${ }^{75}$ T. Suzuki, T. Sato, J. Zhang, M. Kanao, M. Higuchi, and H. Maki, "Electrochemically switchable photoluminescence of an anionic dye in a cationic metallo-supramolecular polymer", Journal of Materials Chemistry C 4, 1594-1598 (2016).

${ }^{76}$ J. Coppeta and C. Rogers, "Dual emission laser induced fluorescence for direct planar scalar behavior measurements", Exp. Fluids 25, 1-15 (1998).

${ }^{77}$ A. Bonnefont, F. Argoul, and M. Z. Bazant, "Asymptotic Analysis of DiffuseLayer Effects on Time-Dependent Interfacial Kinetics", J. Electroanal. Chem. 500, 52-61 (2000).

${ }^{78}$ U. Retter, "Electrified Interfaces in Physics, Chemistry and Biology", Zeitschrift für Physikalische Chemie 177, 120-121 (1992).

${ }^{79}$ T. Pajkossy and D. Kolb, "Double layer capacitance of Pt(111) single crystal electrodes", Electrochim. Acta 46, 3063-3071 (2001).

${ }^{80}$ T. Casalini, M. Salvalaglio, G. Perale, M. Masi, and C. Cavallotti, "Diffusion and Aggregation of Sodium Fluorescein in Aqueous Solutions", J. Phys. Chem. B 115, 12896-12904 (2011).

${ }^{81}$ F. H. Stillinger, "Proton Transfer Reactions and Kinetics in Water", in Theoretical chemistry: advances and perspectives, Vol. 3 (1978), pp. 177234. 
${ }^{82}$ Q. Nie, Y.-T. Zhang, and R. Zhao, "Efficient semi-implicit schemes for stiff systems", J. Comp. Phys. 214, 521-537 (2006).

${ }^{83}$ C. S. Chou, Y. T. Zhang, R. Zhao, and Q. Nie, "Numerical methods for stiff reaction-diffusion systems", Discrete Contin. Dyn. Syst. Ser. B 7, 515-525 (2007).

${ }^{84}$ R. M. Pytkowicz and D. R. Kester, "Harned's rule behavior of nacl-na 2 so 4 solutions explained by an ion association model", American Journal of Science 267, 217-229 (1969).

${ }^{85}$ M. M. Santos, J. R. F. de Guedes, Carvalho, and R. A. Guedes de Carvalho, "Determination of the association constant of NaSO 4 - with the sodiumselective electrode", Journal of Solution Chemistry 4, 25-29 (1975).

${ }^{86}$ D. E. Irish and H. Chen, "Equilibria and proton transfer in the bisulfatesulfate system", J. Phys. Chem 74, 3796-3801 (1970).

${ }^{87}$ R. Zenit and J. Rodríguez-Rodríguez, "The fluid mechanics of bubbly drinks", Physics Today 71, 44-50 (2018).

${ }^{88}$ F. Karnbach, X. Yang, G. Mutschke, J. Fröhlich, J. Eckert, A. Gebert, K. Tschulik, K. Eckert, and M. Uhlemann, "Interplay of the Open Circuit Potential-Relaxation and the Dissolution Behavior of a Single H 2 Bubble Generated at a Pt Microelectrode", J. Phys. Chem. C 120, 15137-15146 (2016).

${ }^{89}$ O. Heavens, Optical properties of thin solid films, Vol. 23, 5 (Dover Publications, 1955).

${ }^{90}$ Á. Moreno Soto, A. Prosperetti, D. Lohse, and D. Van Der Meer, "Gas depletion through single gas bubble diffusive growth and its effect on subsequent bubbles", J. Fluid Mech. 831, 474-490 (2017).

${ }^{91}$ M. D. Morris and J. J. Lingane, "The effect of electrical migration on the chronopotentiometric transition time", J. Electroanal. Chem. 6, 300-313 (1963).

${ }^{92}$ J. S. Newman and K. E. Thomas-Alyea, Electrochemical Systems, 3rd (wiley, 2004).

${ }^{93}$ D. D. Gray and A. Giorgini, "The validity of the boussinesq approximation for liquids and gases", Int. J. Heat Mass Transfer 19, 545-551 (1976).

${ }^{94}$ M. S. Plesset and P. Epstein, "On the stability of gas bubbles in liquid-gas solutions", Journal of chemical physics, 10.1007/BF00385944 (1950). 
${ }^{95} \mathrm{~S}$. Takagi and Y. Matsumoto, "Surfactant effects on bubble motion and bubbly flows", Ann. Rev. Fluid Mech. 43, 615-636 (2011).

${ }^{96}$ P. Peñas-López, M. A. Parrales, J. Rodríguez-Rodríguez, and D. Van Der Meer, "The history effect in bubble growth and dissolution. Part 1. Theory", J. Fluid Mech. 800, 180-212 (2016).

${ }^{97}$ K. L. Chong, Y. Li, C. S. Ng, R. Verzicco, and D. Lohse, "Convectiondominated dissolution for single and multiple immersed sessile droplets", J. Fluid Mech. 892, 10.1017/jfm.2020.175 (2020).

${ }^{98}$ J. J. Kwan and M. A. Borden, "Microbubble Dissolution in a Multigas Environment", Langmuir 26, 6542-6548 (2010).

${ }^{99}$ E. P. van der Poel, R. Ostilla-Mónico, J. Donners, and R. Verzicco, "A pencil distributed finite difference code for strongly turbulent wall-bounded flows", Computers and Fluids 116, 10-16 (2015).

${ }^{100} \mathrm{M}$. D. de Tullio and G. Pascazio, "A moving-least-squares immersed boundary method for simulating the fluid-structure interaction of elastic bodies with arbitrary thickness", J. Comp. Phys. 325, 201-225 (2016).

${ }^{101}$ V. Spandan, V. Meschini, R. Ostilla-Mónico, D. Lohse, G. Querzoli, M. D. de Tullio, and R. Verzicco, "A parallel interaction potential approach coupled with the immersed boundary method for fully resolved simulations of deformable interfaces and membranes", J. Comp. Phys. 348, 567-590 $(2017)$.

${ }^{102} \mathrm{H}$. Vogt, "The role of single-phase free convection in mass transfer at gas evolving electrodes-II. Experimental verification", Electrochim. Acta 38, 1427-1431 (1993).

${ }^{103}$ Z. Yan, J. L. Hitt, J. A. Turner, and T. E. Mallouk, "Renewable electricity storage using electrolysis", Proc. Natl. Acad. Sci. U.S.A 117, 12558-12563 (2020).

${ }^{104}$ R. L. LeRoy, "Industrial water electrolysis: Present and future", Int. J. Hydrog. Energy 8, 401-417 (1983).

${ }^{105}$ C. Wagner, "The Role of Natural Convection in Electrolytic Processes", J. Electrochem. Soc 95, 161 (1949).

${ }^{106}$ I. Rubinstein and B. Zaltzman, "Electro-osmotically induced convection at a permselective membrane", Phys. Rev. E 62, 2238-2251 (2000). 
${ }^{107}$ C. Druzgalski and A. Mani, "Statistical analysis of electroconvection near an ion-selective membrane in the highly chaotic regime", Phys. Rev. Fluids 1, 073601 (2016).

${ }^{108}$ S. M. Rubinstein, G. Manukyan, A. Staicu, I. Rubinstein, B. Zaltzman, R. G. H. Lammertink, F. Mugele, and M. Wessling, "Direct Observation of a Nonequilibrium Electro-Osmotic Instability", Phys. Rev. Lett. 101, 236101 (2008).

${ }^{109}$ G. Yossifon and H.-C. Chang, "Selection of Nonequilibrium Overlimiting Currents: Universal Depletion Layer Formation Dynamics and Vortex Instability", Phys. Rev. Lett. 101, 254501 (2008).

${ }^{110}$ S. Kang and R. Kwak, "Pattern Formation of Three-Dimensional Electroconvection on a Charge Selective Surface", Phys. Rev. Lett. 124, 154502 (2020).

${ }^{111}$ V. V. Nikonenko, A. V. Kovalenko, M. K. Urtenov, N. D. Pismenskaya, J. Han, P. Sistat, and G. Pourcelly, "Desalination at overlimiting currents: State-of-the-art and perspectives", Desalination 342, 85-106 (2014).

${ }^{112}$ V. Fleury, J.-N. Chazalviel, and M. Rosso, "Theory and experimental evidence of electroconvection around electrochemical deposits", Phys. Rev. Lett. 68, 2492-2495 (1992).

${ }^{113}$ V. Fleury, J. N. Chazalviel, and M. Rosso, "Coupling of drift, diffusion, and electroconvection, in the vicinity of growing electrodeposits", Phys. Rev. E 48, 1279-1295 (1993).

${ }^{114}$ J. M. Huth, H. L. Swinney, W. D. McCormick, A. Kuhn, and F. Argoul, "Role of convection in thin-layer electrodeposition", Phys. Rev. E 51, 34443458 (1995)

${ }^{115}$ P. Bai, J. Li, F. R. Brushett, and M. Z. Bazant, "Transition of lithium growth mechanisms in liquid electrolytes", Energy Environ. Sci. 9, 32213229 (2016).

${ }^{116}$ N. Pande, S. K. Chandrasekar, D. Lohse, G. Mul, J. A. Wood, B. T. Mei, and D. Krug, "Electrochemically Induced pH Change: Time-Resolved Confocal Fluorescence Microscopy Measurements and Comparison with Numerical Model", J. Phys. Chem. Lett., 7042-7048 (2020).

${ }^{117}$ K. Obata, R. van de Krol, M. Schwarze, R. Schomäcker, and F. Abdi, "In-situ Observation of $\mathrm{pH}$ Change during Water Splitting in Neutral $\mathrm{pH}$ Conditions: Impact of Natural Convection Driven by Buoyancy Effects", Energy Environ. Sci. 10, 147-154 (2020). 
${ }^{118}$ A. De Wit, "Chemo-Hydrodynamic Patterns and Instabilities", Ann. Rev. Fluid. Mech. 52, 531-555 (2020).

${ }^{119}$ M. Orlik, Self-organization in electrochemical systems II spatiotemporal patterns and control of chaos (2012).

${ }^{120}$ Y. Han and D. G. Grier, "Colloidal electroconvection in a thin horizontal cell. II. Bulk electroconvection of water during parallel-plate electrolysis", J. Chem. Phys. 125, 10.1063/1.2349486 (2006).

${ }^{121}$ K. Scida, A. Eden, N. Arroyo-Currás, S. MacKenzie, Y. Satik, C. D. Meinhart, J. C. T. Eijkel, and S. Pennathur, "Fluorescence-Based Observation of Transient Electrochemical and Electrokinetic Effects at Nanoconfined Bipolar Electrodes", ACS Appl. Mater. Interfaces 11, 13777-13786 (2019).

${ }^{122}$ I. Rubinstein and L. Shtilman, "Voltage against current curves of cation exchange membranes", J. Chem Soc., Faraday Trans. 2 75, 231-246 (1979).

${ }^{123}$ L. Onsager, "Deviations from Ohm's Law in Weak Electrolytes", J. Chem. Phys 2, 599-615 (1934).

${ }^{124}$ Y. Tanaka, "Water dissociation reaction generated in an ion exchange membrane", J. Mem. Sci. 350, 347-360 (2010).

${ }^{125}$ J. C. de Valença, R. M. Wagterveld, R. G. H. Lammertink, and P. A. Tsai, "Dynamics of microvortices induced by ion concentration polarization", Phys. Rev. E 92, 031003(R) (2015).

${ }^{126}$ J. C. de Valença, A. Kurniawan, R. M. Wagterveld, J. A. Wood, and R. G. H. Lammertink, "Influence of Rayleigh-Bénard convection on electrokinetic instability in overlimiting current conditions", Phys. Rev. Fluids 2, 033701 (2017).

${ }^{127}$ M. van Soestbergen, P. M. Biesheuvel, and M. Z. Bazant, "Diffuse-charge effects on the transient response of electrochemical cells", Phys. Rev. E 81, 021503 (2010).

${ }^{128} \mathrm{M}$. Van Soestbergen, "Frumkin-Butler-Volmer theory and mass transfer in electrochemical cells", Russ. J. Electrochem. 48, 570-579 (2012).

${ }^{129}$ D. Yan, M. Z. Bazant, P. M. Biesheuvel, M. C. Pugh, and F. P. Dawson, "Theory of linear sweep voltammetry with diffuse charge: Unsupported electrolytes, thin films, and leaky membranes", Phys. Rev. E 95, 033303 (2017).

${ }^{130}$ K. C. Neyerlin, W. Gu, J. Jorne, and H. A. Gasteiger, "Study of the Exchange Current Density for the Hydrogen Oxidation and Evolution Reactions", J. Electrochem. Soc. 154, B631 (2007) 
${ }^{131}$ B. Conway and B. Tilak, "Interfacial processes involving electrocatalytic evolution and oxidation of $\mathrm{H} 2$, and the role of chemisorbed $\mathrm{H}$ ", Electrochim. Acta 47, 3571-3594 (2002).

${ }^{132}$ I. Streeter and R. G. Compton, "Numerical simulation of potential step chronoamperometry at low concentrations of supporting electrolyte", J. Phys. Chem. C 112, 13716-13728 (2008).

${ }^{133}$ E. J. Dickinson and R. G. Compton, "The zero-field approximation for weakly supported voltammetry: A critical evaluation", Chem. Phys. Lett. 497, 178-183 (2010).

${ }^{134}$ E. Karatay, M. B. Andersen, M. Wessling, and A. Mani, "Coupling between Buoyancy Forces and Electroconvective Instability near Ion-Selective Surfaces", Phys. Rev. Lett. 116, 194501 (2016).

${ }^{135}$ L. H. Brickwedde, "Properties of aqueous solutions of perchloric acid", J. Res. Natl. Bureau Stand. 42, 309 (1949).

${ }^{136}$ E. M. Sparrow, R. J. Goldstein, and V. K. Jonsson, "Thermal instability in a horizontal fluid layer: Effect of boundary conditions and non-linear temperature profile", J. Fluid Mech. 18, 513-528 (1964).

${ }^{137}$ K. K. Tan and R. B. Thorpe, "The onset of convection caused by buoyancy during transient heat conduction in deep fluids", Chem. Engg. Sci. 51, 4127-4136 (1996).

${ }^{138}$ J. W. Swan and E. M. Furst, "A simpler expression for Henry's function describing the electrophoretic mobility of spherical colloids", J. Colloid Interface. Sci 388, 92-94 (2012).

${ }^{139}$ O. Schnitzer and E. Yariv, "Strong electro-osmotic flows about dielectric surfaces of zero surface charge", Phys. Rev. E 89, 043005 (2014).

${ }^{140}$ W. Sheng, H. A. Gasteiger, and Y. Shao-Horn, "Hydrogen Oxidation and Evolution Reaction Kinetics on Platinum: Acid vs Alkaline Electrolytes", J. Electrochem. Soc 157, B1529 (2010).

${ }^{141}$ A. Bashkatov, S. S. Hossain, X. Yang, G. Mutschke, and K. Eckert, "Oscillating Hydrogen Bubbles at Pt Microelectrodes", Phys. Rev. Lett. 123, 214503 (2019)

${ }^{142}$ C. Amatore, S. Szunerits, L. Thouin, and J.-S. Warkocz, "The real meaning of Nernst's steady diffusion layer concept under non-forced hydrodynamic conditions. A simple model based on Levich's seminal view of convection", J. Electroanal. Chem. 500, 62-70 (2001) 
${ }^{143}$ R. A. Robinson and R. H. Stokes, Electrolyte Solutions (Dover Publicationsa, 2002).

${ }^{144}$ S. Daniele, M. A. Baldo, C. Bragato, M. E. Abdelsalam, and G. Denuault, "Steady-state voltammetry of hydroxide ion oxidation in aqueous solutions containing ammonia", Anal. Chem. 74, 3290-3296 (2002).

${ }^{145}$ S. R. Heil, M. Holz, T. M. Kastner, and H. Weingärtner, "Self-diffusion of the perchlorate ion in aqueous electrolyte solutions measured by $35 \mathrm{Cl}$ NMR spin-echo experiments", J. Chem Soc., Faraday Trans. 91, 1877-1880 (1995).

${ }^{146}$ R. G. Bates and J. B. Macaskill, "Standard Potential of the Silver-Silver Chloride Electrode", Pure Appl. Chem. 50, 1701-1706 (1978).

${ }^{147}$ Y. B. Vogel, C. W. Evans, M. Belotti, L. Xu, I. C. Russell, L.-j. Yu, A. K. K. Fung, N. S. Hill, N. Darwish, V. R. Gonçales, M. L. Coote, K. Swaminathan Iyer, and S. Ciampi, "The corona of a surface bubble promotes electrochemical reactions", Nat. Comm. 11, 6323 (2020).

${ }^{148}$ S. R. German, M. A. Edwards, H. Ren, and H. S. White, "Critical Nuclei Size, Rate, and Activation Energy of H2 Gas Nucleation", J. Am. Chem. Soc. 140, 4047-4053 (2018). 


\section{Summary}

In this thesis, the (electrolytic) hydrogen evolution reaction has been investigated to better understand the transport of the reacting $\mathrm{H}^{+}$ions, and product $\mathrm{H}_{2}$ gas near the electrode. Such gas-evolving electrolytic reactions further form bubbles on the electrode surface whose effect on the overall cell resistance is not completely clear. So, in Chapter 1 we begin by imaging an entire electrode while simultaneously measuring its current response. The growth of bubbles on the electrode was correlated to changes in the measured current. The most striking result was the re-increase in current after its initial drop which, moreover, coincided with the appearance of bubbles at the edge of the electrode. A possible mechanism for this increase in current was proposed to be the removal of product $\mathrm{H}_{2}$ gas from the saturated electrode surface by these 'scavenger bubbles' which would increase the local reaction rate on the electrode in the bubble neighborhood. It was suggested that the measurement of the spatial distribution of $\mathrm{H}^{+}$ions around the bubbles on the electrode would provide indirect evidence to support this hypothesis. Thus following this, in Chapter 2, we established a non-intrusive time-resolved $\mathrm{pH}$ measurement technique using fluorescence microscopy. Specifically, we measure successfully the 1-D pH profiles at a $\mathrm{H}^{+}$consuming platinum electrode. The results moreover highlight the effect of the non-linear bulk wat0er dissociation reaction on the $\mathrm{pH}$ profiles which propagate as sharp fronts into the solution. On applying this technique to the measurement of $\mathrm{pH}$ around a bubble on an electrode, preliminary results do indicate a preference for lower $\mathrm{H}^{+}$concentration near the bubble (see Fig. 5.1). This could be the result of a higher reaction rate near the bubble but further measurements are required for a conclusive result. It is clear that the measurement of dissolved product gas, here $\mathrm{H}_{2}$, near electrodes is relevant to understand the current (or voltage) response of the electrolytic cell. Thus in Chapter $\mathbf{3}$ we measure the bubble growth and dissolution rate in response to a well-defined short voltage pulse, since they serve as indicators of the local $\mathrm{H}_{2}$ concentration. However with the help of nu- 
merical simulations it was established that there are a number of factors that affect the bubble growth/dissolution rates such as convective mixing, bubble distribution and even dissolved air in the electrolyte.

Lastly. in Chapter 4 a better understanding of transport processes and instabilities in electrochemical cells was gained by driving currents greater than the diffusive transport limit. Using a $\mathrm{pH}$ and temperature insensitive dye, electroconvective patterns were visualized for a $\mathrm{H}^{+}$reduction reaction. This further raises questions about the mechanism of ion transport that drive the current when $\mathrm{H}^{+}$ions are depleted at the electrode. A mechanism for transport in the bulk solution could either be electroconvection as shown in Chapter 4 , but could also be buoyancy driven convection due to gradients in the supporting salt concentration in the electrolyte. On the other hand, near the electrodes an increased water dissociation rate due to large local electric fields is likely what drives these large currents. 


\section{Samenvatting}

In dit proefschrift is de (elektronische) waterstofevolutiereactie onderzocht om meer inzicht te verkrijgen in het transport van de reagerende $\mathrm{H}^{+}$-ionen en het geproduceerde $\mathrm{H}_{2}$-gas aan de elektrode. Dergelijke gas producerende elektro-katalytische reacties vormen vervolgens bellen op het elektrodeoppervlak, waarvan het effect op de algehele cel weerstand niet helemaal duidelijk is. Hierom beginnen we in Hoofdstuk 1 met het in beeld brengen van de gehele electrode terwijl ook de stroomrespons wordt gemeten. De groei van de bellen op de elektrode word gecorreleerd aan de veranderingen in de gemeten stroom. Het meest opvallende resultaat was de opnieuw toenemende stroom na de initiële afname welke samenvalt met het verschijnen van bellen aan de rand van de elektrode. Een mogelijk mechanisme is voorgedragen waarbij de toename in de stroom het gevolg is van de verwijdering van het geproduceerde $\mathrm{H}_{2}$ gas, weg van het verzadigde elektrodeoppervlak, door deze 'verzamelde bellen' met als gevolg dat de reactiesnelheid toeneemt in de buurt van de bubbel op de elektrode. Voorgesteld is dat het meten van de ruimtelijke verdeling van de $\mathrm{H}^{+}$-ionen rond de bubbels op de elektrode een indirect bewijs kan leveren om deze hypothese te ondersteunen. Hier opvolgend, in Hoofdstuk 2, hebben wij een niet-intrusieve tijdsgeresolveerde $\mathrm{pH}$-meettechniek op gezet gebruik makend van fluorescentiemicroscopie. Hiermee meten wij specifiek en succesvol de 1-D pH-profielen bij de $\mathrm{H}^{+}$-consumerende platina elektrode. De resultaten benadrukken verder ook het effect van de niet-lineaire splitsingsreactie van bulk water op de $\mathrm{pH}$-profielen die als scherpe fronten door de oplossing propageren. Bij het toepassen van deze techniek om de $\mathrm{pH}$ rond de bubbel op een elektrode te meten, laten de voorlopige resultaten zien dat er de voorkeur bestaat voor een lage $\mathrm{H}^{+}$-concentratie in de nabijheid van de bubbel (Zie Fig. 5.1). Dit zou het resultaat kunnen zijn van een hogere reactiesnelheid nabij de bubbel, echter zijn er meer metingen nodig voor een sluitend resultaat. Het is duidelijk

\footnotetext{
Translated into Dutch by Ronald P.H. Jong
} 
dat het meten van het opgeloste gasproduct, in dit geval $\mathrm{H}_{2}$, nabij de elektroden relevant is voor het begrijpen van de stroom (of voltage) -respons van de elektrische cel. In Hoofdstuk 3 meten wij hierom de groei van de bubbel en de oplossnelheid in reactie op een goed gedefinieerde korte voltagepuls, omdat deze dienen als indicatoren voor de lokale $\mathrm{H}_{2}$-concentratie. Echter, met behulp van numerieke simulaties is aangetoond dat er meerdere factoren bestaan die van invloed zijn op de groei/oplossnelheid van de bubbel zoals; menging door convectie, verdeling van de bellen en zelfs lucht opgelost in het elektrolyt.

Tot slot, in Hoofdstuk 4, is er een beter begrip verkregen van transportprocessen en instabiliteiten in elektrochemische cellen door grotere stromen te gebruiken dan de limiet voor diffusietransport. Gebruikmakend van een $\mathrm{pH}$ en temperatuur gevoelige kleurstof, zijn elektroconvectie patronen gevisualiseerd voor een $\mathrm{H}^{+}$-reductiereactie. Dit brengt verdere vragen met betrekking tot het mechanisme voor ionentransport dat leidend is voor de stroom wanneer het aantal $\mathrm{H}^{+}$-ionen bij de elektrode sterk is afgenomen. Een mechanisme voor het transport in de bulkoplossing kan enerzijds elektroconvectie zijn zoals is laten zien in hoofdstuk 4 of anderzijds kan het ook drijfvermogen gedreven convectie zijn door gradiënten in de concentratie van het ondersteunende zout in het elektrolyt. Aan de andere kant, nabij de elektrodes is het waarschijnlijk dat de toegenomen watersplitsingssnelheid, veroorzaakt door de grote lokale elektrische velden, wat tot deze hoge stromen leidt. 


\section{Acknowledgements}

I would first like to thank my promoters Detlef and Guido for the opportunity to work on this project. I am also thankful to the research and support staff of both groups especially Dennis, Gert-wim and Robert for their help in designing experimental setups.

I owe thanks to Bastian and Dominik without whose help I would not have been able to finish this thesis. I am grateful for their guidance especially during the trying years of my PhD. I am also grateful to Jeff who first suggested looking into ion-transport in this system.

I was lucky to have colleagues (friends) with whom drinking beer and talking science went together. A big 'thank you!' to Ronald, Devin, Piotr and Robert B., who taught me how to work in a chemistry lab and in general taught me all things chemistry. Also a special thanks to Anjali, my go-to organic molecules guide, for help with science and much more.

Lastly I am grateful for the constant support of my parents and my sister. 